IZA DP No. 10200

Genes, Education, and Labor Market Outcomes: Evidence from the Health and Retirement Study

Nicholas W. Papageorge

Kevin Thom

September 2016 


\title{
Genes, Education, and Labor Market Outcomes: Evidence from the Health and Retirement Study
}

\author{
Nicholas W. Papageorge \\ Johns Hopkins University \\ and IZA
}

Kevin Thom

New York University

Discussion Paper No. 10200
September 2016

\author{
IZA \\ P.O. Box 7240 \\ 53072 Bonn \\ Germany \\ Phone: +49-228-3894-0 \\ Fax: +49-228-3894-180 \\ E-mail: iza@iza.org
}

Any opinions expressed here are those of the author(s) and not those of IZA. Research published in this series may include views on policy, but the institute itself takes no institutional policy positions. The IZA research network is committed to the IZA Guiding Principles of Research Integrity.

The Institute for the Study of Labor (IZA) in Bonn is a local and virtual international research center and a place of communication between science, politics and business. IZA is an independent nonprofit organization supported by Deutsche Post Foundation. The center is associated with the University of Bonn and offers a stimulating research environment through its international network, workshops and conferences, data service, project support, research visits and doctoral program. IZA engages in (i) original and internationally competitive research in all fields of labor economics, (ii) development of policy concepts, and (iii) dissemination of research results and concepts to the interested public.

IZA Discussion Papers often represent preliminary work and are circulated to encourage discussion. Citation of such a paper should account for its provisional character. A revised version may be available directly from the author. 
IZA Discussion Paper No. 10200

September 2016

\section{ABSTRACT}

\section{Genes, Education, and Labor Market Outcomes: Evidence from the Health and Retirement Study*}

Recent advances have led to the discovery of specific genetic variants that predict educational attainment. We study how these variants, summarized as a genetic score variable, are associated with human capital accumulation and labor market outcomes in the Health and Retirement Study (HRS). We demonstrate that the same genetic score that predicts education is also associated with higher wages, but only among individuals with a college education. Moreover, the genetic gradient in wages has grown in more recent birth cohorts, consistent with interactions between technological change and labor market ability. We also show that individuals who grew up in economically disadvantaged households are less likely to go to college when compared to individuals with the same genetic score, but from higher-SES households. Our findings provide support for the idea that childhood SES is an important moderator of the economic returns to genetic endowments. Moreover, the finding that childhood poverty limits the educational attainment of high-ability individuals suggests the existence of unrealized human potential.

JEL Classification: $\quad$ I24, J24

Keywords: $\quad$ human capital, inequality, education, genes

Corresponding author:

Nicholas W. Papageorge

Johns Hopkins University

Department of Economics

Wyman 521

3400 N. Charles St

Baltimore, MD 21218

USA

E-mail: papageorge@jhu.edu

\footnotetext{
${ }^{*}$ We thank Aysu Okbay for constructing and sharing the polygenic score used for HRS respondents. For helpful comments and conversations, we thank Joseph Altonji, Robert Barbera, Daniel Belsky, Jonathan Beauchamp, Pietro Biroli, David Cesarini, Dora Costa, Stefanie Deluca, Jason Fletcher, Seth Gershenson, Barton Hamilton, Stephanie Heger, Erik Hurst, Steven Lehrer, Lance Lochner, Robert Moffitt, Aysu Okbay, Robert Pollak, Paul Romer, Victor Ronda, Petra Todd and Matthew Wiswall along with participants in seminars at Johns Hopkins University, New York University, the Census Bureau and SOLE 2016. We also thank Andrew Gray for excellent research assistance. The usual caveats apply.
} 


\section{Introduction}

Economists generally accept that the skills rewarded in the labor market arise from a combination of endowed abilities, economic environments, and endogenous human capital investments. Endowments, environments and investments almost certainly interact in complicated ways, transforming the distribution of abilities drawn at birth into a distribution of education, wages, and labor supply outcomes over the life-cycle. Understanding this web of interactions and its implications for economic inequality has been a long-standing project in labor economics (Mincer, 1958, Becker and Chiswick, 1966, Griliches and Mason, 1972). Indeed, selecting an appropriate policy response to inequality requires an accurate diagnosis of its origins. Poor households possess limited household resources, which naturally suggests a role for redistributive policies. However, disparities in ability might also play a part. If individuals with unfavorable ability draws do not acquire more human capital for reasons unrelated to resources (e.g. lower returns to these investments), then simply relaxing resource constraints and expanding access to education may not substantially reduce inequality. However, understanding the mapping between ability, investments, and economic outcomes is challenging: ability is notoriously difficult to observe and typical proxies (such as IQ test scores) are subject to the critique that they reflect earlier investments.

A common assumption is that genes and other biological factors at least partially determine ability endowments across individuals (e.g. Todd and Wolpin (2003)). In this study we exploit recent advances in genetics to explore the relationship between a genetic index, educational attainment, and labor market outcomes in the Health and Retirement Study $(H R S)$. Specifically, we utilize a polygenic score (a weighted sum of individual genetic markers) constructed with the results from Okbay et al. (2016) to predict educational attainment 1 The markers most heavily weighted in this index are implicated in neuronal development and other biological processes that affect brain tissue. We interpret the polygenic score as a measure of one type of endowed ability ${ }^{2}$ Even if this score is correlated with parental characteristics, its use is not subject to the critique that it is the product of earlier investments, since it is fixed at conception. 3 Pairing this type of genetic information

\footnotetext{
${ }^{1}$ Research reported in Okbay et al. (2016) represents the cutting edge in behavioral genetics relating specific genetic variants to education. We discuss their paper and the research leading up to it in Section 2 where we provide further details on the genetic data used in this project. Additional background information on the genetic data we use is in Appendix A

${ }^{2}$ Consistent with this view, Belsky et al. (2016) show evidence that some of the genes forming part of the score constructed in Okbay et al. (2016) are implicated in early childhood development, e.g., beginning to talk earlier.

${ }^{3}$ As we explain throughout the paper, the genetic index is correlated with environments and investments, since parents pass on their genes in addition to shaping environments and making investments. Nevertheless, the fact that environments and investments do not change the genetic score offers an important exclusion
} 
with rich longitudinal data allows us to study the structure of ability endowments, including how they interact with childhood environments, human capital investments, and changing macroeconomic conditions.

The use of observed genetic variation offers advantages relative to existing methods for the analysis of ability. In empirical labor economics, ability is typically subsumed into an error term, averaged out with additive fixed-effects, or relegated to a "black box" of permanent unobserved heterogeneity that must be integrated out of econometric models (Lillard and Willis, 1978). In such approaches the structure of ability, including its interactions with environments, is assumed rather than observed. This is defensible if the goal is to reduce bias in estimation by controlling for omitted factors. However, it becomes problematic when the goal is to learn about the structure of ability and the implications for policy. A popular alternative has been to use proxies, such as IQ or AFQT test scores, as measures of cognitive ability. However, a number of studies indicate that these proxies are significantly influenced by investments and environmental changes (Flynn, 1987, Turkheimer et al., 2003, Todd and Wolpin, 2007) 4 Among other things, this means that two individuals with the same cognitive test scores but different childhood circumstances (e.g. parental socio-economic status or poverty) are unlikely to have started with the same underlying ability endowments. Reliance on these proxies may therefore lead the analyst to mis-attribute observed disparities in economic outcomes to unequal ability endowments rather than to unequal investments over the life-cycle. In turn, this could lead to incorrect conclusions on the returns to highquality public education, the effect of college subsidies, and other policy-relevant estimands.

We present three main sets of results. First, we document associations between the polygenic score, educational attainment, and childhood socio-economic status (henceforth $S E S$ ). Using the HRS data, we replicate the strong relationship between the genetic score and educational attainment found in Okbay et al. (2016). The polygenic score accounts for a large percentage of the variation in years of schooling (3.2\%-6.6\% depending on the control set) $!^{5}$ Next, we examine the relationship between the polygenic score and retrospective measures of childhood SES. Here, a surprising descriptive fact emerges. While the polygenic score is positively correlated with childhood SES, these associations are modest. The distribution of the score is strikingly similar across SES groups. We observe comparable numbers of

restriction.

${ }^{4}$ Proxies for endowments measured among children or newborns are also subject to this type of critique (Almond and Currie, 2011).

${ }^{5}$ Twin studies have established that roughly $40 \%$ of the variation in educational attainment can be attributed to genetic endowments, suggesting that genes represent an important component of endowed ability (Branigan, McCallum, and Freese, 2013). The polygenic score captures some of this variation. It is important to keep in mind that twin studies do not identify the specific genetic variants associated with educational attainment. 
individuals growing up in low-SES and high-SES environments for any range of score values. This empirical pattern makes it possible to compare economic outcomes for a large set of individuals with similar genetic scores, but different childhood SES. Specifically, we study interactions between childhood SES and educational outcomes. We find that while high childhood SES seems to reduce the association between genes and the probability of completing high school, it increases the genetic gradient in the propensity to earn a college degree. These findings could reflect different patterns of substitutability between genes and family resources in producing early versus later human capital outcomes. This provides some evidence that gene-environment interactions may be important for understanding economic disparities and the distributional consequences of interventions. ${ }^{6}$

Our second set of results concerns adult labor market outcomes. We first show a strong relationship between the polygenic score and wages, but only for the college educated 17 Coupled with the earlier finding that the relationship between genetic endowments and college education is weaker for individuals reporting low childhood SES, the wage results highlight a policy-relevant concern. Individuals born into disadvantaged circumstances with high genetic scores are less able to capitalize on their endowed ability in the labor market. More strikingly, we do not find this pattern when we use a more conventional adult cognitive test score as a proxy of ability. Instead, cognitive test scores predict higher wages for individuals regardless of college completion, which could lead to inaccurate conclusions about how individuals benefit from their ability in the labor market. The observability of genetic endowments may add a new dimension to our understanding of skill-biased technological change. Among college graduates the genetic premium has grown to become substantial in more recent cohorts. We argue that these results are consistent with recent literature on income inequality showing not only an increase in the college premium, but also a rise in the residual wage variance within educational groups (Lemieux, 2006). This link to technological change is supported by a positive association between the score and the kinds of non-routine job tasks that are complemented by computerization (Autor, Levy, and Murnane, 2003).

A recurring theme in our first two sets of results is that individuals born into low-SES families see lower returns to their ability endowments (as measured by the polygenic score)

\footnotetext{
${ }^{6}$ This is linked to work on treatment effect heterogeneity, which has emerged as an important topic in econometrics and applied work. Heckman and Vytlacil (2005) develop econometric methods for the case of heterogeneous treatment effects, either due to choices or responses. Many studies document a range of heterogeneous responses to interventions related to labor, including welfare reform (Bitler, Gelbach, and Hoynes, 2006), information about payoffs to education (Wiswall and Zafar, 2015) and education subsidies (Todd and Wolpin 2006). Related, Keane, Moffitt, and Runkle (1988) study how heterogeneity affects responses to shocks, in their case labor supply decisions over the business cycle.

7 Taubman (1976) is an early contribution using data on twins, who have similar or identical genotypes, to assess the amount of variation in earnings attributable to genes.
} 
compared to those born into high-SES families. This suggests the existence of unrealized human potential. In our third set of results, we explore this more directly by comparing economic outcomes for individuals with similar genetic scores who grew up in different environments. Here, we go beyond measures of family SES and also consider low-probability acutely adverse events, such as physical abuse during childhood and drug or alcohol problems of parents. In general, we show that these various measures of childhood circumstances predict different economic outcomes, such as employment and wealth near retirement - sometimes considerably. For example, even after we control for childhood SES, a report of abuse predicts a $40 \%$ reduction in wealth near retirement for individuals with similar genetic scores. We also find, however, that some (but not all) disparities in economic outcomes are moderated by education.

This paper adds to an emerging literature examining molecular genetic associations with educational attainment 8 To clarify our contribution, to our knowledge, this is the first study to estimate the returns to genetic ability in the labor market using molecular genetic data and disaggregated measures of wages and labor force participation. Doing so using a rich data set, we provide novel evidence that the wage returns to genes associated with education appear only for those with at least a college degree and that this return appears to have grown across birth cohorts. These results implicate genetic heterogeneity in a series of important and welldocumented patterns in labor economics, including skill-biased technological change. Our results on interactions between childhood SES and educational attainment provide another distinct contribution. For example, using an older (and less statistically powerful) version of the score we use, Belsky et al. (2016), studying a sample of New Zealanders, suggest that there may be a weaker association between genetic ability and lifetime success for high-SES households. Our results, using a larger data set, indicate a more nuanced story in which SES can moderate the genetic gradient for some outcomes but exacerbate the gradient for high-level human capital accumulation.

The remainder of the paper is organized as follows. In Section 2 , we discuss recent developments in behavioral genetics (and their limits), focusing on techniques used to establish links between genes and economic outcomes. In Section 3, we relate the polygenic score to education and childhood SES. In Section 4 , we discuss how the polygenic score relates to labor market outcomes. In Section 5, we compare outcomes for individuals with similar polygenic scores but different childhood SES and address the idea of unrealized human potential. Section 6 concludes.

\footnotetext{
${ }^{8}$ For example, in a recent paper, Schmitz and Conley $(2016)$ demonstrate that the effect of military service on educational attainment is moderated by the same polygenic score considered here. In Section 2 . we discuss more papers in this line of research.
} 


\section{Genetic Data, GWAS, and Their Limits}

In this section, we provide some basic information about molecular genetic data and attempt to highlight why estimating gene-behavior associations has been problematic in the past. Moreover, we discuss how advances in the field (especially genome-wide association studies or $G W A S$ ) have allowed researchers to overcome these problems. We also discuss the origin of the polygenic score for education used in this study. Appendix A provides additional detail 9

The human genome consists of approximately 3 billion nucleotide pairs spread out over 23 chromosomes.10 A DNA molecule is often thought of as double-helix ladder, with the nucleotide base pairs forming the "rungs" of the ladder. Each rung can either be an adeninethymine pair, or a guanine-cytosine pair. Thus, the human genome can be thought of as a series of 3 billion genetic addresses, each of which contains a particular base pair molecule in a particular position 111 Furthermore, each individual possesses two copies of each chromosome, one from each parent. A gene is a subsequence of base pairs within a chromosome, which vary in length but may contain thousands of base pairs.

At the vast majority of locations in the genome (about 99\%), there is no variation across individuals in the nucleotide pair that is present. At the remaining locations (less than $1 \%$ ), the base pair may differ across individuals. ${ }^{12}$ Such locations are referred to as singlenucleotide polymorphisms (SNPs, pronounced "snips"). Particular SNPs are referred to by a name (e.g. rs7937), which indicates its position in the genome. For each individual and at each SNP location, we can typically record an individual's genotype by counting the number of copies of a reference molecule (or allele) that an individual possesses at a particular location. Since each individual has two copies of each chromosome, an individual can either have zero, one, or two instances of the reference allele. Molecular genetic data thus most

\footnotetext{
${ }^{9}$ We are grateful to Aysu Okbay for clarifying a number of questions on the description we provide in this section. However, any erroneous statements are the sole responsibility of the authors.

${ }^{10}$ Most of the background information presented here on the human genome follows Beauchamp et al. (2011) and Benjamin et al. (2012).

${ }^{11}$ If the DNA strand can be thought of as a ladder with the nucleotide pairs being the rungs, then the rails or sides of the ladder are formed by phosphate and sugar molecules. These rails can be distinguished as either the positive $(+)$ or negative $(-)$ strands. At a particular location, it will matter which nucleotide molecule is attached to which strand. For example, if there is an adenine-thymine pair in a particular position where the adenine molecule is attached to the positive strand, this would be denoted by an A. However, if instead the thymine molecule were attached to the positive strand, this would be denoted by a T. This means that four possible variants could exist at a given address: A, T, G, or C, depending on which nucleotide pair is present, and the position of that pair relative to the positive strand. However, most SNPs are biallelic, meaning that there are only two observed alleles at a particular location.

${ }^{12} \mathrm{We}$ also note that other forms of genetic variation exist. Such variation is typically referred to as structural variation and may include deletions, insertions, and copy-number variations. (Feuk, Carson, and Scherer, 2006).
} 
commonly take the form of a series of count variables indicating the number of copies of the reference allele possessed by individual $i$ at a particular SNP (e.g. $r s 7937_{i} \in\{0,1,2\}$ ). A major task of behavioral genetics involves determining which, if any, of these SNP variables are associated with behavioral outcomes.

\subsection{Gene-Behavior Associations and GWAS}

A traditional approach to discovering gene-behavior associations rests on examining candidate genes. Under this paradigm, researchers use some knowledge of the relevant biological processes to suggest locations in the genome that might contain variation associated with a particular outcome. Unfortunately, this approach has also generated a large number of reported associations that have failed to replicate outside of their discovery samples. This problem has been so widespread that an editorial statement from the journal Behavior Genet$i c s$ stated that "[t]he literature on candidate gene associations is full of reports that have not stood up to rigorous replication," and that "it now seems likely that many of the published findings of the last decade are wrong or misleading and have not contributed to real advances in knowledge," (Hewitt, 2012). This pattern emerged, in part, because traditional candidate gene studies have been severely underpowered to detect real genetic effects. Sample sizes in general have been too small relative to plausible effect sizes for individual SNPs, making it likely that statistically significant associations are the result of chance. This problem is exacerbated when studies search over many candidate genes, creating a multiple hypothesis testing problem that increases the likelihood of finding false positive results Benjamin et al. 2012 .

An alternative to candidate genes is an approach called a genome-wide association study (GWAS). Under the GWAS methodology, researchers scan the entire genome for SNPs that are associated with a particular phenotype (trait or outcome), but adopt strong measures to deal with multiple hypothesis-testing. In practice, this involves regressing an outcome variable of interest (e.g., years of education) against hundreds of thousands of individual SNPs, and adopting stringent $p$-value thresholds for identifying an association. If found significant using these thresholds, the gene-behavior association is considered genome-wide significant. It is standard GWAS practice to include principal components of the full matrix of SNP data as essential controls. As indicated by Price et al. (2006) (and discussed at length in Benjamin et al. (2012) in the context of economic outcomes) the principal components can correct for population stratification and account for genetic differences across ethnic groups. The presence of these controls limits the concern that gene-behavior associations reflect associations with specific ethnic ancestry groups as opposed to specific biological 
pathways 13

The rise of GWAS studies has produced a number of credible, replicable gene-outcome associations. GWAS findings are also able to point to important genetic variants that have not yet emerged as candidate genes. For example, GWAS methods have led to the discovery of important variants that predict obesity and type 2 diabetes (Benjamin et al. 2012 ). Existing work has also demonstrated the importance of credibly identified SNPs for several economically relevant outcomes. These SNPs either directly emerged from a GWAS or were candidate genes that were validated by later GWAS results. An established literature documents a number of credible genetic associations with smoking behaviors (Bierut 2011, Thorgeirsson 2010). Fletcher (2012) demonstrates that a SNP associated with smoking intensity also appears to moderate the effect of tobacco taxes. More closely related to our work, another set of studies suggests indirect linkages between genetic variants and human capital. For example, Fletcher and Lehrer (2011) use a set of SNPs associated with health outcomes to provide exogenous within-family variation to estimate a causal relationship between health and education. Thompson (2014) shows that a variant associated with the MAOA gene (implicated in aggression) appears to moderate the relationship between income and education.

In a series of landmark discoveries, recent GWAS have identified some of the first direct associations between specific SNPs and educational attainment (Rietveld et al., 2013; Okbay et al. 2016). This is remarkable given that the paths linking biology to education are less direct than those associated with traits such as eye color, or a heritable disease. After documenting the first genome-wide significant associations for education (Rietveld et al. 2013), the Social Science and Genetics Consortium has recently extended their analysis to perform an educational attainment GWAS with an unprecedented sample size of 293,723. This follow-up study, Okbay et al. (2016) discovered 74 SNPs that attained genome-wide significance. Many of these SNPs were linked to biological processes known to be involved in fetal brain development.14

GWAS results are often aggregated into polygenic scores for the purposes of prediction. Such scores are linear combinations of individual SNP measures.15 While the weights as-

\footnotetext{
${ }^{13}$ In our subsequent analysis we always control for population stratification using the first 10 principle components of the full matrix of genetic data, which is a standard practice in the genetics literature.

${ }^{14}$ We note that Okbay et al. (2016) also find a significant "but very small" association between this genetic score and and height, which suggests that the score may be picking up some variants that do not exclusively work through cognitive channels. Nevertheless, the evidence presented in Okbay et al. (2016) heavily implicates cognitive mechanisms in the biological pathways that link the score to educational attainment.

${ }^{15}$ The polygenic score that we use is constructed using all of the SNPs that we observe, and not just those that attain genome-wide significance. This follows the practice in Okbay et al. $(2016)$, which found that such an all-SNP score does a better job of predicting educational attainment in holdout samples.
} 
signed to each SNP typically vary across methods, these weights are usually based on the strength of a SNP's association with the outcome of interest and the joint covariance matrix of the SNPs. As detailed in Appendix A, our genetic measure in this study is a polygenic score for education constructed by Okbay et al. (2016). Importantly, although HRS data is used in the published results for Okbay et al. (2016), the score used here (supplied by the authors of Okbay et al. (2016)) has been calculated without HRS data, ensuring that the score does not mechanically predict educational outcomes. We refer to this as the EA Score, where EA stands for "educational attainment." Since this is the only polygenic score we examine in this paper, we use the terms "EA Score", "polygenic score" and "genetic score" interchangeably.

Existing work suggests that polygenic scores usefully summarize genetic information contained by some of the SNPs associated with education. Most existing studies work with an older, less predictive polygenic score based on the results of Rietveld et al. (2013). Domingue et al. (2015) demonstrate that this polygenic score predicts educational attainment in the Add Health study, and that this association appears to operate separately from childhood environments since it predicts higher education within sibling groups. Indeed, Rietveld et al. (2014) find similar coefficients on a related polygenic score using either within-family variation or within and across family variation. Also related, Conley and Domingue $(2016)$ find evidence of changing patterns of assortative mating across cohorts and Schmitz and Conley (2016) use the same genetic index that we use to show that genetic heterogeneity can moderate the impact of military service during the Vietnam War on subsequent educational attainment. Finally, and closer to our work, Belsky et al. (2016) examine a sample of 918 New Zealanders and show that a similar polygenic score not only predicts education, but also an index of adult success conditional on education. In relating genes predicting education to an aggregated measure of success in the labor market, their study provides important crossvalidation to our own work, though with a different sample and a substantially different set of outcomes and research questions ${ }^{16}$

We conclude this section by briefly discussing three important caveats and points of clarification. First, it is important to note that the genetic variants used in the construction of this genetic score are not located on sex chromosomes. For this reason, the distribution of these variants should be identical across men and women. Second, we do not claim to estimate causal effects of particular genetic variants. Any gene-outcome association that we observe in general reflects a combination of a direct effect and an indirect effect operating through the environments that parents make for their children. Parents with advantageous

\footnotetext{
${ }^{16}$ For example, their analysis does not specifically estimate returns in a wage equation or examine how college degree status or birth cohort appears to moderate such returns.
} 
genetic endowments (which they pass on to their children) are more likely to have the resources or capacity to create better environments. Even so, an individual's genetic makeup is not changed by human capital investments. In contrast, IQ and other cognitive test scores are subject to the critique that they reflect environmental factors, such as earlier human capital investments. For example, Bharadwaj, Løken, and Neilson (2013) find that variation in health care received by newborns has an impact on academic achievement years later ${ }^{17}$ Genetic indices are not subject to this critique since they are fixed at conception. As we elaborate on below, this generates an important exclusion restriction which can be used to correctly sign ability-environment interactions.

A final caveat to our use of genetic data is that it may misrepresent ability. By aggregating a number of genetic variants into a single score, we are implicitly assuming that these factors work together in determining a single scalar value that can be thought of as labor market ability. However, a growing literature suggests that ability is multi-dimensional. There may be distinct cognitive abilities (e.g., mathematical ability or facility with language) each possessing different associations with economic outcomes (Willis and Rosen, 1979, Heckman, 1995; Cawley et al. 1997). Ability may also encompass not just cognition, but non-cognitive factors as well (Heckman and Rubinstein, 2001) 18 On this point, we are tied to the state of the art in genetics. We do not yet have the tools to credibly determine whether the individual genetic markers that make up the score contribute to distinct abilities.

\section{Genes, Education and Childhood SES}

Our analysis of genes, education and childhood SES proceeds in four steps. First, we discuss construction of our analytic sample from the HRS and provide basic descriptive statistics (Section 3.1). Second, we study associations between the polygenic score and education outcomes (Section 3.2). We confirm that the polygenic score of Okbay et al. (2016) does indeed have considerable explanatory power for the educational outcomes observed among individuals in the HRS. Third, we relate the genetic score to several retrospective measures of childhood SES reported in the HRS (Section 3.3). We also demonstrate that the distribution of the polygenic score is strikingly similar for individuals reporting high childhood SES

\footnotetext{
${ }^{17}$ Even birth weight, another proxy of innate endowments that has been used in prior literature is not immune to this critique as it reflects in utero investments, e.g., mother's smoking behavior (Lien and Evans, 2005), exposure to pollutants (Currie, Neidell, and Schmieder, 2009) stress during pregnancy (Camacho, 2008; Currie and Rossin-Slater, 2013) or mothers' own health (Costa, 1998). See also Aizer and Currie (2014) for a recent discussion.

${ }^{18}$ On multidimensionality, Willis and Rosen (1979) emphasize manual skill, which they distinguish from academic skill.
} 
versus low childhood SES. Fourth, we study gene-environment interactions, comparing the relationship between the polygenic score and education outcomes for individuals who report high versus low childhood SES (Section 3.4).

\subsection{The HRS Sample and the Genetic Score}

The Health and Retirement Study is a longitudinal panel study that follows over 20,000 Americans over age 50 and their spouses. Surveys began in 1992 and occur every two years. The HRS collected genetic samples from 15,680 individuals over the course of three waves (2006, 2008, 2010). Since genetic data from the 2010 wave have not yet been publicly released, our sample only includes individuals genotyped in 2006 and 2008.19 Individuals in the genotyped sample tend to be born in younger birth cohorts, since survival until at least 2006 is required for inclusion. Moreover, women and individuals with more education were more likely to agree to the collection of genetic data.

Our main analysis sample includes all genetically European individuals born before 1965 with non-missing genetic and education data. ${ }^{20}$ We restrict the sample to EuropeanAmericans because the polygenic score we use here was discovered in a sample of all genetic Europeans. The resulting sample includes 8,554 individuals. Table 1 provides some basic descriptives on demographic and educational variables. The mean level of educational attainment is about 13 years, with $13 \%$ of the sample failing to graduate from high school or obtain a GED and about $25 \%$ of the sample earning at least a four year college degree. Roughly $42 \%$ of the sample is male. In our subsequent analysis of educational outcomes, we pool genders, but control for gender interacted with birth year ${ }^{21}$

Table 1 provides descriptive statistics on parental education, as well as a series of categorical variables describing health and various aspects of the socio-economic status of the respondent during childhood. These measures include a self-reported five-point scale for

\footnotetext{
${ }^{19}$ Release of genetic data from the 2010 wave is imminent. Thereafter, the genetic score variable must be re-computed for the larger sample. At that point, it should be straightforward to extend our econometric analysis to include the larger sample.

${ }^{20}$ As part of the genetic data release, the HRS also released a file flagging 8,652 individuals as being of European descent based on their genes. In separate analyses, available on request, we also show that the main results presented in this paper hold when we enlarge the sample to include all 10,045 individuals who self-identify as being white.

${ }^{21}$ Recall from our discussion in Section 2 that the polygenic score does not reflect variants on sex chromosomes, so its distribution should be identical in men and women. In our labor market analysis, we focus on males to bypass considerable issues associated with selection into employment. In Appendix B we explore possible gender differences in how the EA Score relates to years of education. There are some specifications showing larger coefficients on EA Score for men compared to women. The sizes of some gender differences we estimate are not trivial, but it is worth mentioning that results are not very robust, with gender differences showing up only for some very specific sets of SES controls. An obvious direction for future research would be to study how the genetic score interacts with female labor supply decisions and labor outcomes.
} 
health during childhood, a variable indicating the SES of the respondent's family (Well Off, Average, or Poor), as well variables indicating whether the respondent's family suffered various negative economic shocks (moving due to hardship, asking other families for help, or experiencing an extended period of paternal unemployment or economic inactivity). To construct the father's income variable, we first obtain HRS survey responses on the usual occupation of the respondent's father (when the respondent was age 16). This father occupation variable is then matched with average labor income data from the 1960 Census for prime-age male workers to construct an occupation-specific income variable 22

Turning to genetic data, Figure 1 presents a plot of the (kernel-smoothed) density of the EA Score variable in our sample. Values of the score have been demeaned and re-scaled to measure standard deviations relative to the mean. Figure 1 suggests that the distribution of the EA Score is approximately normal.

\subsection{The Polygenic Score and Education in the HRS}

We now study the relationship between the polygenic score and educational attainment in the HRS. Table 2 presents coefficient estimates for regressions explaining years of schooling in our sample. All regressions in Table 2 include a full set of dummy variables for birth year, a male dummy, and a full set of interactions between the birth year and gender dummies. Additionally, every specification includes the first 10 principle components of the full matrix of genetic data. Recall from our discussion in Section 2 that doing so helps us to control for subtle stratification of ethnic groups. Column (1) presents estimates using just this basic set of controls. The estimated coefficient on EA Score suggests that a one standard deviation increase in the score is associated with 0.663 more years of schooling. ${ }^{23}$ Note that the incremental $R^{2}$ associated with the genetic score in this regression is 0.066 , indicating that the score is capable of explaining a large fraction of the variance in educational attainment.

We argue that the EA Score measures biological factors that enhance an individual's ability to acquire new skills or reduce the effort costs of learning. Such an interpretation would be threatened if the score-education relationship were largely driven by correlations between genetic factors and environments that are more conducive to learning. For example, it could be the case that the EA Score predicts household resources that reduce the cost of more schooling, but not an individual's learning ability or capacity for skill acquisition. We therefore explore the robustness of the association as more demographic controls are added.

In Column (2), we add separate measures for father's education and mother's education

\footnotetext{
${ }^{22}$ These retrospective childhood SES measures are discussed in greater detail in Section 3.3

${ }^{23}$ Patterns of missingness in the genetic data make it difficult to use sampling weights provided by the HRS. All regressions presented here are unweighted.
} 
in addition to our basic regressors ${ }^{24}$ As expected, both measures of parental education are positively and significantly related to educational attainment. However, even after controlling for parental education, the EA Score still exhibits a strong association with educational attainment, with a coefficient of 0.491 . The incremental $R^{2}$ associated with the EA Score falls, but remains large at about 0.035. It is unsurprising that controlling for parental education attenuates the relationship between the EA Score and educational attainment. Parental EA Scores are necessarily highly correlated with those of their biological children. As long as parental EA Scores are associated with parental education, there will be a mechanical relationship between parental education, children's EA Scores, and children's education. The fall in the coefficient may also reflect the fact that individuals with higher scores are receiving higher levels of investment from their better education parents. However, the results of Domingue et al. (2015) and Rietveld et al. (2014) suggest that cross-household differences in resources or investments are unlikely to explain much of the score-education relationship, given the similarity of estimates using within-family variation and those using within and across-family variation. Nevertheless, in our subsequent analysis, we will control for parental education in virtually all of our regressions. If we do not, our main results stay the same or become stronger.

In Column (3), we add a set of categorical variables reflecting self-reported health during childhood. An extensive existing literature links childhood health to socio-economic status and labor market outcomes later in life (see Currie (2009) for a review). Indeed, we find that lower self-reported health levels (relative to the Excellent reference category) exhibit a significant negative association with educational attainment. It is worth noting that these health variables have a combined incremental $R^{2}$ of about 0.006 in this specification $(0.015$ when parental education is not included), which is substantially smaller than the incremental $R^{2}$ associated with the EA Score. ${ }^{25}$ In Column (4), we add a battery of controls measuring socio-economic status during childhood. These include dummies for whether or not the

\footnotetext{
${ }^{24}$ As seen in Table 1. parental education is missing for a non-trivial number of individuals. We address this issue by adding separate dummy variables indicating missing values of father's and mother's education.

${ }^{25}$ In results available from the authors, we experiment with specifications adding a series of more specific controls related to health during childhood. These include indicators for measles, mumps, chicken pox, school absences, sight problems, parental smoking, asthma, diabetes, respiratory problems, speech problems, allergies, heart conditions, ear problems, epilepsy, migraines, stomach problems, blood conditions, depression, drug use, psychological conditions, concussions, disabilities, childhood smoking, learning disabilities and other problems. When these are added to a basic regression explaining years of education (i.e., Column (1) in Table 2 but excluding the EA Score), they have a combined incremental $R^{2}$ of 0.104 . Even when we control for these variables, we find that results on the relationship between EA Score and educational attainment are consistent with the results in Table 2 For example, adding all of these childhood health dummies to the specification in the last column of Table 2 yields a point estimate of 0.423 for the coefficient on the EA Score, which is within the 95 percent confidence interval of the estimate without these added controls.
} 
individual's family moved due to financial stress, whether the family ever asked another family for financial help, whether or not the individual's father was ever unemployed for a significant time, and a measure for the average income of the father's occupation in the 1960 Census. Adding these controls does not significantly reduce the coefficient estimate on the EA Score. In Column (5), we show that our estimates are robust to the addition of dummies for the region of birth and an individual's religious affiliation. Comparing Columns (1) and (5), the entire battery of childhood socio-economic and health controls boosts $R^{2}$ by about 0.166 . The incremental $R^{2}$ of 0.032 associated with the EA Score is substantial by comparison 26

Table 3 considers the relationship between the EA Score and dummy variables indicating different types of highest earned degree (No Degree, Two-Year College, College, or Graduate (MA or Professional Degree)). The EA Score is significantly negatively associated with having no degree, but positively associated with having a college degree and earning a graduate degree. It is not associated with having a two-year degree. Additionally, the genetic score not only predicts educational attainment, but also educational performance. Column (4) presents coefficient estimates from a specification in which the dependent variable is an indicator for whether the individual reported having to repeat a grade of schooling. These regressions include controls for education (years) and a complete set of dummies for degree earned. The results suggest that even conditional on completed education, the EA Score is significantly negatively associated with the probability of repeating a grade. A one standard deviation increase in the genetic score is associated with a 3.7 percentage point reduction in the risk of ever failing a grade. Panel B of Table 3 shows that these relationships hold even when we control for parental education.

Taken together, the results in Tables 2 and 3 provide support for two propositions. First, the genetic variation captured in the EA Score is strongly associated with educational attainment along nearly every margin. Compared to other observables, the EA Score accounts for a large fraction of the variation in educational attainment. Second, this relationship does not appear to be driven strongly by childhood environmental factors, at least those that are

\footnotetext{
${ }^{26}$ It should be noted that many of these SES measures may be highly correlated with parental education. Thus the change in $R^{2}$ across specifications is not necessarily a good measure of the relative importance of each new set of controls, since their relationship with education may already be reflected in the relationship between parental education and own-education (Gelbach, 2016). However, the aim here is not to demonstrate the relative importance of each set of controls. Rather, we are concerned with the range of explanatory power of the polygenic score as we control for additional measures of childhood circumstances. If we include the maximal set of SES controls but exclude parental education (a modified version of Column (5) in 2), this yields an $R^{2}$ of 0.212 . Compared to the result in Column (1), this suggests a incremental $R^{2}$ of 0.088 for all SES controls when ignoring parental education. In this specification the EA Score has a incremental $R^{2}$ of 0.049. Much of the explanatory power of our SES variables is being picked up by parental education. Nevertheless, the incremental predictive power of the EA Score is substantial in any of these comparisons.
} 
measurable in the HRS. The inclusion of several controls for different aspects of childhood SES does little to attenuate the relationship between the EA Score and education. ${ }^{27}$ We now take a closer look at the relationship between childhood SES and the EA Score.

\subsection{The Polygenic Score and Childhood SES}

One aim of our subsequent analysis in this section is to better understand how genes and the environment interact. To accomplish this, we use information on childhood environments. Although the HRS surveys individuals at older ages, it contains a set of retrospective questions about childhood circumstances. These can be used to construct variables related to the SES of an individual's household during childhood. Here, we introduce four childhood SES measures in the HRS constructed from the retrospective questions in the Demographics file. All of the measures we construct are binary variables that take the value 1 for high childhood SES and 0 otherwise. We also demonstrate that although some childhood SES variables predict a higher genetic score, the distributions of the polygenic score for highchildhood-SES and low-childhood-SES individuals are strikingly similar. The four variables we construct are:

1. Family Well Off: High SES indicates respondents who reported that their family was "pretty well off financially" or "average" from birth to age 16. Low SES indicates respondents who reported that their family was "poor".

2. Father Income: Based on respondent-provided information about father's usual occupation, we use income data from the 1960 Census to impute an annual salary / work income for each father. We calculate the median for this father's income variable and classify individuals whose fathers earned above median incomes as experiencing High SES during childhood.

3. Move or Help: The HRS asks separate questions about whether a respondent's family ever had to move residences or ask relatives for help due to financial reasons. Since these events are similar (capturing an extraordinary household response), we combine them into a single variable. This combination increases variation in this measure since moving or asking for help are each less frequent events. ${ }^{28}$ High SES indicates respondents whose family never had to move or ask relatives for help for

\footnotetext{
${ }^{27}$ The exception is parental education. However, as discussed earlier, controlling for parental education likely captures the association between parents' and children's genetic endowments.

${ }^{28}$ About 18 percent of respondent families had to move, and about 14 percent had to ask for help. When combined, about 25 percent had to take at least one of these actions.
} 
financial reasons. Low SES indicates respondents whose families did either move or ask relatives for help.

4. Father Employment: High SES indicates respondents whose father never experienced a significant unemployment spell ("several months or more"). Low SES indicates respondents whose father did experience a significant unemployment spell, or those whose fathers were dead or never lived with them. Notice that this variable incorporates information on family structure since it takes the value 0 if the child is raised without a father 29

These SES variables have several shortcomings. For one, they are retrospective, which may lead to non-random measurement or reporting error. For example, an individual's socio-economic status during adulthood could affect how they recall or report childhood circumstances. Alternatively, perceptive individuals may be more aware of their parents' financial difficulties during childhood. If so, then the "Move or Help" variable may capture unobserved skills that also lead to better economic outcomes. Potential measurement problems motivate the use of several SES variables, which allows us to assess whether empirical patterns are robust across measures. Moreover, though the variable "Father Income" is based on averages, it is unlikely to be subject to the same types of reporting error as the other variables. ${ }^{30}$ Finally, we note that there are other measures we could use, including questions about parents' drug or alcohol abuse or physical abuse during childhood. These are relatively rare events, but we discuss them further in Section 5.

Despite possible measurement and reporting issues, we show that the SES variables exhibit consistent relationships with education attainment and the polygenic score. As shown in Panel A of Table 4, each of the childhood SES indicators is associated with significantly higher levels of educational attainment. The strongest relationship is shown for the measure based on father's income. Having a father with above-median income is associated with an increase in educational attainment of 0.76 years, even after controlling for parental education. In Panel B, we present coefficient estimates when the respondent's EA Score is the dependent variable. These results allow us to assess the extent to which environments might be correlated with an individual's genotype because of an association with parental genotype and economic outcomes. The results in Panel B suggest that the relationship between EA

\footnotetext{
${ }^{29}$ All results using this variable are robust to treating cases where the father is dead or never lived nearby as missing.

${ }^{30}$ These issues also motivate ongoing work, where we study younger cohorts. It is worth mentioning, however, that findings in Belsky et al. (2016) provide support for the idea that the polygenic score is related to learning during childhood. Though results are difficult to compare since they use a polygenic score from an earlier GWAS, they find evidence that children with higher scores began talking earlier and, by age 7 , were stronger readers.
} 
Score and environments is positive, but not particularly strong. There is no statistically significant relationship between EA Score and the SES measure based on family's economic situation. Paternal income displays the largest relationship between an SES measure and the genetic score. Individuals having a father with above-median occupational income have genetic scores that are on average higher by a little over one-tenth of a standard deviation 31 Once we control for parental education, the incremental $R^{2}$ associated with each SES measure is very small, ranging from less than 0.001 to 0.004 .32

To further explore the relationship between measures of childhood SES and the polygenic score, we plot the distribution of the score separately for high-childhood-SES and lowchildhood-SES individuals using each of the four measures. These plots are found in Figure 2. The most striking pattern is that, for each SES measure, the polygenic score distributions are similar across SES groups. ${ }^{33}$ In other words, there is little evidence that individuals who grew up in poverty have systematically low genetic endowments. This contrasts sharply with Figure 3, which demonstrates the substantial difference between the distributions of the EA Score for individuals that completed at least a college degree and those that did not. Taken together, these results and the associations in Tables 2-4 provide support for two ideas. First, it appears that both genetic endowments and environmental factors play important roles in generating educational attainment. Second, the links between childhood SES and education are not primarily driven by selection on ability, which would be reflected by more apparent differences in the polygenic scores across groups.34 What remains to explain is how genes and childhood environments interact to produce education outcomes, which we study in the following section.

\footnotetext{
${ }^{31}$ To put this into perspective, the average difference in imputed father's income between the high and low SES individuals based on the father's income measure is approximately $\$ 14,000$. Using evidence from the Earned Income Tax Credit, Dahl and Lochner (2012) find that a $\$ 1,000$ increase in family income contemporaneously raises a combined reading and math achievement score for children by 6 percent of a standard deviation. If the degree of association between parental resources and the genetic score matched this association between family income on achievement scores, then one would expect that individuals in our sample from high and low income households should differ in their average EA Score by about 84 percent of a standard deviation. The observed difference of 13 percent of a standard deviation (or 23 percent without parental controls) is small by comparison.

${ }^{32}$ As expected, if we do not control for parental education (Panel $\mathrm{C}$ of Table 4), high SES predicts the EA Score more strongly. Coefficients on the high SES variables increase in magnitude and the incremental $R^{2}$ associated with each SES measure ranges from 0.002 to 0.012 , where the larger number is for the SES measure based on father's income.

${ }^{33}$ For each measure of childhood SES, we use a Kolmogorov-Smirnov test to reject the null hypothesis that the distributions are equal.

${ }^{34} \mathrm{~A}$ somewhat similar point is made by Altonji, Elder, and Taber (2005), who study labor market returns to Catholic schooling. The concern is that higher wages among individuals with Catholic schooling might be selected on unobservables so that estimated returns are spurious. They argue that if the two groups are similar on observables, they are unlikely to be so selected on unobservables as to undermine estimated returns.
} 


\subsection{Childhood SES and the Gene-Education Gradient}

A large literature explores the extent to which conditions during childhood affect completed education and later-life outcomes (Black, Devereux, and Salvanes, 2005; Heckman and Cunha, 2007). Since government policies can affect resources available during a child's early life, understanding more about the relationship between childhood environments and human capital accumulation has clear policy relevance. Our results highlight an important sign change in the interaction between childhood SES and the polygenic score in equations predicting educational attainment. In particular, environments that promote human capital are substitutes for ability for lower educational outcomes, such as high school completion. However, they are complements to ability for higher educational outcomes, such as college completion. These findings suggest that, for individuals who grew up in poverty, ability predicts high school graduation more strongly than it predicts college completion.

To explore whether SES moderates the relationship between the genetic score and educational attainment, we estimate regressions of the form

$$
\begin{aligned}
\text { DegreeAtLeast }_{i}^{j} & =X_{i} \beta_{0}+\beta_{\text {SES HighSES }}+\beta_{\text {Score }_{\text {EAScore }}} \\
& +\beta_{\text {Int }} \text { HighSES } \times \text { EASCore }_{i}+\epsilon_{i}
\end{aligned}
$$

where DegreeAtLeast ${ }_{i}^{j}$ indicates whether individual $i$ completed at least degree $j$, with $j \in\{G E D$, High School, Two Yr. College, College, Grad $\}$. Here $X_{i}$ contains our standard controls (a full set of birth year dummies, a male dummy, interactions between the birth year and male dummies, and the principle components from the full matrix of genetic data) along with the parental education controls. To further control for population stratification, we also interact the principle components with HighSES and include them as further controls. ${ }^{35}$ Figure 4 plots point estimates of $\beta_{\text {Int }}$ for different measures of SES and for different degree measures $j$. Each panel presents estimates for a different SES measure. Within each panel, the successive estimates plot the point estimate and the $95 \%$ confidence interval for the different dependent variables. The striking pattern that emerges is that there tends to be a significant negative interaction between SES and the score for completing at least low levels of education (high school equivalent or high school), but there tends to be significant positive interaction for more advanced degrees (at least college or graduate school) 36

\footnotetext{
${ }^{35}$ Throughout the paper, in specifications where we interact the EA Score with some other moderating variable, we also include interactions between the principle components and the moderating variable.

${ }^{36}$ It is worth mentioning that, rather than using parental education variables as controls, we can instead use them as an additional measure of SES that we interact with the polygenic score in regressions explaining educational attainment. Doing so, we obtain the same patterns as we do with the SES measures considered here, i.e., higher parental education is associated with a steeper genetic gradient for college completion and above and with a less steep gradient for lower educational outcomes.
} 
The linear interactions presented in Figure 4 do not appear to be driven by outliers or by very specific ranges of the EA Score. The continuous nature of the interaction is apparent from non-parametric (Lowess) regressions explaining educational outcomes as a function of the EA Score for different SES groups, which are presented in Figures $5.6{ }^{37}$ To construct each panel of Figure 5, we regress an indicator for having at least a high school degree on a basic set of regressors: the genetic principal components, birth year dummies, a male dummy, and interactions between birth year and male dummies. We then plot Lowess regression parameters relating the residuals to the EA Score separately for high and lowSES groups. In the panels of Figure 6, we do the same, but the education outcome indicator is college degree or more. According to Figure 5, a higher polygenic score predicts higher education for both SES groups. However, the relationship is stronger for individuals who grew up in low-SES households. In contrast, Figure 6 shows that for higher educational attainment (college degree or more), the positive relationship is stronger for children who grew up in households with more resources.

The patterns in Figures 4,6 are consistent with human capital production functions that allow the roles of family resources and ability to be distinct across outcomes. Specifically, early investments in human capital (proxied by childhood family SES) may substitute for ability in preventing very low levels of educational attainment. However, these same investments could complement ability in generating higher levels of educational attainment such as college completion. It is worth mentioning that our findings on higher degrees are in line with a large literature showing that ability and investments are complements (Becker and Tomes, 1986; Heckman and Cunha, 2007; Aizer and Cunha, 2012). However, the idea that ability and investments might be substitutes along some dimensions merits further exploration. In terms of policy, our findings suggest that access to public education may already prevent high-ability individuals born into poverty from forgoing high school. On the other hand, high ability does not appear to suffice for college completion. In other words, individuals with similar abilities, but who are born into unfavorable circumstances, face lower returns to their ability in comparison to those who enjoyed more advantages during childhood. A number of factors could potentially explain this complementarity. For example, households

\footnotetext{
${ }^{37}$ Results are generally robust if we use probit specifications instead of linear probability models, although the differences are not statistically significant in several specifications. As described in Ai and Norton (2003), it may be misleading to assess the presence of interactions in nonlinear models such as the probit by looking at the coefficient on the actual interaction term between SES and the EA Score. Instead, we calculate the estimated discrete effect of SES for a number of different values of the polygenic score assuming typical values of the other regressors. For (at least) completing college, we find evidence of statistically significant positive differences in the effect of SES as the polygenic score increases when using the Family SES and Father's Income measures. We also find positive (but not statistically significant) differences for the Unemployment and Move / Help variables. For (at least) completing high school, the estimates are less precise, but we consistently find a declining effect of SES as the EA Score increases.
} 
with more resources could invest more in their children starting even before birth. They might also make higher quality investments (e.g., time investments) which could likewise raise the likelihood of a high-score child completing college. Finally, these households could face fewer credit constraints, which could also lower the probability that high-genetic-score individuals from poorer households attain higher education.

Our estimates of interactions between the polygenic score and family SES are consistent with different roles for family resources depending on the education outcome, which would suggest restrictions on the production function for human capital ${ }^{38}$ However, we cannot rule out other accounts related to measurement error or correlations between environmental factors and advantageous parental genetic endowments. For example, it could be the case that actual investment levels (which we proxy with SES), are a positive function of both observed SES and the child's genetic endowment ${ }^{39}$ If this is true, then SES will increasingly underestimate investment as the child's genetic endowment grows. In Appendix C, we show that, under a reasonable set of assumptions, such a scenario will result in bias in the magnitude but not the sign of gene-investment interaction effects that we estimate. Therefore, the sign change in the estimated interaction between genes and investments in low versus high educational outcomes is key. It is not a necessary condition for differences in the interaction effect, but it is a sufficient condition for the existence of such differences. We also show in Appendix C that we cannot guarantee the identification of the interaction sign if we use a more traditional measure of ability such as IQ or cognitive test scores, which may be directly affected by investments. In other words, a key benefit of using genetic data to infer how innate ability interacts with human capital investments is that genetic endowments are fixed and therefore not simultaneously affected by investments, even if they are correlated with them. It is also noteworthy that our pattern of interactions is robust across a number of distinct measures of SES. Indeed, this pattern holds even in the case of the "Family Well Off" measure, which is uncorrelated with the EA Score. This suggests that the interactions we find do not primarily reflect correlation between parental genetic endowments and environments.

Another possibility is that the interactions that we estimate arise from non-linearities in the human capital production function. Suppose that the genetic score is related to education in a non-linear fashion, and that SES is correlated with the genetic score. Then we could estimate significant score-SES interactions that have nothing to do with differences

\footnotetext{
${ }^{38}$ Relatedly, Todd and Wolpin (2003) suggest that typical approaches to estimating the production of cognition may be overly restrictive. Our findings are related since they suggest that ability and investments interact in complex ways (that possibly vary by schooling level) to generate educational outcomes.

${ }^{39}$ Investments could rise with the child's genetic endowment because parents target resources, or because children with high endowments also have parents with high endowments who provide more resources.
} 
in the production function across SES groups. That is, an interaction between the score and observed SES may simply reflect an underlying non-linear relationship between the score and education ${ }^{40}$ In Appendix D, we demonstrate that our results are robust even when we control for non-linearities through a cubic in the EA Score.

We still worry about other threats to identification of the interaction. An omitted third factor could affect education, but exhibit a different relationship with EA Score for each SES group. One possibility is that our binary childhood SES measures mask differences in how household resources rise with genetic endowments. Another possibility is that there are additional genetic factors driving education that relate to the polygenic score in different ways across SES groups. In both cases, we have not identified true complementarities, but instead have captured omitted factors. Finally, there may also be classification error that differs by group if, for example, individuals with lower polygenic scores are more likely to mis-classify their childhood SES. The ideal experiment to test for these effects would involve a random assignment of resources that can be manipulated by policy (e.g. household income) to individuals with different genetic scores.

While we cannot rule out the threats to identification rooted in selection on unobservables, we do believe that the distributions of the polygenic score by SES group plotted in Figure 2 help to allay some concerns. The reasoning is similar to that in Altonji, Elder, and Taber (2005). The plots demonstrate that when we divide the sample by childhood SES, the resulting groups are quite similar with regard to an important and relevant observed source of heterogeneity. Similar polygenic scores across groups provides some support for the assumption that individuals are similar on unobserved factors as well, i.e., that estimated differences in returns to genetic endowments by childhood SES are not the result of selection on unobservables. 41

\section{Genes, Education and Labor Market Outcomes}

Observing the EA Score in a rich data set with information on several key labor market outcomes allows us to explore a number of economic questions that would otherwise be difficult to address. In particular, the HRS data allow us to learn about the relationship between ability and wages, and the conditions under which this relationship is intensified or moderated. In Section 4.1, we demonstrate that the polygenic score predicts wages even after

\footnotetext{
${ }^{40}$ We thank Jonathan Beauchamp for pointing out this possibility.

${ }^{41}$ In results available from the authors, we show that estimates are robust if we restrict attention to individuals who are not in the tails, i.e., if we re-rerun regressions dropping individuals with EA Scores in the top or bottom $10 \%$. In other words, estimated interactions are not driven by individuals in the tails.
} 
controlling for education. We also provide novel evidence that the wage returns to ability are concentrated among the college educated. This is particularly important since our results in the previous section suggest that low-SES children with high abilities are less likely to finish college than high-SES children with similar abilities. Moreover, we demonstrate that the wage returns to ability among the college educated have risen across birth cohorts. Section 4.2 explores this pattern further. We provide evidence that rising returns across cohorts could reflect a genetic basis for adaptation to skill-biased technological change. We also consider (and rule out) several alternative interpretations of estimated empirical patterns. In Section 4.3 , we demonstrate that wage returns to cognition (as measured by a cognitive test score) exhibit rather different patterns over time. This discrepancy may arise because cognitive test scores not only reflect endowed abilities, but are also likely to capture ongoing human capital investments. This difference illustrates the value of incorporating genetic measures of ability into the economic analysis of labor market outcomes. Finally, in Section 4.4. we further leverage rich information in the HRS to assess whether the EA Score relates to other adult labor outcomes, including wealth and labor supply. For these measures, we show that the polygenic score predicts better outcomes for individuals regardless of education. Contrary to results on wages, these results suggest that some of the adult benefits of a high genetic score are not limited to individuals with a college degree.

\subsection{Wage Returns to Ability}

At least since Becker and Chiswick (1966), labor economists have been concerned with ability bias in estimating the relationship between schooling and various economic outcomes. If the unobserved factors that promote education also independently predict labor market success, then estimates of the return to schooling might be biased. This concern not only raises an econometric point; it also poses fundamental questions about the structure of heterogeneity in labor market decisions and outcomes. How and to what extent do the characteristics or traits that promote education also affect labor supply, wages, and retirement? Observing the EA Score allows us to make some progress on this question, demonstrating how previously unobserved factors might not only drive education, but also several other outcomes conditional on education.

In this section, we demonstrate two key patterns. First, the EA Score is associated with higher wages even after we have controlled for education, but only among the college educated. Second, this association has risen across birth cohorts. Table 5 examines the relationship between the EA Score and the log wages of men who work at least 20 hours per week. All regression results pool person-year observations for ages 50-64, and cluster 
standard errors at the person level. As seen in Column (1) of Panel A, without any controls for own education a one standard deviation increase in the EA Score is associated with an increase in log wages of 0.099 (or an increase in wages of approximately 10 percent) 42 When we add own education controls in Column (2), this average relationship declines to 0.021, but is still statistically significant at the 0.10 level. We also explore whether there is any interaction between the genetic score and having at least a college degree. This is motivated by a literature that stresses possible complementarities between human capital investments and ability (Heckman and Cunha, 2007; Cunha, Heckman, and Schennach, 2010). In Column (3), we find a statistically significant interaction between the EA Score and having at least a college degree in determining log wages.43 Indeed, our point estimates suggest that the wages of individuals without a college degree do not rise with genetic ability. By contrast, a one standard deviation increase in the score is associated with an increase in log wages of 0.062 for those with a college degree. Moreover, this interaction is not driven by nonlinearities in the relationship between the score and log wages: we obtain a coefficient of $0.061(p$-value $<0.05)$ when a cubic in the EA Score is added to the specification in Column (3).

In Columns (1)-(3) of Panel B, we restrict the sample to those with a college degree and examine whether the association between the score and wages has evolved over time or across cohort groups. This is motivated by the large literature in labor economics demonstrating a rise in the return to skill and an increase in residual income inequality over the last several decades (Lemieux, 2006, Autor, Katz, and Kearney, 2008, Acemoglu and Autor, 2011; Lochner and Shin, 2014). In Column (1), we interact the score with an indicator for years after 2000 (median year in the wage sample). We find a statistically significant and economically substantial interaction, as the estimates suggest that the coefficient on the genetic score rose by 0.09 in the post-2000 period ${ }^{44}$ However this could reflect either a time or cohort interaction, since the correlation coefficient between year of birth and calendar year in our wage sample is over 0.80. In Column (2), we instead interact the genetic score with an indicator for being born after 1942 (median birth year in the wage sample). This interaction is also large and highly significant. In Column (3), we add both interaction terms and we only find a significant interaction with the indicator for later birth years. This suggests that the returns to genetic ability have been rising across birth cohorts for individuals with a

\footnotetext{
${ }^{42}$ All wage specifications include controls for parental education unless otherwise specified.

${ }^{43}$ To control for possible population stratification, we also include interaction terms between the principal components and the indicator for a college degree

${ }^{44}$ To control for population stratification, we always include interactions between the principle components and the "Year > 2000" and "Birth Year > 1942" indicators whenever these binary variables are interacted with the EA Score in Panel B of Table 5
} 
college degree. We find no statistically significant interactions (or main effects for the EA Score) when Panel B is repeated for the population that did not go to college.

The results in Table 5 do not appear to be driven by anomalous cohorts or outliers. In Figure 7, we plot the estimated coefficient (and 95 percent confidence intervals) on the EA Score when the sample is sub-divided into four disjoint birth-year groups. Panels A and $\mathrm{B}$ show the results separately for those without a college degree and those with at least a college degree, respectively. For no period do we find a significant relationship between the EA Score and log wages for those without a college education. However, among college graduates, the point estimate smoothly increases and becomes statistically significant and economically substantial for the two latest birth-year groups.

These results suggest that high-ability individuals with a college degree face a widening ability gradient in the labor market which has gotten steeper for more recent cohorts. Seen another way, these results indicate that high-ability individuals that do not have a college degree are not able to profit from their ability in the labor market. This is especially concerning given previous results suggesting that childhood SES is an important factor determining whether high-ability children go to college. Low childhood SES does not simply

reduce mean education and wages. It also diminishes the capacity of high-ability individuals to access career paths in which they can profit from their ability. In the following section, we discuss possible interpretations of the empirical patterns established in this section.45

\subsection{Genes, Job Tasks and Skill-Biased Technological Change}

In the previous section, we showed evidence of rising wage returns to ability across birth cohorts among the college educated. In this section, we discuss economic theories that could help to explain these patterns. We also conduct sensitivity analyses to rule out some competing hypotheses, which could also explain these empirical patterns.

\subsubsection{Skill Biased Technology Change}

The empirical patterns demonstrated in the previous section are consistent with the ongoing rise in the returns to skill. This phenomenon is often explained by the complementarity

\footnotetext{
${ }^{45}$ Our results in this section on wages coupled with results from the previous section on gene-SES interactions suggest that, if we regress wages onto genes, childhood SES and an interaction, the interaction would be positive. In results available upon request, we confirm find this is true for three of our four SES measures. However, the interactions in such specifications are not significant at conventional levels. For example, if we use the "Family Well Off" measure, we estimate a positive interaction with a $p$-value of about 0.14 . It is worth mentioning that there are some sets of controls where we obtain significance at conventional levels, but significance is highly dependent on the particular control set and therefore fragile. Thus, we do not present these results.
} 
between certain skills or abilities and the introduction of new technologies (Acemoglu, 1998). Some individuals may have a greater capacity for learning how to use new technologies, either because of endowed abilities or because of past human capital investments. Such individuals may find it easier to adapt to technological shocks and use them to enhance their productivity in the workplace. If the EA Score captures such an ability to learn new skills, then the rising return to genetic ability may be a consequence of skill-biased technological change (SBTC).

To explain differences in the wage returns to ability across cohorts, we further note that different cohorts in our sample witnessed the introduction of new technologies at different points in their life-cycle. The older cohorts observed in the 1990s were well into their careers when computerization and other processes spread in the 1980s. Even with a high genetic score, the incentives for the older cohorts to invest in learning these new technologies would be lower than the incentives faced by the younger cohorts that we observe in the 2000s. This is quite consistent with the logic of the Ben-Porath (1967) model of life-cycle human capital investment. As individuals age, they are less likely to make costly human capital investments (in this case adapting to new technologies, such as computers) given their shorter time horizons.46 As a result, we would expect to see a higher genetic wage premium for the younger cohorts who chose to invest more heavily in adapting to computers and other technologies arriving in the 1980s.

\subsubsection{Job Tasks}

To buttress the argument that SBTC can help to explain wage returns to ability across birth cohorts, we next consider how the EA Score relates to job tasks. The literature on SBTC has implicated computerization as an important driver of rising returns to cognitive skills. In a review of the literature Katz and Autor (1999) discuss many reasons why increased access to computers shifts the demand for skilled labor. For example, it could be the case that skilled workers are "more flexible and facilitate the adoption of new technologies so that all technological change increases the relative demand for more-skilled labor." (p. 1535). Alternately, more skilled workers might be able to work more creatively with available information.

In an influential study, Autor, Levy, and Murnane (2003) link computerization and SBTC to the tasks that workers perform on the job. Specifically, Autor, Levy, and Murnane (2003) argue that computerization should substitute for the labor of workers with jobs that involve repetitive tasks that follow explicit rules or patterns (routine tasks). Conversely, computerization should complement the labor of workers who carry out non routine tasks that involve "problem-solving and complex communication activities." Autor, Levy, and Murnane (2003)

\footnotetext{
${ }^{46}$ Willis $(2013)$ makes a related point when using the HRS to study age differences in adoption of computers.
} 
use the Department of Labor's Dictionary of Occupational Titles to measure the intensity of five relevant tasks types: 1) non-routine analytic (use of math), 2) non-routine interactive (direction, control, and planning), 3) routine cognitive (set limits, standards, and tolerances), 4) routine manual tasks (finger dexterity), and 5) non-routine manual (eye, hand, and foot coordination). Examining patterns within education, occupation, and industry groups, $\mathrm{Au}-$ tor, Levy, and Murnane (2003) indeed find that computerization has been associated with a rise in non-routine cognitive tasks, and a reduction in routine cognitive and routine manual tasks.

Using data from Autor, Levy, and Murnane (2003), we are able to assign to each occupation group observed in the HRS data a measure of task intensity for each of the five job tasks listed above ${ }^{47}$ We restrict our analysis to occupation observations over the period 2006-2014 48 Since a given task intensity has no natural interpretation, we create dummy variables for each worker indicating whether or not their occupation has an above-median task intensity within the HRS wage sample. Table 6 presents estimates of the relationship between the genetic score and working in an occupation with an above-median intensity of various tasks. The specification here follows the same sample definition and uses the same controls as our basic wage sample 49 Our results are consistent with the proposition that the EA Score is associated with job tasks that were complemented by computerization. We find that the polygenic score is positively associated with working in occupations that have above-median values of the non-routine cognitive tasks Columns (1)-(2). We also find a statistically significant negative association between the score and jobs requiring manual dexterity. We find no statistically significant association with the routine cognitive task measure or the non-routine manual task 50

\footnotetext{
${ }^{47}$ Data on the task intensities associated with each occupation can be found on David Autor's website: http://economics.mit.edu/faculty/dautor/data/autlevmurn03. The Autor, Levy, and Murnane (2003) task intensity measurements that we use are based on the 1991 Dictionary of Occupational Titles associated with male workers. The public-release version of the HRS data masks specific occupations, but aggregates them into broader categories. We link the Autor, Levy, and Murnane (2003) data on task intensities to Census and American Community Survey data to create average task intensities for the occupation categories used by the HRS.

${ }^{48}$ There are three different masking schemes covering different time periods: 1992-2004, 2006-2010 and 2012-2014. The masking scheme used in the earliest period features 17 categories while the schemes in the latter two periods use substantially more (25 and 23 categories, respectively). Since we rely on average task intensities across these masked categories, we opt to focus on the observations allocated using finer categories, as this maximizes variation in the intensity measures. In particular, Category 2 in the 1992-2004 masking scheme "Professional specialty operation and technical support" appears to be problematic, as it captures a large fraction of individuals in our wage sample under this scheme (over 20 percent of observations) and appears to contain many disparate occupations that are reallocated to smaller distinct groups in the later masking schemes.

${ }^{49}$ That is, Column (2) of Panel A in Table 5

${ }^{50} \mathrm{As}$ noted earlier, we restrict attention to the observations where the HRS masks occupational categories using finer groups. If we include those observations where occupations are coded according to the 1992-2006
} 
The results presented in this section add some nuance to our conclusions regarding genetic ability and labor market outcomes. While we find that the college educated alone tend to experience a return to genetic ability, this gradient only appears in later years or cohorts. This pattern appears quite consistent with complementarities between technological change, a college education and genetic proclivity for learning. This account is bolstered by the positive association between the score and non-routine cognitive job tasks. These results also imply that there is a subset of the population with high genetic ability that may not profit from new technologies because they do not obtain a college degree. Coupled with our earlier finding that college completion for individuals with similar scores depends in part on childhood SES, results in this section suggest that there may be unrealized human potential in the economy. Greater access to education may help to unlock it.

\subsubsection{Sensitivity Analysis}

It is possible that mechanisms unrelated to skill-biased technological change could explain our results on wages. Here, we explore three alternative mechanisms, which we believe we are able to rule out. First, changing returns to the EA Score could stem from differential selection into college over time. As seen in Panel A of Figure 8, college degree rates rise substantially across the cohorts in our sample. If college graduates are an increasingly less selected group, then this could explain why the importance of genetic factors among college graduates might rise over time. Among early birth cohorts, college graduates with low EA Scores might have had particularly high values of other endowments, nullifying a genetic gradient. However, as shown in Panel A, college degree rates stabilized for individuals born in 1944 or later in our wage sample. Furthermore, as seen in Panel B, the average EA Score among college graduates in our wage sample is more or less the same with the exception of the oldest cohorts. Taken together, these patterns suggest that any bias from differential selection into college could only come through patterns in these older groups. Appendix E demonstrates that our main results continue to hold even when we restrict the sample to individuals born in later cohorts (1944 or later). In this restricted sample we continue to find a larger return for college graduates born after the median birth year (now 1949). The estimates imply that a one standard deviation increase in the EA Score is associated with

scheme, our results become attenuated or tend toward zero. However, we still find a statistically significant positive association between the EA Score and the non-routine analytic task (coefficient of 0.023, with $p$-value $<0.05)$. All other coefficients are small and statistically insignificant.

${ }^{51}$ The HRS asks some questions about job characteristics, including questions about computer use. We find that the EA Score is associated with computer use (negatively associated with the lowest computer intensity). However, the question does not allow us to differentiate the kinds of tasks performed with computers on the job. 
6.9 percent higher wages for college graduates born 1944-1949 or earlier, but it is associated with about 17.1 percent higher wages for college graduates born after 1949.

A second alternate account involves mortality-driven selection bias. Since individuals had to be alive in the 2000 s to be genotyped, our estimates could suffer from selection bias if older birth cohorts feature a different mix of unobserved abilities due to selective mortality. Suppose that the EA Score is positively associated with longevity. In this case, sample selection might attenuate the relationship between the EA Score and wages for early cohorts (who are observed in the 1990s), since low EA Score individuals who survive until the 2000s might be positively selected on other unobservables. Panel $\mathrm{C}$ of Figure 8 plots the average EA Score for individuals in the wage sample across the four birth cohort groups studied above. We do not find statistically significant differences in the average EA Scores across these cohorts, which is inconsistent with severe selection bias 52 Furthermore, as indicated in Appendix E, our results still hold even when we exclude the earliest birth cohorts.

A third alternate explanation centers on selection bias related to retirement. It could be the case that the relationship between wages and the timing of retirement is different for individuals of different genotypes, resulting in an apparent change in the genetic premium across cohorts. For example, suppose that individuals with both high values of the EA Score and high wages are more likely than other groups to retire young. For older cohorts, we may not observe many of these individuals working in the time frame of our sample, dampening the genetic gradient in wages. Among younger cohorts, we will observe more person-year observations for such individuals before their early retirement. This shift in selectivity across cohorts would generate an apparent cohort effect. However, this does not appear to be driving our results. First, because new cohorts are introduced over the course of the HRS, the average age in the wage sample falls over birth cohorts, but not dramatically. For college graduates the average age in the wage sample is 58.3 for individuals born during or before 1942, and 57.2 for younger cohorts. Furthermore, in results available upon request, we show that the result on cohort effects continues to hold if we restrict the sample to individuals aged 50-59, a range before most retirement decisions (only 15.5 percent of men in our wage sample aged 59 are retired).

\footnotetext{
${ }^{52}$ We do find statistically significant differences using sufficiently fine birth cohort groups for the overall analysis sample (i.e., not restricting to the wages sample). Individuals born before 1930 are observed to have higher EA Scores than later birth cohorts. This is quite consistent with differential mortality based on the EA Score. However, this does not generate bias in our wage results because very few people born before 1930 are present in our wage sample.
} 


\subsection{Cognitive Test Scores}

Our results on the rising return to genetic ability relate to an existing literature on cognitive skills and income inequality. Murnane et al. (1995) find that the returns to cognitive skills (measured by math test scores) were larger in the 1980s compared to the 1970s for young workers. Gould (2002), using a cognitive test score, argues that there is a rise in the returns to intelligence. Heckman and Vytlacil (2001) show mixed evidence on rising returns to cognition when relaxing parametric assumptions 53 One important issue is that previous work may be capturing results from endowed cognitive abilities, acquired cognitive skills or both. A strength of our analysis of the polygenic score is that we know that our measure is fixed at conception and that it therefore is not influenced by investments thereafter.

In this section, we ask if the polygenic score and a typical proxy for ability (a cognitive test score) exhibit similar patterns of association with labor outcomes. If the patterns are similar across measures, this would validate the use of cognitive scores as a measure of genetic ability. However, if there are differences, then the two scores may be measuring different abilities or acquired skills. This would suggest that measuring cognitive ability endowments using test scores could be problematic, leading to inaccurate policy-relevant conclusions.

We consider a more traditional measure of cognitive ability: scores from a cognitive test administered to individuals in the HRS. Details on how we construct the Cognition Score variable are relegated to Appendix F, where we also present results from regressions where we include Cognition Score as a regressor. Here, we provide a summary. We find that the EA Score and the Cognition Score are positively correlated $(\rho=0.193)$. The modest degree of correlation could arise from two different possibilities. First, it could be the case that both the EA Score and the Cognition Score are noisy measures of the same underlying factor. In this case, the relatively weak correlation could reflect measurement error in both scores, or the fact that the Cognition Score may also capture endogenous human capital investments. However, it could also be the case that the EA Score and the Cognition Score reflect distinct but related abilities.

Regarding their relationship to economically relevant outcomes, both scores tend to predict educational attainment and labor outcomes, even conditioning on the other score. A critical difference emerges in later life labor market outcomes, however, which we highlight here. Most notably, the Cognition Score seems to predict higher log wages for all workers, but does not show a larger association for college workers, or for more recent cohorts. In particular, we repeat the exercise in Figure 7 for Cognition Score. The panels of Figure 9

\footnotetext{
${ }^{53}$ Further contributions to this literature include Juhn, Murphy, and Pierce (1993), Taber (2001) and Tobias (2003).
} 
plot the coefficient on Cognition Score for successively later time periods for individuals with and without a college degree. We find that the coefficient on Cognitive Score is generally positive and less than 0.10 for all time periods and both education groups. There does not appear to be any discernible time trend in these estimated coefficients. By contrast, we only find a statistically significant relationship between the EA Score and log wages for college graduates, and there appears to be substantial growth in this association over time. With these data, using the available Cognition Score as a proxy for ability would mask important interactions between ability, formal education, and the macroeconomy. The Cognition Score may be picking up a combination of ability and endogenous investments in human capital. 54 If the the Cognition Score and the EA Score reflect different factors, as our results seem to suggest, then cognitive test scores (and other measures that may reflect endogenous investments) are perhaps the wrong measure with which to conduct policy analysis related to ability endowments. 55

\subsection{The Polygenic Score, Labor Supply and Wealth}

We continue our study of the relationship between the EA Score and economic outcomes, asking if its relationship extends to employment, retirement and wealth. For these outcomes, we find that the polygenic score predicts better labor outcomes even after we control for education. In contrast to our findings on wages, we demonstrate that these benefits are not limited to individuals with a college degree. Results therefore suggest the possibility that high-ability individuals are able to distinguish themselves in ways that do not require college education (and the household resources that would make college education possible).

\subsubsection{Labor Supply}

Panels A and B of Table 7 provide estimated associations between the EA Score and work status and retirement, respectively. As with wages, only men are included in these regressions

\footnotetext{
${ }^{54} \mathrm{An}$ alternate possibility is that the Cognition Score also reflects some investments which improve performance on exams (test taking skills), without actually boosting productivity in learning new skills. Indeed, a fairly typical critique of standard proxies of cognition is that they measure factors that are not particularly valuable or productive, but are more likely to be found among more privileged groups (Jencks and Phillips, 2011; Polachek et al. 2015). Our results are not exactly consistent with this line of argument, since we do find a non-trivial association between the Cognition Score and wages.

${ }^{55}$ This does not mean that measures similar to the Cognition Score are not useful in economic research. Rather, they are problematic if used as measures of ability endowments. In a seminal paper, Neal and Johnson (1996) use AFQT to measure how "pre-market" skills, stating "...we view the test as a test of achievement and learned skill, not of innate ability (p. 887)." Similarly, Autor et al. (2015) argue that they identify post-natal environmental effects on gender gaps by controlling for infant health and comparing siblings.
} 
because of the substantial amount of selection governing female labor force participation for these cohorts. Panel A investigates the relationship between the EA Score score and a binary variable indicating whether or not the respondent is working for pay. Column (1) reports results when the only controls are the principal components of the genetic data, a full set of dummy variables for age, dummy variables for each birth year, and dummy variables for each calendar year. For ease of exposition, we use a linear probability model. The coefficient in Column (1) of 0.032 suggests that a one standard deviation increase in the EA Score is associated with a 3.2 percentage point increase in the probability of working. In Column (2), we add controls for own education (years of schooling and a complete set of degree dummies) as well as parental education. Adding these controls causes the coefficient on EA Score to fall to 0.019, though it remains statistically significant. In Column (3), we also allow for an interaction between EA Score and a dummy for obtaining at least a college degree to allow for possible complementarities between schooling and genetic factors that promote education. We find no evidence of such complementarities for this measure of work.

In Panel B of Table 7, we consider the discrete-time hazard of retiring given employment in the previous wave of the HRS. We restrict the sample to those who were not retired and who were working for pay in the previous HRS wave. We regress a binary outcome for whether or not an individual declares that they are currently retired onto the same sets of regressors used in the wage equations. The estimated coefficient on the EA Score is -0.013 in the first two specifications and -0.011 in the third. The magnitude of this association is particularly striking. The probability of retirement in any year of our sample is about 12.5 percent. The estimated associations here suggest that a one standard deviation change in the EA Score is associated with a roughly 10 percent reduction in retirement probability, even after controlling for own and parental education 56

\subsubsection{Wealth}

We end this section by examining the relationship between the polygenic score and household financial wealth. Wealth reflects the combination of lifetime labor market performance, investment decisions and additional factors, such as assortative mating and bequests. In Table 8, we present results from regressing log wealth onto the polygenic score and our standard set of controls 57 The magnitudes of estimated coefficients are striking. In Column

\footnotetext{
${ }^{56}$ An extension would look at retirement more carefully, taking into account that a discrete time hazard may overlook important non-linearities in retirement probability as individuals age.

${ }^{57}$ The sample is restricted to the financial respondent in each household-year. The household respondent might be of either gender (52 percent of financial respondents are female in our sample) regardless of the identity of the primary breadwinner in the household. Therefore, we do not restrict the sample to men in response to sample selection concerns as we did with the wage and labor supply regressions.
} 
(1), the dependent variable is the log of marketable wealth, which includes liquid or easily liquidated assets: cash or cash equivalents, bonds, stocks and stock mutual funds. We find that a one-standard deviation increase in the score is associated with a 0.183 rise in log marketable wealth. In Column (2), the dependent variable is a total wealth variable that also includes housing wealth and the value of pension accounts. With this total wealth measure, we estimate a coefficient on the EA Score of 0.085. In Columns (3)-(4), we continue to focus on total wealth but split the sample by college education. A one-standard deviation increase in polygenic score for individuals without a degree predicts a 0.082 rise in log total wealth. For individuals with a degree, the corresponding estimate is 0.080. It appears that we do not find evidence of complementarities between college education and genetic endowments in the accumulation of wealth. This finding contrasts with our results on wages. It also suggests that individual financial wealth reported in the HRS is not solely driven by an individual's wages, but also reflects additional lifecycle decisions and outcomes, each of which can exhibit a complex relationship with the polygenic score.58 One caveat to our wealth results is that we do not address possible assortative matching, which likely plays a role if individuals with similar scores form households and accumulate wealth together 59

\section{Childhood Environments and Unrealized Potential}

Studies from a variety of fields have demonstrated substantial intergenerational persistence in socio-economic status (Black, Devereux, and Salvanes, 2005, Alexander, Entwisle, and Olson, 2014). ${ }^{60}$ In comparison to children born into well-off families, children born into poor families tend to end up less educated, less healthy, more prone to violence and contact with the police, more likely to be unemployed and more likely to earn low wages.

The inheritance of ability is one possible mechanism explaining these patterns. However, it is also likely that low-SES parents are less likely to invest in their children than are high-SES parents. If differences in investments play a role, then the intergenerational persistence of socio-economic status suggests substantial inefficiency in the form of wasted human potential. In particular, high-ability children trapped in poor households may face

\footnotetext{
${ }^{58}$ Indeed, in ongoing work, we explore the relationship between genes and financial wealth further. We assess whether the relationship between the EA Score and wealth is mechanical, arising since college educated individuals earn more money. Alternatively, we ask if individuals with similar earnings and education, but different polygenic scores, appear to make systematically different investment decisions that would leave them with less wealth at retirement. In particular, we study the EA Score in relation to variables that capture investment behavior and wealth accumulation, including financial literacy, portfolio choice, beliefs about the stock market and savings.

${ }^{59}$ Ongoing work using the HRS will address assortative matching and mating.

${ }^{60}$ Related, Hilger (2016) studies patterns of intergenerational mobility across time in the U.S.
} 
substantially worse economic outcomes than children born into better circumstances. Our findings on the gene-college gradient exemplify this concern, suggesting that individuals with high genetic scores born into low-SES families face lower returns to their ability endowments in comparison to their high-SES counterparts. The efficiency case for interventions becomes stronger if the goal is to reduce wasted human potential by devising policies that mitigate under-investment in human capital (Heckman and Masterov, 2007).

To assess the extent of wasted potential at different ability levels, we examine how childhood SES predicts a number of economic outcomes for individuals with similar genetic endowments. In Table 9, we divide the sample by terciles of the EA Score and regress economic outcomes on a dummy variable for high childhood SES. The dummy variable takes a value of 1 if an individual reports a high value of SES for each of the four measures examined in Section 5. We also consider two additional measures of acute childhood hardship: an indicator for whether parents abused alcohol or drugs and an indicator for child abuse. All specifications control for the EA Score to ensure that results are not driven by within-tercile differences in ability endowments. Recall that plots of the polygenic score by childhood SES presented in Figure 2 show considerable overlap. Therefore, in comparing individuals with similar genetic scores born into different childhood SES, we do not need to rely on individuals whose polygenic score puts them in the tail of their respective SES distribution.

In Columns (1)-(3) of each tercile panel, we consider education outcomes (years of education, at least college degree and at least high school diploma). In all cases, high SES predicts higher education. This means that even when we compare individuals with similar abilities, we find that the environment plays an important role in determining the amount of education an individual eventually obtains. In Columns (4) and (5), we consider log wages and $\log$ wealth, respectively, but do not control for education. For low-ability individuals, high SES during childhood predicts higher wages and wealth. For individuals in the middle of the ability distribution, high SES predicts higher wealth. For high-ability individuals, there is no effect on either wages or wealth. In Column (6), we consider Cognition Score. For medium and high-ability individuals, Cognition Score rises with childhood SES if we do not control for education.

In Columns (7) - (9), we again consider wages, wealth, and Cognition Score, but include education controls. The measure of wealth considered here is the log of total wealth, which includes the value of real estate and pension accounts. A striking finding is that, across the ability distribution, there is no statistically significant relationship between SES and wages or wealth once we have controlled for educational attainment and the genetic score. This result may have implications for policies targeting the economic outcomes of low-SES children. Comparing individuals with similar ability endowments, but possibly divergent 
environments, we find little evidence of a continued impact of early life SES once we control for schooling. Ensuring access to quality education for high-ability children in poor circumstances may therefore be a critical strategy to prevent wasted human potential. Further, there is no relationship between Cognition Score and childhood SES once we have controlled for schooling. Our results in Column (9) suggest that across the ability distribution, the relationship between cognitive test scores and childhood SES can be explained by the role that family circumstances play in determining a child's education.

We also consider other measures of bad environments during childhood and the estimates are striking. After controlling for childhood SES, parental drug and alcohol abuse (reported by $16 \%$ of the sample) does not seem have any significant relationship with economic outcomes. Child abuse is another matter.61 Across the board, there appears to be no statistically significant relationship between abuse and educational outcomes. For low-ability individuals, when we control for education, physical abuse is associated with lower wages and lower wealth (19 and 23 percent declines, respectively). For middle and high-ability individuals, we find no association between abuse and wages. For wealth, childhood abuse is associated with a 28 percent decline in wealth for middle ability individuals, and a 39 percent decline for high ability individuals. The role played by bequests versus different labor market performance, employment decisions or consumption patterns in explaining these wealth differences merits further exploration if we are to make specific policy recommendations. Moreover, policies that reduce child abuse do not require a justification based on long-term wealth losses. Still, the magnitude of the wealth differences we estimate could potentially provide support for interventions to reduce child abuse that might otherwise be deemed too costly.

\section{Discussion}

Recent breakthroughs in behavioral genetics - most notably the research presented in Okbay et al. (2016) - allow researchers to identify genetic endowments that robustly explain educational attainment. Using HRS data, we show that up to $6.6 \%$ of the variation in educational attainment is explained by the genetic index presented in Okbay et al. (2016). We demonstrate that the genetic endowments that predict educational attainment also predict employment, a longer work life, earnings, and wealth. We also provide evidence that childhood SES moderates the relationship between genes and various educational outcomes. Finally, we provide novel evidence that the wage premium associated with the genetic in-

\footnotetext{
${ }^{61}$ Respondents were asked if they experienced physical abuse by either one of their parents before they turned 18. $6.93 \%$ of our sample reported that they had.
} 
dex is limited to individuals with a college education. Moreover, the premium appears to have risen across birth cohorts. We argue that structural changes in the economy may have contributed to a rise in the genetic gradient in wages among individuals with a college degree.

Our findings based on observing genetic heterogeneity could be incorporated into structural models that are often devised for use in ex ante policy evaluation. The structure of heterogeneity assumed in these models is often tremendously important in driving predictions about labor market dynamics. For example, in a seminal contribution to the field, Keane and Wolpin (1997) suggest that 70\% of the variability in the career paths of young men is driven by heterogeneity in unobserved (age 16) factors. When building these kinds of models, researchers face a large number of choices about how to model heterogeneity - from picking which parameters to make random, to determining the structure of correlation between unobservables. The results presented here may offer some restrictions on the structure of heterogeneity in these models. For example, our estimates suggest some restrictions on how the unobservable factors that drive education relate to wages and wealth, conditional on education. Our findings also point to possible differences in the education production function for high school versus college completion.

Our results also suggest several interesting avenues for future research. A natural extension would seek to combine the polygenic score studied here with more exogenous measures of childhood SES. We believe that plausible assumptions allow us to at least sign the interaction between genetic endowments and childhood SES even through these may be simultaneously determined by parental genes. Nevertheless, more robust inferences could be made with access to randomly assigned childhood circumstances or investments. Indeed, in any ex-post evaluation of an existing policy, the genetic score can be used to detect the presence of heterogeneous effects by ability.

Another important task is to better understand the mechanisms that link the polygenic score studied here and economic outcomes. In ongoing work, we try to understand the relationship between the score, beliefs formation and the ways in which people make health and financial decisions. If the genetic underpinnings of education function through their impact on how people process new information, then this might offer clues to how policies could be designed to better maximize the potential of individuals with disparate ability endowments. Such insights might ultimately guide the design of school curricula or the content of interventions such as job-training programs.

More broadly, a recurring theme in our empirical results is that individuals with similar abilities, but born into different socioeconomic circumstances, face diverging economic outcomes. These findings suggest an important role for policies that invest in poor children and, more generally, provide some support that such investments could mitigate inefficiently 
low investments in human capital (Heckman and Masterov, 2007). Our findings on wasted potential complement mounting evidence from a variety of fields suggesting the misallocation or squandering of human resources. Researchers have reached this conclusion in different ways. For example, Hsieh et al. (2013) show evidence that innate talent, especially among blacks and women, is likely misallocated across occupations, and highlight the implications of misallocation for economic growth in the U.S. In another study, Chetty, Henden, and Katz (2016) demonstrate that randomly assigned vouchers that move children from high-poverty to less poor neighborhoods can improve labor market performance in the long run. This suggests that policy-relevant factors affect how well a child with a given set of endowments will eventually perform. Finally, recently-published qualitative research indicates that individuals growing up in disadvantageous environments, though resilient and ambitious, may not reach their full potential. Regarding a sample of blacks growing up in poverty in Baltimore, whom the authors study for a decade, DeLuca, Clampet-Lundquist, and Edin (2016) write, "[W]hen we left them in 2012, too few had become all that they hoped to be -and were probably capable of becoming." Using genetic information matched to a large longitudinal data set, our findings support the authors' speculation that children born into poverty are capable of achieving more than they do.

\section{References}

Acemoglu, Daron. 1998. "Why Do New Technologies Complement Skills? Directed Technical Change and Wage Inequality." Quarterly Journal of Economics :1055-1089.

Acemoglu, Daron and David Autor. 2011. "Skills, Tasks and Technologies: Implications for Employment and Earnings." Handbook of Labor Economics 4:1043-1171.

Ai, Chunrong and Edward C Norton. 2003. "Interaction Terms in Logit and Probit models." Economics letters 80 (1):123-129.

Aizer, Anna and Flavio Cunha. 2012. "The Production of Child Human Capital: Endowments, Investments and Fertility." Mimeo, Brown University.

Aizer, Anna and Janet Currie. 2014. "The Intergenerational Transmission of Inequality: Maternal Disadvantage and Health at Birth." Science 344 (6186):856-861.

Alexander, Karl, Doris Entwisle, and Linda Olson. 2014. The Long Shadow: Family Background, Disadvantaged Urban Youth, and the Transition to Adulthood. Russell Sage Foundation.

Almond, Douglas and Janet Currie. 2011. "Killing me softly: The Fetal Origins Hypothesis." Journal of Economic Perspectives 25 (3):153-172.

Altonji, Joseph G, Todd E Elder, and Christopher R Taber. 2005. "Selection on Observed and Unobserved Variables: Assessing the Effectiveness of Catholic Schools." Journal of Political Economy 113 (1):151-184. 
Autor, David, David N. Figlio, Krzysztof Karbownik, Jeffrey Roth, and Melanie Wasserman. 2015. "Family Disadvantage and the Gender Gap in Behavioral and Educational Outcomes." Mimeo, University of Florida.

Autor, David H, Lawrence F Katz, and Melissa S Kearney. 2008. "Trends in US Wage Inequality: Revising the Revisionists." Review of Economics and Statistics 90 (2):300-323.

Autor, H, David, Frank Levy, and Richard J Murnane. 2003. "The Skill Content of Recent Technological Change: An Empirical Exploration." Quarterly Journal of Economics 118 (4).

Beauchamp, Jonathan P., David Cesarini, Magnus Johannesson, Matthijs J. H. M. van der Loos, Philipp D. Koellinger, Patrick J.F. Groenen, James H. Fowler, J. Niels Rosenquist, A. Roy Thurik, and Nicholas A. Christakis. 2011. "Molecular Genetics and Economics." Journal of Economic Perspectives 25 (4):57-82.

Becker, Gary S and Nigel Tomes. 1986. "Human Capital and the Rise and Fall of Families." Journal of Labor Economics 4 (3):S1-39.

Becker, G.S. and Barry R. Chiswick. 1966. "Education and the Distribution of Earnings." American Economic Review, Proceedings 56:358-369.

Belsky, Daniel W., Terrie E. Moffitt, David L. Corcoran, Benjamin Domingue, HonaLee Harrington, Sean Hogan, Renate Houts, Sandhya Ramrakha, Karen Sugden, Benjamin S. Williams, Richie Poulton, and Avshalom Caspi. 2016. "The Genetics of Success: How Single-Nucleotide Polymorphisms Associated With Educational Attainment Relate to Life-Course Development." Psychological Science, forthcoming.

Ben-Porath, Yoram. 1967. "The Production of Human Capital and the Life Cycle of Earnings." Journal of Political Economy 75 (4):352-365.

Benjamin, Daniel J, David Cesarini, Christopher F Chabris, Edward L Glaeser, David I Laibson, Vilmundur Guðnason, Tamara B Harris, Lenore J Launer, Shaun Purcell, Albert Vernon Smith et al. 2012. "The Promises and Pitfalls of Genoeconomics." Annual Review of Economics 4:627662.

Bharadwaj, Prashant, Katrine Vellesen Løken, and Christopher Neilson. 2013. "Early Life Health Interventions and Academic Achievement." American Economic Review 103 (5):1862-1891.

Bierut, Laura Jean. 2010. "Convergence of Genetic Findings for Nicotine Dependence and Smoking Related Diseases with Chromosome 15q24-25." Trends in Pharmacological Sciences 31 (1):46-51.

Bitler, Marianne P, Jonah B Gelbach, and Hilary W Hoynes. 2006. "What Mean Impacts Miss: Distributional Effects of Welfare Reform Experiments." American Economic Review :988-1012.

Black, Sandra E, Paul J Devereux, and Kjell G Salvanes. 2005. "Why the Apple Doesn't Fall Far: Understanding Intergenerational Transmission of Human Capital." American Economic Review 95 (1):437-449.

Branigan, Amelia R, Kenneth J McCallum, and Jeremy Freese. 2013. "Variation in the Heritability of Educational Attainment: An International Meta-Analysis." Social Forces :109-140. 
Camacho, Adriana. 2008. "Stress and Birth Weight: Evidence from Terrorist Attacks." American Economic Review :511-515.

Cawley, John, Karen Conneely, James Heckman, and Edward Vytlacil. 1997. "Cognitive Ability, Wages, and Meritocracy." In Intelligence, Genes, and Success: Scientists Respond to The Bell Curve, edited by Bernie Devlin, StephenE. Fienberg, Daniel P. Resnick, and Kathryn Roeder. Springer New York, 179-192.

Chetty, Raj, Nathaniel Henden, and Lawrence F. Katz. 2016. "The Effects of Exposure to Better Neighborhoods on Children: New Evidence from the Moving to Opportunity Experiment." American Economic Review 106:855-902.

Conley, Dalton and Benjamin Domingue. 2016. "The Bell Curve Revisited: Testing Controversial Hypotheses with Molecular Genetic Data." Sociological Science 3:520-539.

Costa, Dora L. 1998. "Unequal at Birth: A Long-Term Comparison of Income and Birth Weight." The Journal of Economic History 58:987-1009.

Cunha, Flavio, James J Heckman, and Susanne M Schennach. 2010. "Estimating the Technology of Cognitive and Noncognitive Skill Formation." Econometrica 78 (3):883-931.

Currie, J. 2009. "Healthy, Wealthy, and Wise: Socioeconomic Status, Poor Health in Childhood, and Human Capital Development." Journal of Economic Literature 47 (1):87-122.

Currie, Janet, Matthew Neidell, and Johannes F Schmieder. 2009. "Air Pollution and Infant Health: Lessons from New Jersey." Journal of Health Economics 28 (3):688-703.

Currie, Janet and Maya Rossin-Slater. 2013. "Weathering the Storm: Hurricanes and Birth Outcomes." Journal of Health Economics 32 (3):487-503.

Dahl, Gordon B and Lance Lochner. 2012. "The Impact of Family Income on Child Achievement: Evidence from the Earned Income Tax Credit." American Economic Review 102 (5):1927-1956.

DeLuca, Stefanie, Susan Clampet-Lundquist, and Kathryn Edin. 2016. Coming of Age in the Other America. Russell Sage Foundation.

Domingue, Benjamin W., Daniel W. Belsky, Dalton Conley, Kathleen Mullan Harris, and Jason D. Boardman. 2015. "Polygenic Influence on Educational Attainment." AERA Open 1 (3). URL http://ero.sagepub.com/content/1/3/2332858415599972.

Feuk, Lars, Andrew R. Carson, and Stephen W. Scherer. 2006. "Structural variation in the human genome." Nature Reviews Genetics 7:85-97.

Fletcher, Jason M. 2012. "Why Have Tobacco Control Policies Stalled? Using Genetic Moderation to Examine Policy Impacts." PLoS ONE 7 (12):1-6.

Fletcher, Jason M and Steven F Lehrer. 2011. "Genetic Lotteries within Families." Journal of Health Economics 30 (4):647-659.

Flynn, James R. 1987. "Massive IQ Gains in 14 nations: What IQ Tests Really Measure." Psychological Bulletin 101 (2):171-191. 
Gelbach, Jonah B. 2016. "When Do Covariates Matter? And Which Ones, and How Much?" Journal of Labor Economics forthcoming.

Gould, Eric D. 2002. "Rising Wage Inequality, Comparative Advantage, and the Growing Importance of General Skills in the United States." Journal of Labor Economics 20 (1):105-147.

Griliches, Zvi and William M Mason. 1972. "Education, Income, and Ability." Journal of Political Economy :S74-S103.

Heckman, James and Edward Vytlacil. 2001. "Identifying the Role of Cognitive Ability in Explaining the Level of and Change in the Return to Schooling." Review of Economics and Statistics $83(1): 1-12$.

Heckman, James J. 1995. "Lessons from the Bell Curve." Journal of Political Economy :1091-1120.

Heckman, James J and Dimitriy V Masterov. 2007. "The Productivity Argument for Investing in Young Children." Applied Economic Perspectives and Policy 29 (3):446-493.

Heckman, James J and Yona Rubinstein. 2001. "The Importance of Noncognitive Skills: Lessons from the GED Testing Program." American Economic Review 91 (2):145-149.

Heckman, James J and Edward Vytlacil. 2005. "Structural Equations, Treatment Effects, and Econometric Policy Evaluation." Econometrica 73 (3):669-738.

Heckman, J.J. and F. Cunha. 2007. "The Technology of Skill Formation." American Economic Review 97 (2):31-47.

Hewitt, John K. 2012. "Editorial Policy on Candidate Gene Association and Candidate Gene-byEnvironment Interaction Studies of Complex Traits." Behavior Genetics 42 (1):1-2.

Hilger, Nathaniel G. 2016. "The Great Escape: Intergenerational Mobility in the United States since 1940." NBER Working Paper.

Hsieh, Chang-Tai, Erik Hurst, Charles I Jones, and Peter J Klenow. 2013. "The Allocation of Talent and US Economic Growth." NBER Working Paper.

Jencks, Christopher and Meredith Phillips. 2011. The Black-White Test Score Gap. Brookings Institution Press.

Juhn, Chinhui, Kevin M Murphy, and Brooks Pierce. 1993. "Wage Inequality and the Rise in Returns to Skill." Journal of Political Economy :410-442.

Katz, Lawrence F and David H Autor. 1999. "Changes in the Wage Structure and Earnings Inequality." Handbook of Labor Economics 3:1463-1555.

Keane, Michael, Robert Moffitt, and David Runkle. 1988. "Real Wages over the Business Cycle: Estimating the Impact of Heterogeneity with Micro Data." The Journal of Political Economy :1232-1266.

Keane, M.P. and K.I. Wolpin. 1997. "The Career Decisions of Young Men." Journal of Political Economy 105 (3):473-522. 
Lemieux, Thomas. 2006. "Increasing Residual Wage Inequality: Composition Effects, Noisy Data, or Rising Demand for Skill?" American Economic Review :461-498.

Lien, Diana S and William N Evans. 2005. "Estimating the Impact of Large Cigarette Tax Hikes: The Case of Maternal Smoking and Infant Birth Weight." Journal of Human Resources $40(2): 373-392$.

Lillard, Lee and Robert J. Willis. 1978. "Dynamic Aspects of Earnings Mobility." Econometrica 46 (5):985-1012.

Lochner, Lance and Youngki Shin. 2014. "Understanding Earnings Dynamics: Identifying and Estimating the Changing Roles of Unobserved Ability, Permanent and Transitory shocks." NBER Working Paper.

McArdle, John J, James P Smith, and Robert Willis. 2009. "Cognition and Economic Outcomes in the Health and Retirement Survey." NBER Working Paper.

Mincer, Jacob. 1958. "Investment in Human Capital and Personal Income Distribution." Journal of Political Economy 66 (4):281-302.

Murnane, Richard J, John B Willett, Frank Levy et al. 1995. "The Growing Importance of Cognitive Skills in Wage Determination." The Review of Economics and Statistics 77 (2):251-66.

Neal, Derek A and William R Johnson. 1996. "The Role of Premarket Factors in Black-White Wage Differences." Journal of Political Economy 104 (5):869-895.

Okbay, Aysu, Jonathan P Beauchamp, Mark Alan Fontana, James J Lee, Tune H Pers, Cornelius A Rietveld, Patrick Turley, Guo-Bo Chen, Valur Emilsson, S Fleur W Meddens et al. 2016. "Genome-Wide Association Study Identifies 74 Loci Associated with Educational Attainment." Nature 533 (7604):539-542.

Polachek, Solomon W, Tirthatanmoy Das, Rewat Thamma-Apiroam et al. 2015. "Micro-and Macroeconomic Implications of Heterogeneity in the Production of Human Capital." Journal of Political Economy 123 (6):1410-1455.

Price, Alkes L, Nick J Patterson, Robert M Plenge, Michael E Weinblatt, Nancy A Shadick, and David Reich. 2006. "Principal Components Analysis Corrects for Stratification in Genome-Wide Association Studies." Nature Genetics 38 (8):904-909.

Rietveld, Cornelius A, Dalton Conley, Nicholas Eriksson, Tõnu Ekso, Sarah E Medland, Anna A E Vinkhuyzen, Jian Yang et al. 2014. "Replicability and Robustness of Genome-Wide-Association Studies for Behavioral Traits." Psychological Science 25 (11):1-12.

Rietveld, Cornelius A, Sarah E Medland, Jaime Derringer, Jian Yang, Tõnu Esko, Nicolas W Martin, Harm-Jan Westra, Konstantin Shakhbazov, Abdel Abdellaoui, Arpana Agrawal et al. 2013. "GWAS of 126,559 Individuals Identifies Genetic Variants Associated with Educational Attainment." Science 340 (6139):1467-1471.

Schmitz, Lauren L and Dalton Conley. 2016. "The Effect of Vietnam-Era Conscription and Genetic Potential for Educational Attainment on Schooling Outcomes.” NBER Working Paper. 
Taber, Christopher R. 2001. "The Rising College Premium in the Eighties: Return to College or Return to Unobserved Ability?" Review of Economic Studies 68 (3):665-691.

Taubman, Paul. 1976. "The Determinants of Earnings: Genetics, Family, and other Environments: A Study of White Male Twins." American Economic Review :858-870.

Thompson, Owen. 2014. "Economic Background and Educational Attainment: The Role of GeneEnvironment Interactions." Journal of Human Resources 49 (2):263-294.

Thorgeirsson, Thorgeir E, Daniel F Gudbjartsson, Ida Surakka, Jacqueline M Vink, Najaf Amin, Frank Geller, Patrick Sulem, Thorunn Rafnar, Tõnu Esko, Stefan Walter et al. 2010. "Sequence Variants at CHRNB3-CHRNA6 and CYP2A6 Affect Smoking Behavior." Nature Genetics $42(5): 448-453$.

Tobias, Justin L. 2003. "Are Returns to Schooling Concentrated Among the Most Able? A Semiparametric Analysis of the Ability-earnings Relationships1." Oxford Bulletin of Economics and Statistics 65 (1):1-29.

Todd, Petra E and Kenneth I Wolpin. 2003. "On the Specification and Estimation of the Production Function for Cognitive Achievement." The Economic Journal 113 (485):F3-F33.

. 2006. "Assessing the Impact of a School Subsidy Program in Mexico: Using a Social Experiment to Validate a Dynamic Behavioral Model of Child Schooling and Fertility." American Economic Review :1384-1417.

. 2007. "The Production of Cognitive Achievement in Children: Home, School, and Racial Test Score Gaps." Journal of Human Capital 1 (1):91-136.

Turkheimer, Eric, Andreana Haley, Mary Waldron, Brian D'Onofrio, and Irving I Gottesman. 2003. "Socioeconomic Status Modifies Heritability of IQ in Young Children." Psychological Science 14 (6):623-628.

Vilhjalmsson, et al., Bjarni J. 2015. "Modeling Linkage Disequilibrium Increases Accuracy of Polygenic Risk Scores." The American Journal of Human Genetics 87:576-592.

Willis, Robert J. 2013. "The Cognitive Demands of Work and the Length of Working Life: The Case of Computerization." mimeo, University of Michigan.

Willis, Robert J. and Sherwin Rosen. 1979. "Education and Self-Selection." Journal of Political Economy 87 (5):S7-S36.

Wiswall, Matthew and Basit Zafar. 2015. "Determinants of College Major Choice: Identification Using an Information Experiment." Review of Economic Studies 82 (2):791-824. 


\section{Tables and Figures}

Table 1: Summary Statistics - HRS Sample

\begin{tabular}{|c|c|c|c|c|c|c|c|}
\hline Variable & "Mean & Std. & $\overline{\mathrm{N}}$ & Variable & Mean & $\overline{\overline{\text { Std }}}$ & $\overline{\mathrm{N}}$ \\
\hline Male & 0.417 & 0.493 & 8554 & Father's Income & 2.73 & 0.946 & 6483 \\
\hline Birth Year: & & & & Family SES (Ch & dhood) & & \\
\hline$<1930$ & 0.227 & 0.419 & 8554 & Well Off & 0.067 & 0.25 & 8554 \\
\hline 1930-1934 & 0.152 & 0.359 & 8554 & Average & 0.645 & 0.479 & 8554 \\
\hline 1935-1939 & 0.183 & 0.386 & 8554 & Poor & 0.273 & 0.446 & 8554 \\
\hline 1940-1944 & 0.161 & 0.368 & 8554 & Varied & 0.013 & 0.114 & 8554 \\
\hline 1945-1949 & 0.126 & 0.332 & 8554 & Missing & 0.002 & 0.039 & 8554 \\
\hline 1950-1954 & 0.152 & 0.359 & 8554 & \multicolumn{4}{|c|}{ Family Moved (Childhood) } \\
\hline Education (Yrs) & 13.162 & 2.542 & 8554 & No & 0.816 & 0.388 & 8554 \\
\hline Degree: & & & & Yes & 0.18 & 0.384 & 8554 \\
\hline None & 0.13 & 0.336 & 8530 & Missing & 0.004 & 0.066 & 8554 \\
\hline GED & 0.045 & 0.207 & 8530 & \multicolumn{4}{|c|}{ Fam. Asked for Help (Childhood) } \\
\hline High School & 0.528 & 0.499 & 8530 & Yes & 0.134 & 0.341 & 8554 \\
\hline College (2 year) & 0.051 & 0.219 & 8530 & No & 0.851 & 0.356 & 8554 \\
\hline College (4 year) & 0.147 & 0.354 & 8530 & Missing & 0.015 & 0.121 & 8554 \\
\hline Masters & 0.077 & 0.267 & 8530 & \multicolumn{4}{|c|}{ Father Lost Job (Childhood) } \\
\hline Advanced & 0.022 & 0.148 & 8530 & Yes & 0.203 & 0.402 & 8554 \\
\hline Redo Grade & 0.14 & 0.347 & 8184 & No & 0.729 & 0.445 & 8554 \\
\hline Education (Yrs) & & & & Never Worked & 0.005 & 0.072 & 8554 \\
\hline Father & 10.228 & 3.599 & 6723 & Never There & 0.055 & 0.229 & 8554 \\
\hline \multirow[t]{8}{*}{ Mother } & 10.664 & 3.025 & 7013 & Missing & 0.008 & 0.087 & 8554 \\
\hline & & & & \multicolumn{4}{|l|}{ Health as Child } \\
\hline & & & & Excellent & 0.544 & 0.498 & 8554 \\
\hline & & & & Very Good & 0.256 & 0.436 & 8554 \\
\hline & & & & Good & 0.143 & 0.35 & 8554 \\
\hline & & & & Fair & 0.045 & 0.207 & 8554 \\
\hline & & & & Poor & 0.012 & 0.109 & 8554 \\
\hline & & & & Missing & 0 & 0.015 & 8554 \\
\hline
\end{tabular}

Summary statistics for the analytic sample, which consists of 8,554 observations from the HRS. We limit attention to the two waves when genetic data are available (2006 and 2008). 
Table 2: Polygenic Score and Educational Attainment

\begin{tabular}{|c|c|c|c|c|c|}
\hline & $\overline{(1)}$ & $(2)$ & $(3)$ & 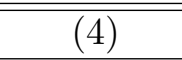 & $(5)$ \\
\hline EA Score & $\begin{array}{c}0.663^{* * *} \\
(0.026)\end{array}$ & $\begin{array}{c}0.491^{* * *} \\
(0.025)\end{array}$ & $\begin{array}{c}0.486^{* * *} \\
(0.025)\end{array}$ & $\begin{array}{c}0.476^{* * *} \\
(0.024)\end{array}$ & $\begin{array}{c}0.470^{* * *} \\
(0.024)\end{array}$ \\
\hline Father Educ & & $\begin{array}{c}0.157^{* * *} \\
(0.009)\end{array}$ & $\begin{array}{c}0.153^{* * *} \\
(0.009)\end{array}$ & $\begin{array}{c}0.117^{* * *} \\
(0.009)\end{array}$ & $\begin{array}{c}0.114^{* * *} \\
(0.009)\end{array}$ \\
\hline Mother Educ & & $\begin{array}{c}0.184^{* * *} \\
(0.011)\end{array}$ & $\begin{array}{c}0.181^{* * *} \\
(0.011)\end{array}$ & $\begin{array}{c}0.165^{* * *} \\
(0.011)\end{array}$ & $\begin{array}{c}0.162^{* * *} \\
(0.011)\end{array}$ \\
\hline Child Health: Very Good & & & $\begin{array}{c}-0.234^{* * *} \\
(0.058)\end{array}$ & $\begin{array}{c}-0.228^{* * *} \\
(0.057)\end{array}$ & $\begin{array}{c}-0.232^{* * *} \\
(0.057)\end{array}$ \\
\hline Child Health: Good & & & $\begin{array}{c}-0.480^{* * *} \\
(0.072)\end{array}$ & $\begin{array}{c}-0.434^{* * *} \\
(0.071)\end{array}$ & $\begin{array}{c}-0.444^{* * *} \\
(0.071)\end{array}$ \\
\hline Child Health: Fair & & & $\begin{array}{c}-0.371^{* * *} \\
(0.118)\end{array}$ & $\begin{array}{c}-0.327^{* * *} \\
(0.117)\end{array}$ & $\begin{array}{c}-0.365^{* * *} \\
(0.117)\end{array}$ \\
\hline Child Health: Poor & & & $\begin{array}{c}-0.796^{* * *} \\
(0.223)\end{array}$ & $\begin{array}{c}-0.753^{* * *} \\
(0.221)\end{array}$ & $\begin{array}{c}-0.783^{* * *} \\
(0.220)\end{array}$ \\
\hline Child Health: Missing & & & $\begin{array}{c}1.121 \\
(1.584)\end{array}$ & $\begin{array}{c}1.241 \\
(1.602)\end{array}$ & $\begin{array}{c}0.962 \\
(1.596)\end{array}$ \\
\hline Obs. & 8554 & 8554 & 8554 & 8554 & 8554 \\
\hline$R^{2}$ & 0.124 & 0.259 & 0.264 & 0.284 & 0.293 \\
\hline Child SES Measures & $\mathrm{N}$ & $\mathrm{N}$ & $\mathrm{N}$ & $\mathrm{Y}$ & $\mathrm{Y}$ \\
\hline Child Region & $\mathrm{N}$ & $\mathrm{N}$ & $\mathrm{N}$ & $\mathrm{N}$ & $\mathrm{Y}$ \\
\hline Religion & $\mathrm{N}$ & $\mathrm{N}$ & $\mathrm{N}$ & $\mathrm{N}$ & $\mathrm{Y}$ \\
\hline Incr.- $R^{2}$, EA Score & 0.066 & 0.035 & 0.034 & 0.033 & 0.032 \\
\hline
\end{tabular}

Regressions relating educational attainment (years) to the EA Score. All regressions include a full set of dummy variables for birth year, a male dummy and a full set of interactions between the birth year and gender dummies. All specifications include the first 10 principle components of the full matrix of genetic data as controls. Some specifications include controls for parental education, childhood health, childhood SES measures, region during childhood and religion, as indicated. The last row reports the incremental $R^{2}$ of the EA-Score. 
Table 3: Polygenic Score and Categorical Education Outcomes

\begin{tabular}{lccccc}
\hline \hline & $(1)$ & $(2)$ & $(3)$ & $(4)$ & $(5)$ \\
Dep Var. & No Degree & Two-Year Coll. & College & College Plus & Redo Grade \\
\hline \hline Panel A: & & & & & \\
EA Score & $-0.054^{* * *}$ & -0.001 & $0.053^{* * *}$ & $0.050^{* * *}$ & $-0.037^{* * *}$ \\
& $(0.004)$ & $(0.002)$ & $(0.004)$ & $(0.003)$ & $(0.004)$ \\
Obs. & 8530 & 8530 & 8530 & 8530 & 8184 \\
$R^{2}$ & 0.072 & 0.020 & 0.045 & 0.055 & 0.062 \\
& & & & \\
Panel B: & & & & & \\
EA Score & $-0.040^{* * *}$ & -0.003 & $0.040^{* * *}$ & $0.040^{* * *}$ & $-0.029^{* * *}$ \\
& $(0.004)$ & $(0.002)$ & $(0.004)$ & $(0.003)$ & $(0.004)$ \\
Father Educ & $-0.009^{* * *}$ & 0.000 & $0.013^{* * *}$ & $0.011^{* * *}$ & $-0.008^{* * *}$ \\
& $(0.001)$ & $(0.001)$ & $(0.001)$ & $(0.001)$ & $(0.001)$ \\
Mother Educ & $-0.017^{* * *}$ & $0.002^{* *}$ & $0.012^{* * *}$ & $0.009^{* * *}$ & $-0.008^{* * *}$ \\
& $(0.002)$ & $(0.001)$ & $(0.002)$ & $(0.001)$ & $(0.002)$ \\
Obs. & 8530 & 8530 & 8530 & 8530 & 8184 \\
$R^{2}$ & 0.129 & 0.023 & 0.082 & 0.087 & 0.079 \\
\hline \hline
\end{tabular}

Regressions relating educational attainment categories or the probability of repeating a grade to the EA Score. Specifications in Panel A do not include parental education. Specifications in Panel B include parental education. All regressions include a full set of dummy variables for birth year, a male dummy and a full set of interactions between the birth year and gender dummies. Additionally, every specification includes the first 10 principle components of the full matrix of genetic data. 
Table 4: Childhood SES Measures and Education

\begin{tabular}{|c|c|c|c|c|}
\hline SES Measure: & $\begin{array}{c}(1) \\
\text { Fam. Well Off }\end{array}$ & $\begin{array}{c}(2) \\
\text { Father Inc. }\end{array}$ & $\begin{array}{c}(3) \\
\text { Never Move or Ask. }\end{array}$ & $\begin{array}{c}(4) \\
\text { Father Emp. }\end{array}$ \\
\hline Frac. High SES & 0.723 & 0.432 & 0.754 & 0.738 \\
\hline \multicolumn{5}{|c|}{ Panel A: Dep. Var - Education } \\
\hline HighSES & $\begin{array}{c}0.392^{* * *} \\
(0.056)\end{array}$ & $\begin{array}{c}0.757^{* * *} \\
(0.060)\end{array}$ & $\begin{array}{c}0.164^{* * *} \\
(0.057)\end{array}$ & $\begin{array}{c}0.201^{* * *} \\
(0.056)\end{array}$ \\
\hline EA Score & $\begin{array}{c}0.487^{* * *} \\
(0.025)\end{array}$ & $\begin{array}{c}0.471^{* * *} \\
(0.028)\end{array}$ & $\begin{array}{c}0.494^{* * *} \\
(0.025)\end{array}$ & $\begin{array}{c}0.491^{* * *} \\
(0.025)\end{array}$ \\
\hline Obs. & 8429 & 6483 & 8401 & 8444 \\
\hline$R^{2}$ & 0.263 & 0.269 & 0.259 & 0.258 \\
\hline \multicolumn{5}{|c|}{ Panel B: Dep. Var - EA Score } \\
\hline HighSES & $\begin{array}{c}0.011 \\
(0.025)\end{array}$ & $\begin{array}{c}0.131^{* * *} \\
(0.027)\end{array}$ & $\begin{array}{c}0.110^{* * *} \\
(0.025)\end{array}$ & $\begin{array}{l}0.052^{* *} \\
(0.025)\end{array}$ \\
\hline Obs. & 8429 & 6483 & 8401 & 8444 \\
\hline$R^{2}$ & 0.067 & 0.069 & 0.069 & 0.067 \\
\hline Incr. $R^{2}$, HighSES & $<0.001$ & 0.004 & 0.002 & $<0.001$ \\
\hline \multicolumn{5}{|c|}{ Panel C: Dep. Var - EA Score (No Parental Educ. Controls) } \\
\hline HighSES & $\begin{array}{c}0.106^{* * *} \\
(0.024)\end{array}$ & $\begin{array}{c}0.228^{* * *} \\
(0.025)\end{array}$ & $\begin{array}{c}0.155^{* * *} \\
(0.025)\end{array}$ & $\begin{array}{c}0.107^{* * *} \\
(0.025)\end{array}$ \\
\hline Obs. & 8429 & 6483 & 8401 & 8444 \\
\hline$R^{2}$ & 0.038 & 0.052 & 0.040 & 0.038 \\
\hline Incr. $R^{2}$, HighSES & 0.002 & 0.012 & 0.004 & 0.002 \\
\hline
\end{tabular}

Regressions relating four measures of childhood SES to education and EA Score. The first row shows the proportion in the sample indicating high SES for each measure among those who report the measure. Panel A contains coefficients on measures of high SES and EA Score in regressions explaining educational attainment (years). Panel B relates measures of high childhood SES to EA Score. Regressions also include a full set of dummy variables for birth year, a male dummy and a full set of interactions between the birth year and gender dummies. Additionally, every specification includes the first 10 principle components of the full matrix of genetic data. 
Table 5: Polygenic Score and Wages

Panel A: Basic Specifications

\begin{tabular}{|c|c|c|c|}
\hline & $(1)$ & $(2)$ & $(3)$ \\
\hline EA Score & $\begin{array}{c}0.099^{* * *} \\
(0.012)\end{array}$ & $\begin{array}{l}0.021^{*} \\
(0.011)\end{array}$ & $\begin{array}{c}0.001 \\
(0.013)\end{array}$ \\
\hline EA Score x College & & & $\begin{array}{c}0.062^{* * *} \\
(0.024)\end{array}$ \\
\hline Obs. & 6629 & 6629 & 6601 \\
\hline$R^{2}$ & 0.061 & 0.223 & 0.232 \\
\hline Ed. Groups & All & All & All \\
\hline Period & All Years & All Years & All Years \\
\hline Educ. Controls & $\mathrm{N}$ & $\mathrm{Y}$ & $\mathrm{Y}$ \\
\hline Parent Controls & $\mathrm{N}$ & $\mathrm{Y}$ & Y \\
\hline \multicolumn{4}{|c|}{ Panel B: Differences by Time and Cohorts } \\
\hline & $(1)$ & $(2)$ & $(3)$ \\
\hline EA Score & $\begin{array}{c}0.014 \\
(0.024)\end{array}$ & $\begin{array}{c}0.007 \\
(0.028)\end{array}$ & $\begin{array}{c}0.004 \\
(0.028)\end{array}$ \\
\hline EA x Post Yr. 2000 & $\begin{array}{c}0.095^{* * *} \\
(0.033)\end{array}$ & & $\begin{array}{c}0.027 \\
(0.034)\end{array}$ \\
\hline EA x Post BY 1942 & & $\begin{array}{c}0.112^{* * *} \\
(0.039)\end{array}$ & $\begin{array}{c}0.094^{* *} \\
(0.044)\end{array}$ \\
\hline Obs. & 2267 & 2267 & 2267 \\
\hline$R^{2}$ & 0.116 & 0.124 & 0.128 \\
\hline Ed. Groups & College & College & College \\
\hline Period & All Years & All Years & All Years \\
\hline Educ. Controls & $\mathrm{Y}$ & $\mathrm{Y}$ & $\mathrm{Y}$ \\
\hline Parent Controls & $\mathrm{Y}$ & $\mathrm{Y}$ & $\mathrm{Y}$ \\
\hline
\end{tabular}

Regressions relating the EA Score to log wages. In all columns the sample is restricted to men between the ages of 50 and 64 who reported working at least 20 hours for pay. The dependent variable is the log wage. All regressions include the first 10 principle components of the full matrix of genetic data along with a full set of dummy variables for birth year, calendar year and age. Because of collinearity, a subset of these dummies is dropped. The specifications in Columns 2 and 3 include controls for parental education (years of paternal and maternal education and dummies indicating missing values for each) and own education (years of schooling and a full set of completed degree dummies). Columns 4-7 include all of the controls in Column 3 but are restricted to sub-samples (by year and college degree) as listed in the table. 
Table 6: Polygenic Score and Job Tasks

\begin{tabular}{lccccc}
\hline \hline Dep Var. & $\begin{array}{c}\text { Above Median: } \\
\text { Non-routine } \\
\text { Analytic }\end{array}$ & $\begin{array}{c}\text { Above Median: } \\
\text { Non-routine } \\
\text { Interactive }\end{array}$ & $\begin{array}{c}\text { Above Median: } \\
\text { Routine } \\
\text { Manual }\end{array}$ & $\begin{array}{c}\text { Above Median: } \\
\text { Routine } \\
\text { Cognitive }\end{array}$ & $\begin{array}{c}\text { Above Median: } \\
\text { Non-routine } \\
\text { Manual }\end{array}$ \\
\hline \hline EA Score & $0.035^{*}$ & $0.041^{* *}$ & $-0.037^{*}$ & -0.013 & -0.011 \\
& $(0.020)$ & $(0.019)$ & $(0.021)$ & $(0.021)$ & $(0.020)$ \\
Obs. & 1477 & 1477 & 1477 & 1477 & 1477 \\
$R^{2}$ & 0.291 & 0.371 & 0.132 & 0.102 & 0.303 \\
\hline \hline
\end{tabular}

Regressions relating EA Score to job tasks. All regressions include the first 10 principle components of the full matrix of genetic data and controls for parental education (years of paternal and maternal education and dummies indicating missing values for each) and own education (years of schooling and a full set of completed degree dummies). All regressions also include a full set of dummies for birth year, calendar year and age. Because of collinearity a subset of these dummies is dropped. In all columns the sample is restricted to men between the ages of 50 and 64 who worked at least 20 hours for pay. 
Table 7: Polygenic Score and Labor Supply Outcomes

\begin{tabular}{lccc}
\hline \hline Panel A: Dep. Var - Work For Pay & & \\
EA Score & $0.032^{* * *}$ & $0.019^{* * *}$ & $0.017^{* *}$ \\
& $(0.006)$ & $(0.007)$ & $(0.008)$ \\
EA Score x College & & & 0.005 \\
& & & $(0.013)$ \\
Obs. & 13562 & 13562 & 13515 \\
$R^{2}$ & 0.091 & 0.108 & 0.111 \\
Educ. Controls & $\mathrm{N}$ & $\mathrm{Y}$ & $\mathrm{Y}$ \\
Parent Controls & $\mathrm{N}$ & $\mathrm{Y}$ & $\mathrm{Y}$ \\
& & & \\
& & & \\
Panel B: Dep. Var - Retired & & \\
EA Score & $-0.013^{* * *}$ & $-0.013^{* * *}$ & $-0.011^{* *}$ \\
& $(0.004)$ & $(0.004)$ & $(0.005)$ \\
EA Score x College & & & -0.007 \\
\multicolumn{1}{l}{ Obs. } & & & $(0.008)$ \\
$R^{2}$ & 0.088 & 0.092 & 8074 \\
Educ. Controls & $\mathrm{N}$ & $\mathrm{Y}$ & $\mathrm{Y}$ \\
Parent Controls & $\mathrm{N}$ & $\mathrm{Y}$ & $\mathrm{Y}$ \\
\hline \hline
\end{tabular}

Regressions relating the EA Score to labor market outcomes. In Panel A, the dependent variable is employment (working for pay). In Panel B, the dependent variable is retirement and conditions on not being retired in the previous period. All regressions include the first 10 principle components of the full matrix of genetic data along with a full set of dummy variables for birth year, calendar year and age. Because of collinearity a subset of these dummies is dropped. The specifications in Columns 2 and 3 include controls for parental education (years of paternal and maternal education and dummies indicating missing values for each) and own education (years of schooling and a full set of completed degree dummies). The specification in Column 3 includes as additional controls interactions between the principle components and an indicator for earning at least a college degree. The sample in Panel A is restricted to men between the ages of 50 and 64 . The sample in Panel B is restricted to men between the ages of 50 and 64 who worked for pay in the last period and were not retired in the last period. 
Table 8: Polygenic Score and Wealth

\begin{tabular}{lcccc}
\hline \hline & $(1)$ & $(2)$ & $(3)$ & $(4)$ \\
Dep Var. & $\log$ Market Wealth & $\log$ Tot. Wealth & $\log$ Tot. Wealth & $\log$ Tot. Wealth \\
\hline \hline EA Score & $0.183^{* * *}$ & $0.085^{* * *}$ & $0.082^{* * *}$ & $0.080^{* * *}$ \\
& $(0.026)$ & $(0.015)$ & $(0.018)$ & $(0.028)$ \\
Father Educ & $0.019^{*}$ & $0.013^{* *}$ & $0.015^{* *}$ & 0.012 \\
& $(0.010)$ & $(0.006)$ & $(0.007)$ & $(0.010)$ \\
Mother Educ & $0.034^{* * *}$ & $0.015^{* *}$ & 0.010 & $0.030^{* * *}$ \\
& $(0.011)$ & $(0.007)$ & $(0.008)$ & $(0.011)$ \\
\hline \hline Obs. & 34721 & 35583 & 26449 & 9054 \\
$R^{2}$ & 0.188 & 0.229 & 0.196 & 0.164 \\
Group & All & All & No College & College \\
\hline \hline
\end{tabular}

Regressions relating the EA Score to log wealth. All regressions include a full set of dummy variables for age, a male dummy and a full set of interactions between the age and gender dummies. Additionally, every specification includes the first 10 principle components of the full matrix of genetic data and controls for parental education (years of paternal and maternal education and dummies indicating missing values for each) and own education (years of schooling and a full set of completed degree dummies). We also include a full set of dummies for birth year and calendar year. Because of collinearity a subset of the birth year, calendar year and age dummies is dropped. We also trim the top 1 percent of person-year wealth values because of substantial outliers. The dependent variable in the Column (1) is the log of marketable wealth, which includes liquid or easily liquidated assets: cash or cash equivalents, bonds, stocks and stock mutual funds. In Columns (2)-(4) the dependent variable is the log of total wealth, which includes marketable wealth, the market vale of pension accounts, and the value of houses (net of mortgage debt). 


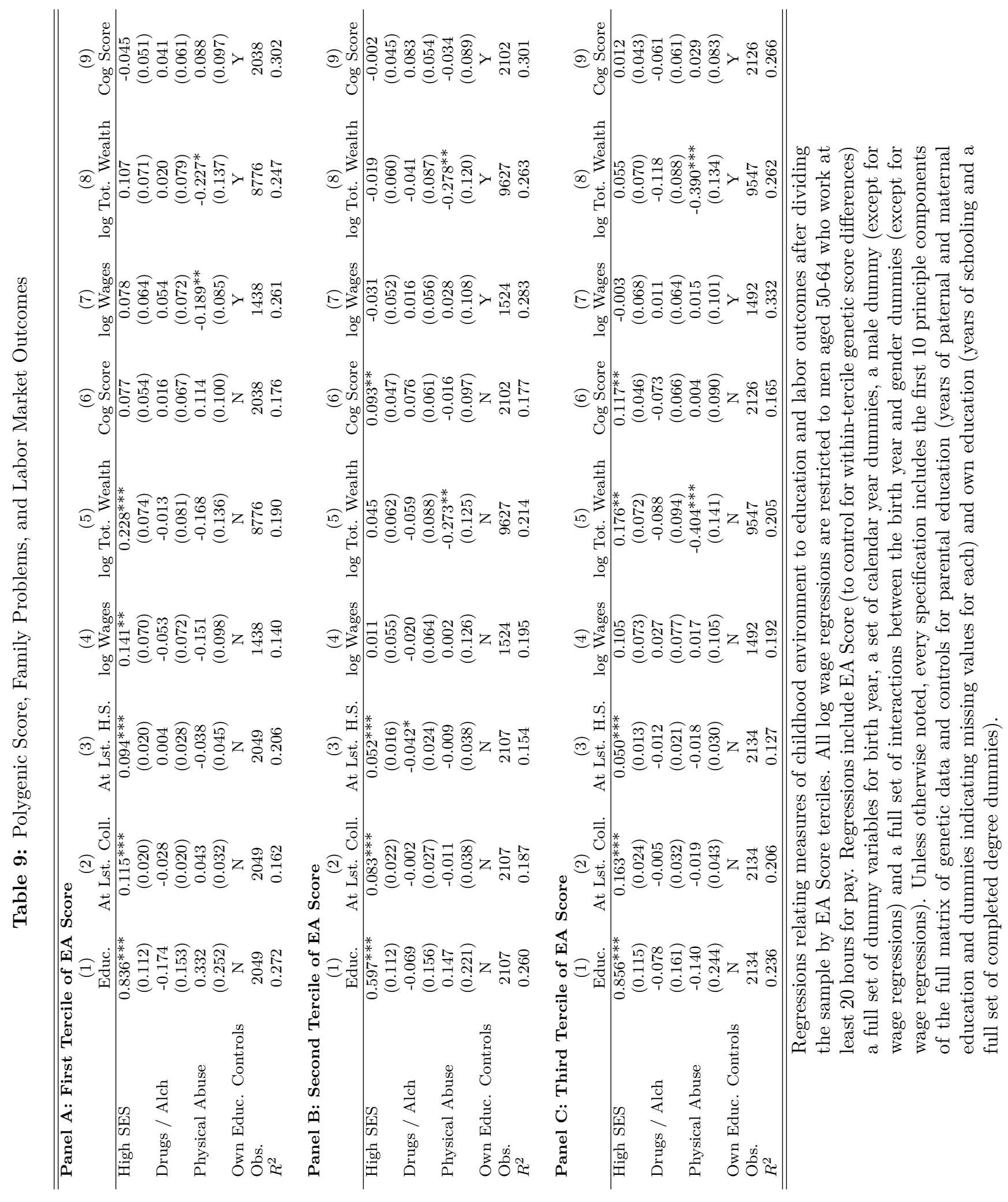




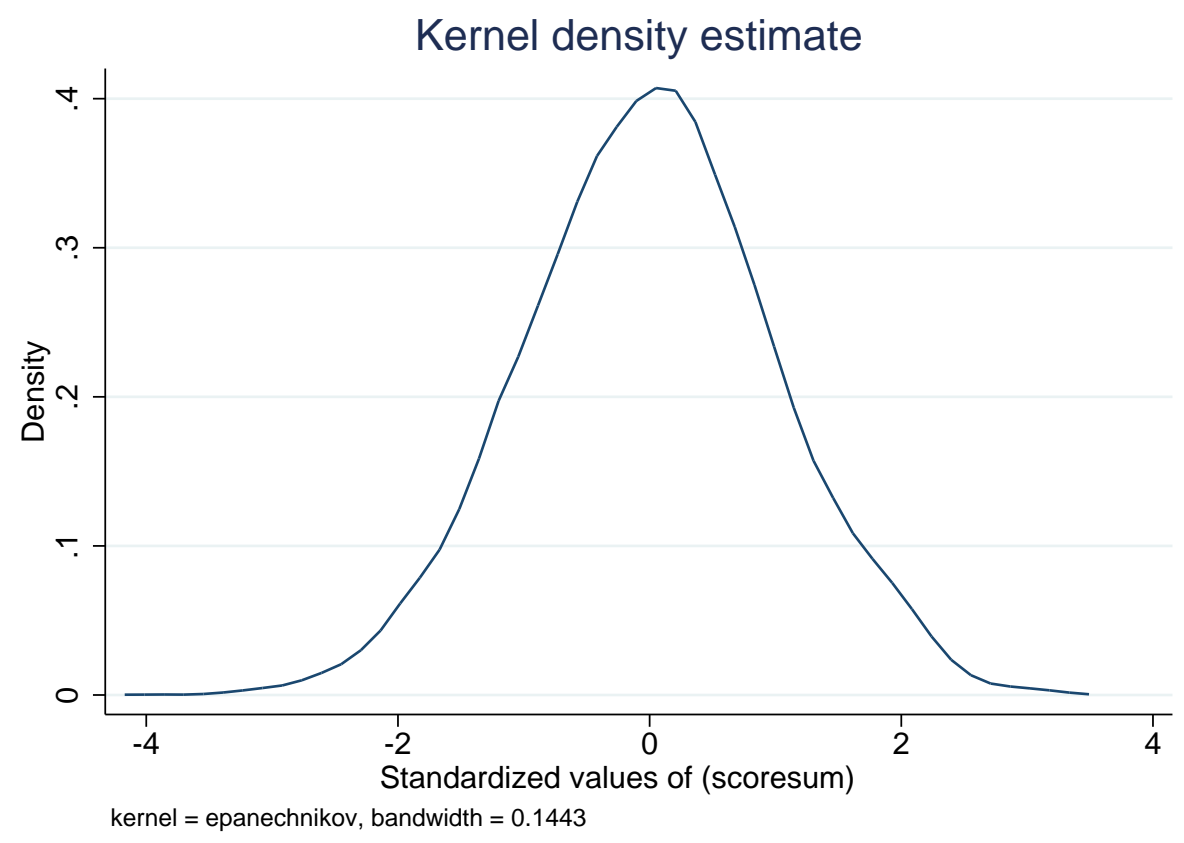

Figure 1: Distribution of the EA Score. 


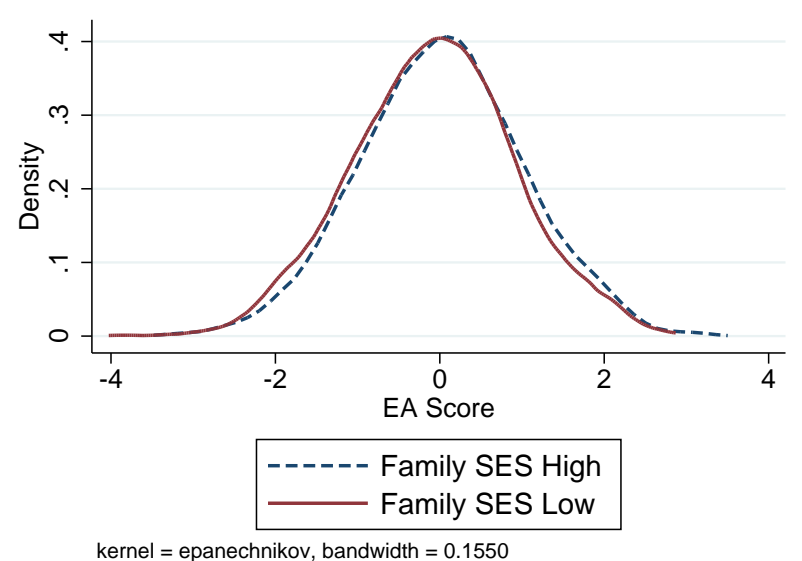

Panel (A) SES Measure: Family Well Off

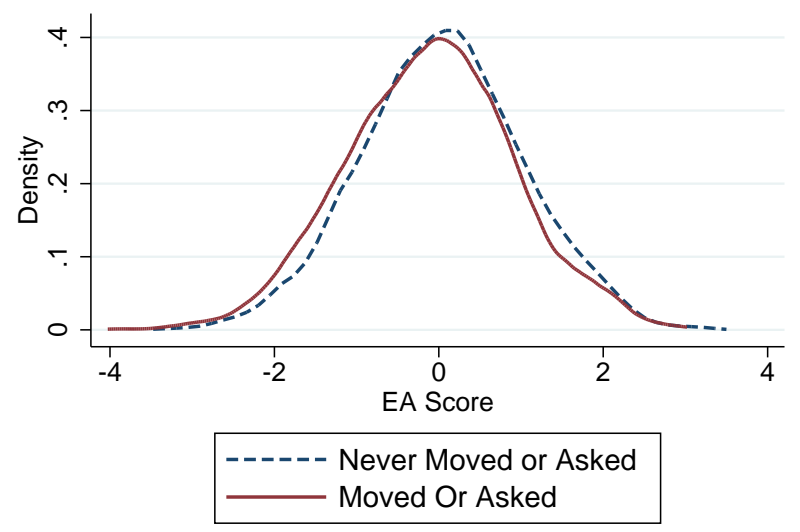

kernel $=$ epanechnikov, bandwidth $=0.1516$

Panel (C) SES Measure: Never Moved/Asked for Help

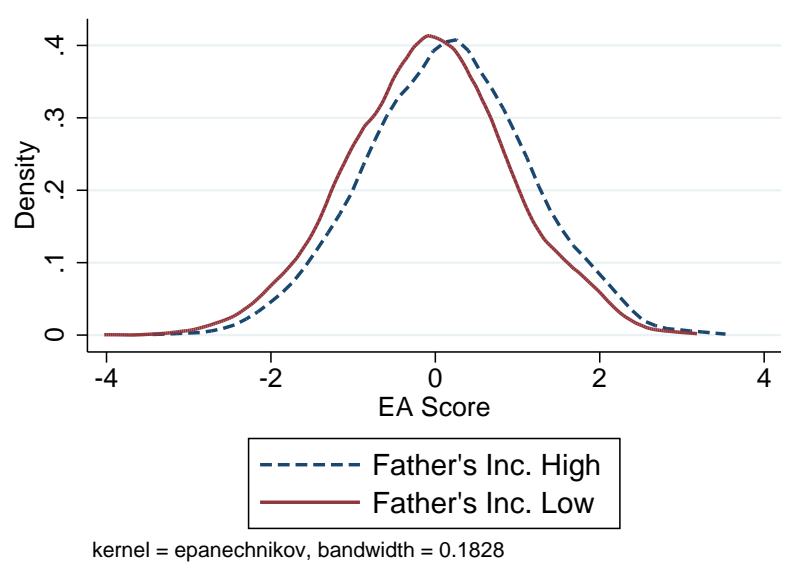

Panel (B) SES Measure: Father's Income

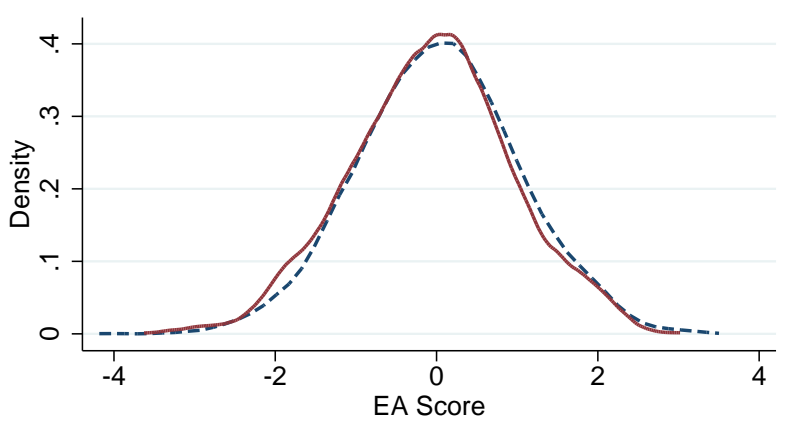

------ Father Never Unemp.

Father Unemp.

kernel $=$ epanechnikov, bandwidth $=0.1549$

Panel (D) SES Measure: Father's Unemployment

Figure 2: EA2 Score Distribution by Family SES. 


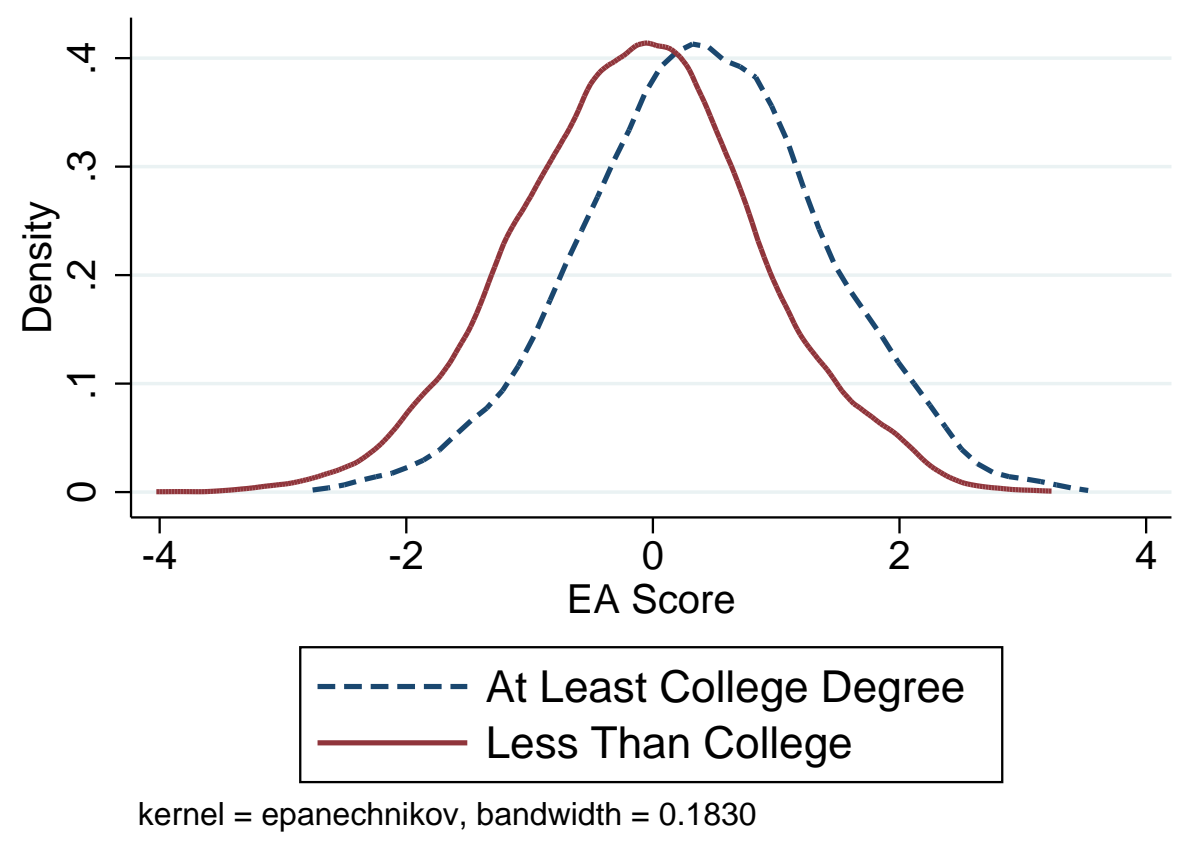

Figure 3: EA2 Score Distribution by Completed Education (College vs. No College) 


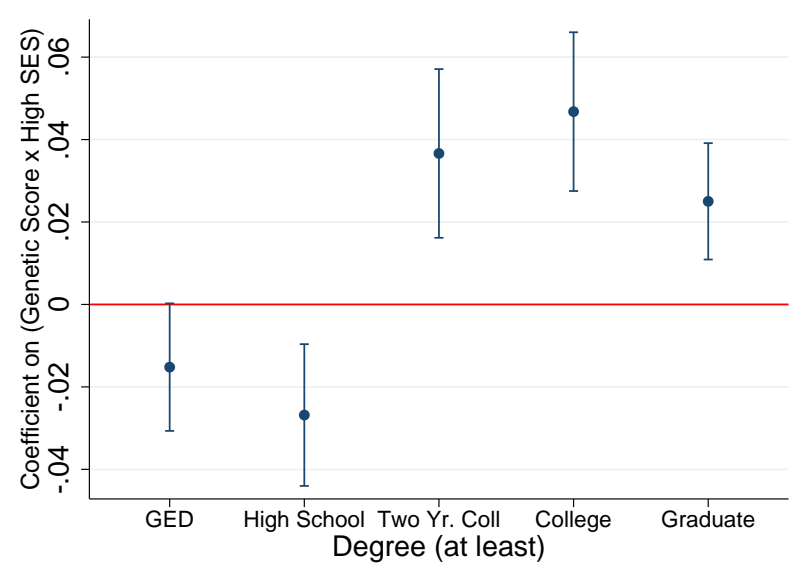

Panel (A) SES Measure: Family Well Off

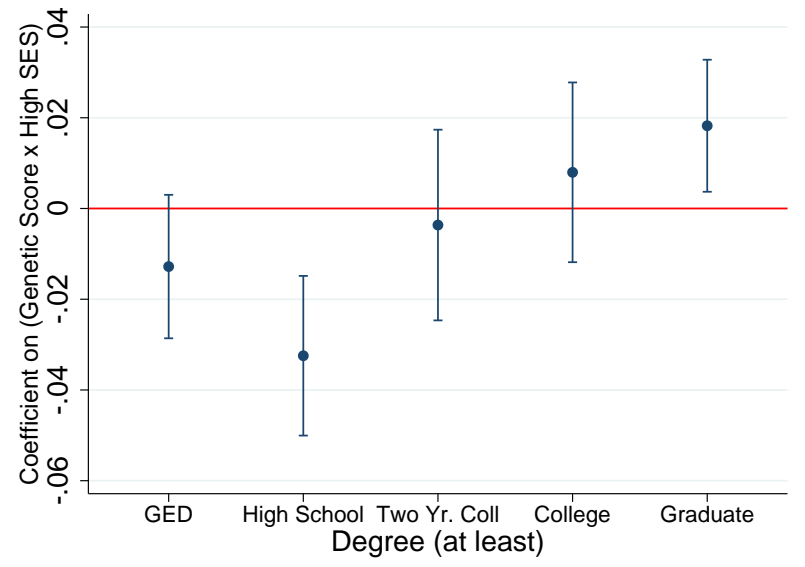

Panel (C) SES Measure: Never Moved/Asked for Help

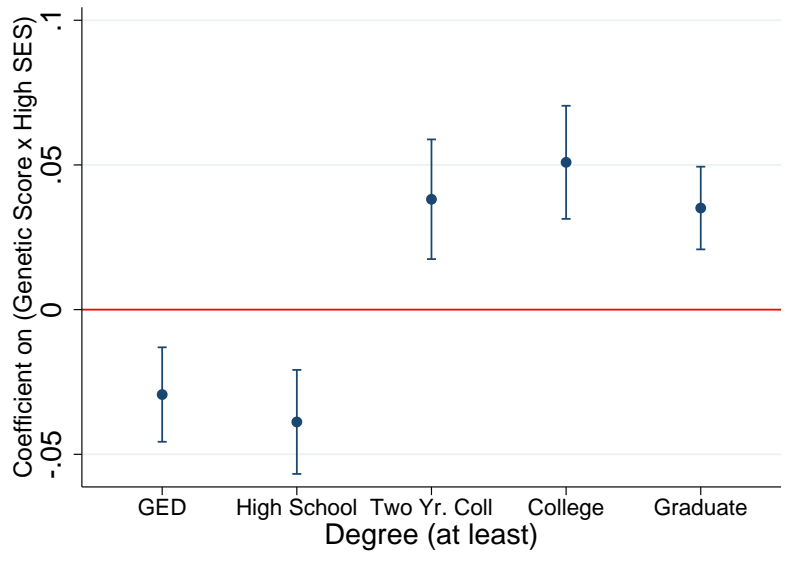

Panel (B) SES Measure: Father's Income

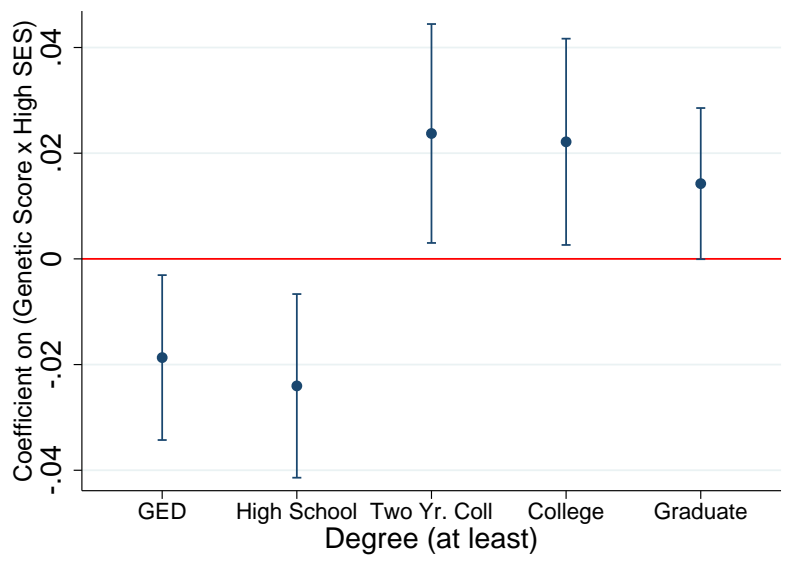

Panel (D) SES Measure: Father's Unemployment

Figure 4: Coefficient on the interaction between EA Score and high SES for different schooling categories. Across SES measures, the interaction is negative at low education levels and positive at high education levels. 


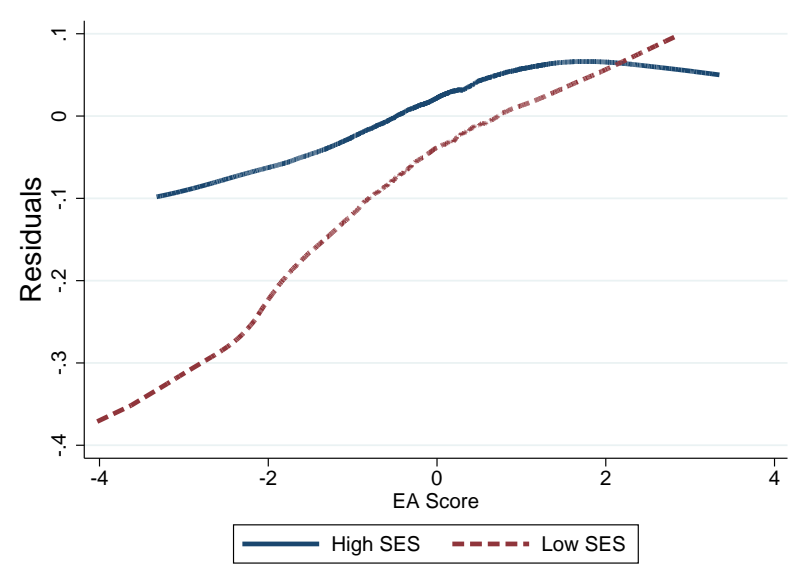

Panel (A) SES Measure: Family Well Off

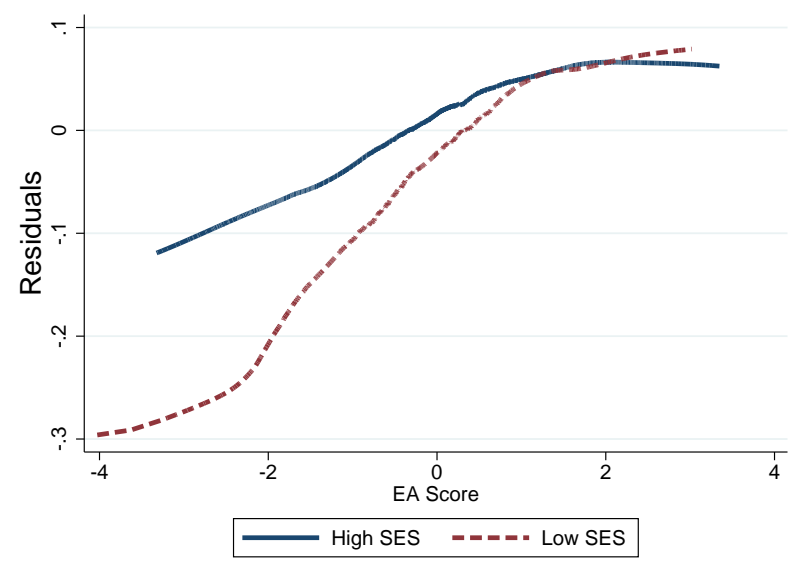

Panel (C) SES Measure: Never Moved/Asked for Help

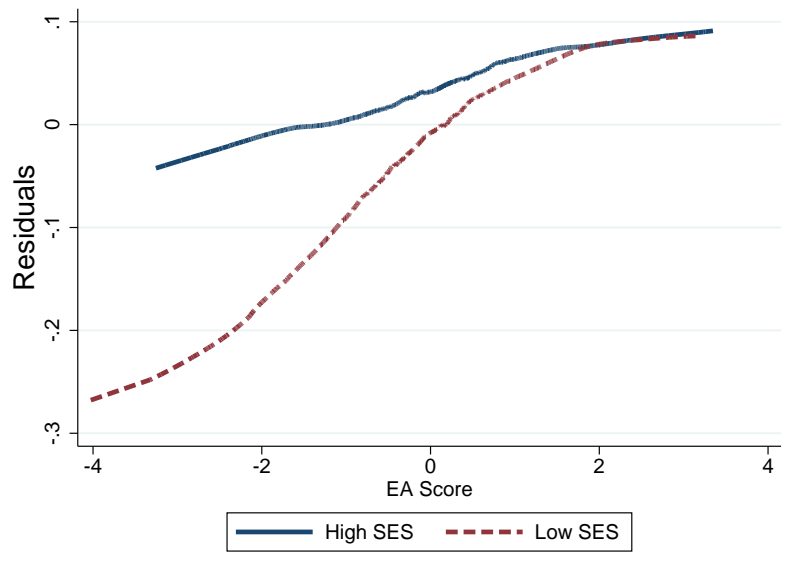

Panel (B) SES Measure: Father's Income

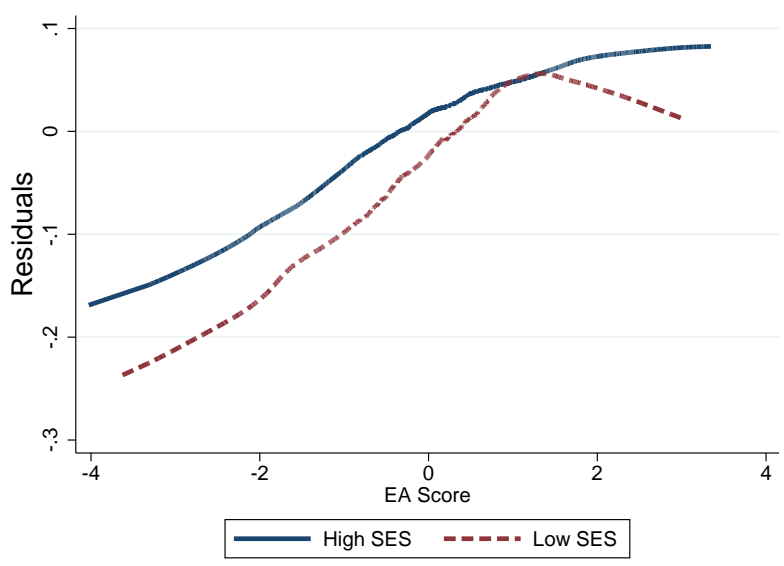

Panel (D) SES Measure: Father's Unemployment

Figure 5: Non-parametric (Lowess) estimation relating the probability of high school degree or more to EA Score for high versus low SES for different measures of childhood SES. In each panel, the outcome variable is the residual from OLS regression of an indicator for completing a high school degree or more onto a set of controls and the regressor is EA Score. Across SES measures, EA Score predicts higher education. However, the gradient is weaker among individuals who report high childhood SES. 


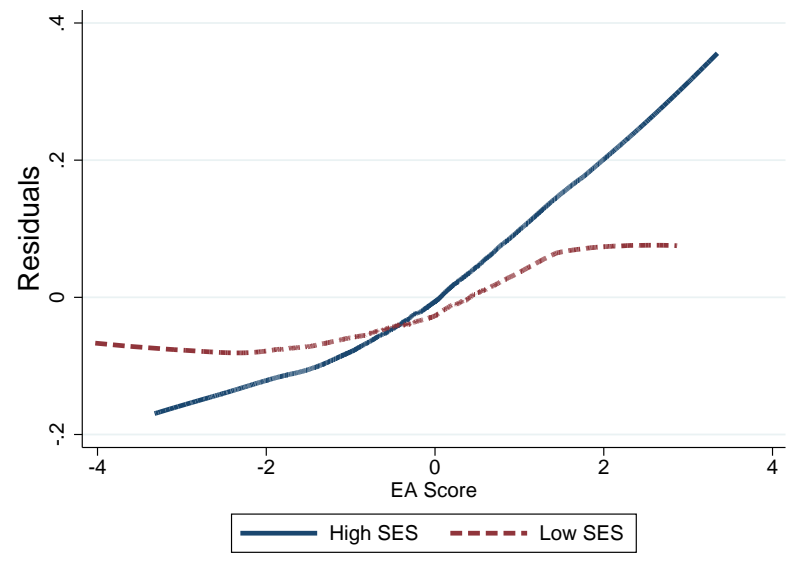

Panel (A) SES Measure: Family Well Off

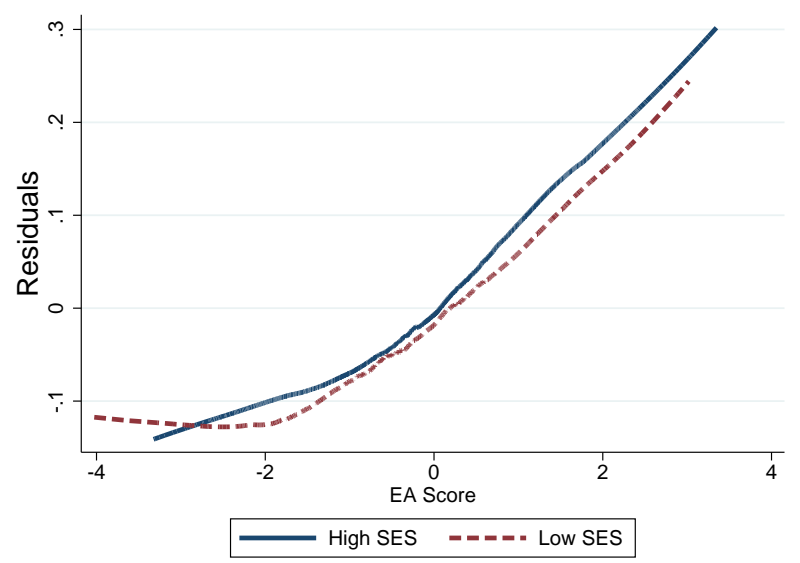

Panel (C) SES Measure: Never Moved/Asked for Help

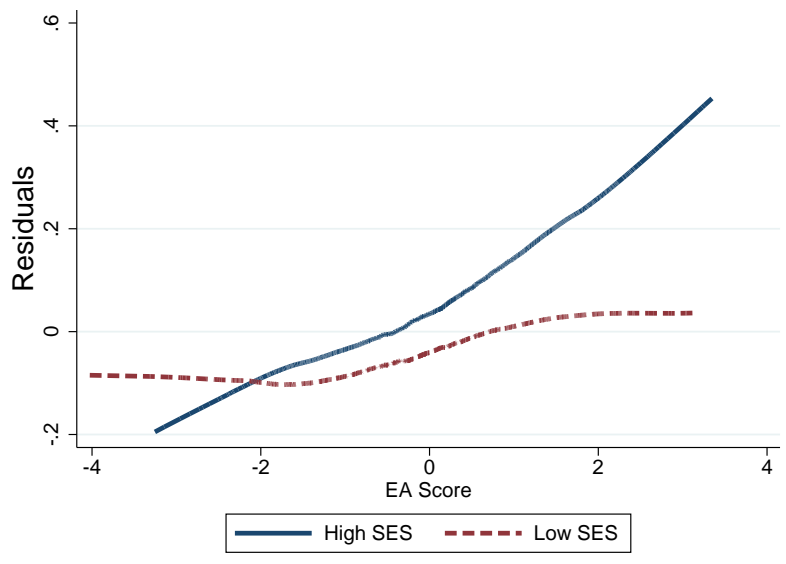

Panel (B) SES Measure: Father's Income

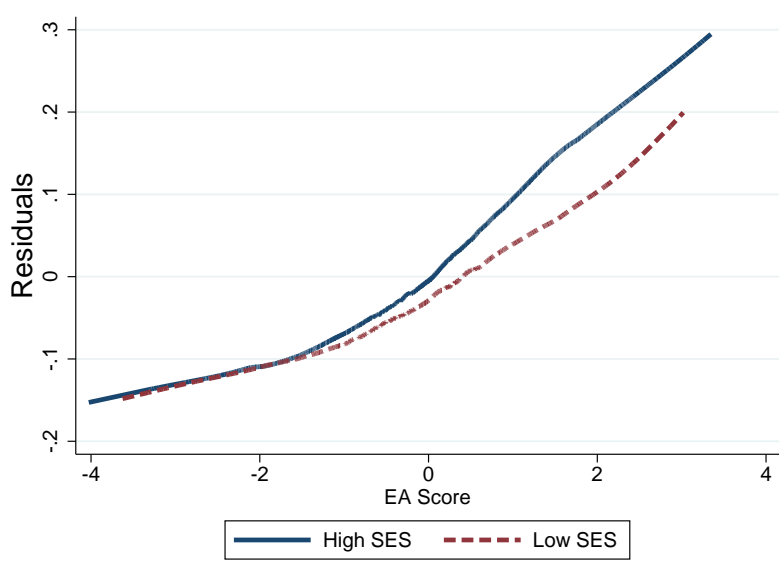

Panel (D) SES Measure: Father's Unemployment

Figure 6: Non-parametric (Lowess) estimation relating the probability of completing a college degree or more to EA Score for high versus low SES for different measures of childhood SES. In each panel, the outcome variable is the residual from OLS regression of an indicator for completing a college degree or higher onto a set of controls and the regressor is EA Score. Across SES measures, EA Score predicts higher education. However, the genetic-college gradient is stronger among individuals who report high childhood SES. 


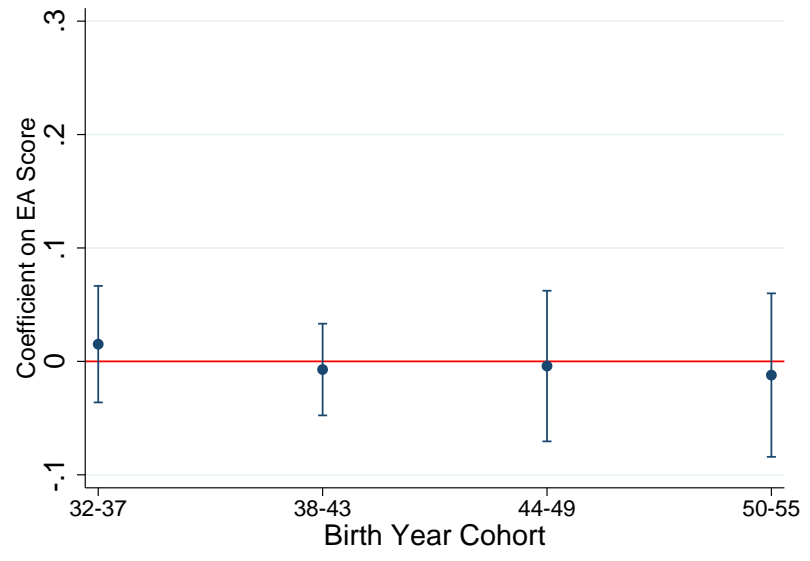

Panel (A): No College Degree

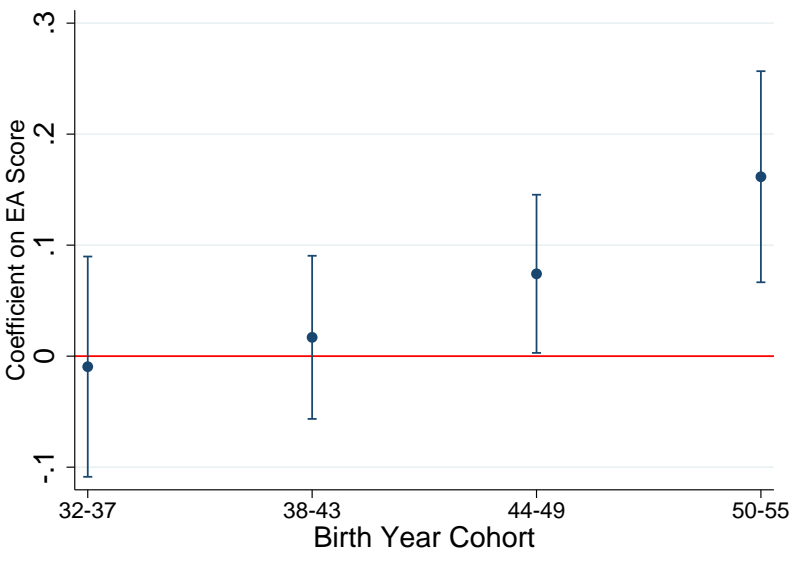

Panel (B): At Least College

Figure 7: EA Score and log wage: results from different time periods. For individuals without a college degree, the coefficient on EA Score in log wage regressions is zero once we have controlled for education. For individuals with a college degree, the coefficient rises after the year 2000. 


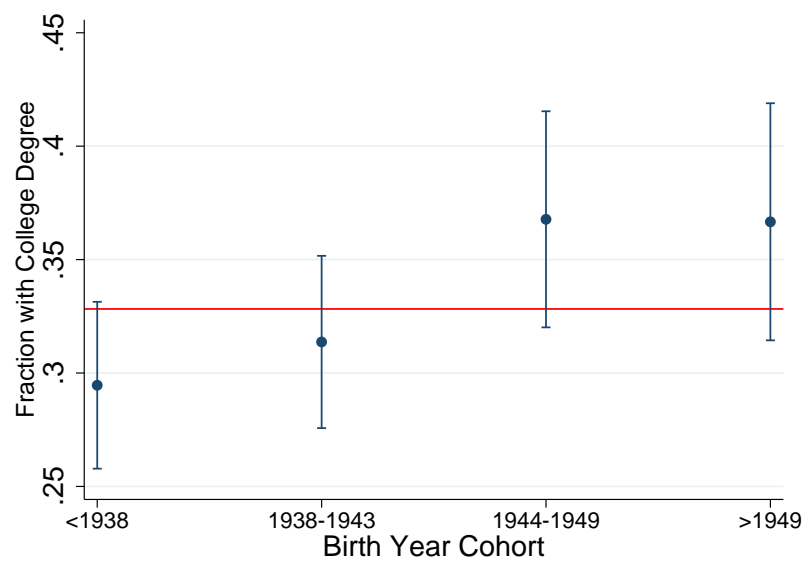

Panel (A): College Degree by Birth Cohort

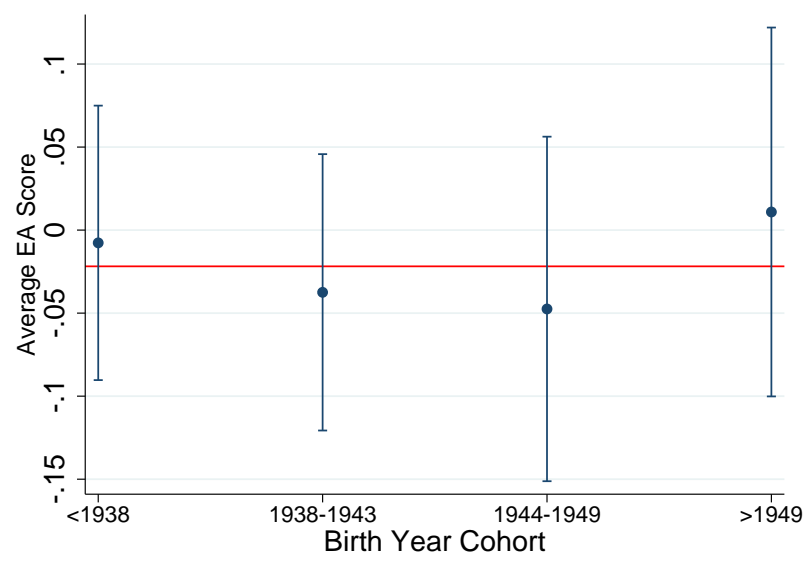

Panel (C): EA Score by Birth Cohort

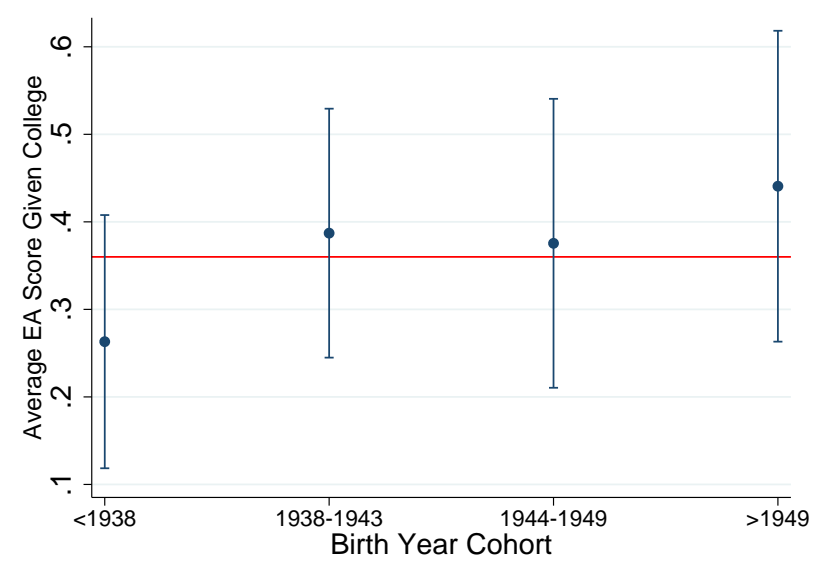

Panel (B): EA Score Given College By Birth Cohort

Figure 8: EA Score and college degree probability by birth cohort for men (mean in red). 


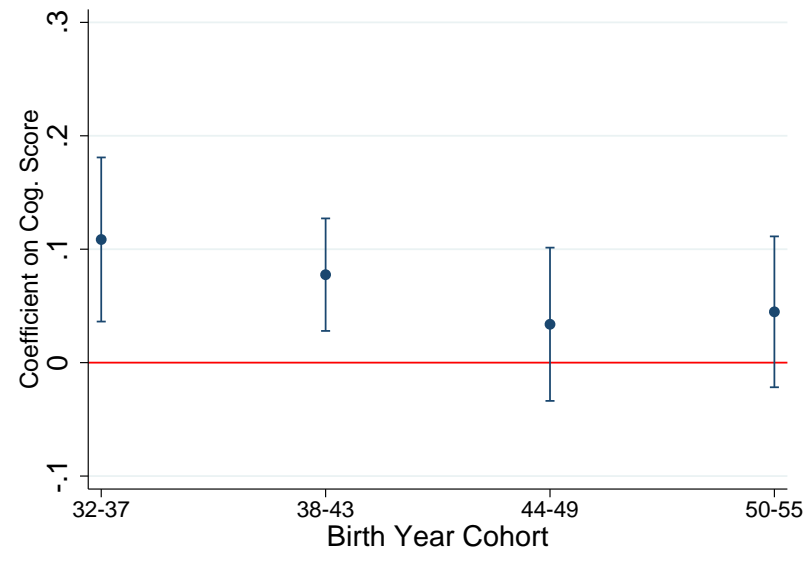

Panel (A): No College Degree

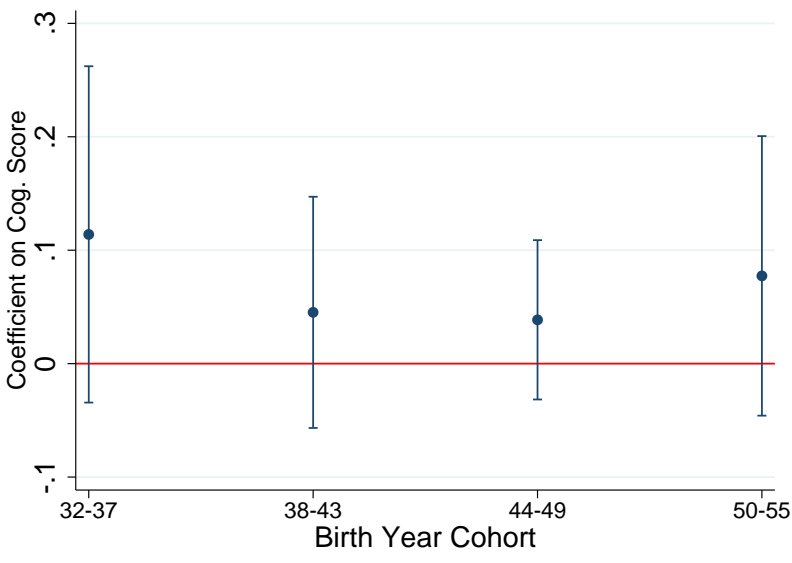

Panel (B): At Least College

Figure 9: Cognition Score and log wage: results from different time periods. For individuals without a college degree, the coefficient on Cognition Score in log wage regressions is positive even after we have controlled for education. For individuals with a college degree, the coefficient falls over time, but is insignificant at all points except for 1992-1996. 


\section{Online Appendix: \\ "Genes, Education and Labor Market Outcomes: \\ Evidence from the Health and Retirement Study" \\ By: Nicholas W. Papageorge and Kevin Thom}

\section{A Additional Details on GWAS and Construction of the EA2 Score}

In this appendix, we provide a brief introduction to molecular genetics and the kinds of genetic data that we use in this study. We repeat some portions of Section 2 so that this appendix can provide a self-contained introduction to GWAS and the EA Score used in our analysis. First, we describe some basic features of the human genome. Next, we discuss how statistical gene-discovery projects can produce scores that are useful for the prediction of economic outcomes such as educational attainment. We highlight how recent advances permit credible and replicable inference.

The human genome consists of approximately 3 billion nucleotide pairs spread out over 23 chromosomes 62 A DNA molecule is often thought of as double-helix ladder, with the nucleotide base pairs forming the "rungs" of the ladder. Each rung can either be an adeninethymine pair, or a guanine-cytosine pair. If the DNA strand can be thought of as a ladder with nucleotide-pair rungs, then the rails or sides of the ladder are formed by phosphate and sugar molecules. These rails can be distinguished as either the positive $(+)$ or negative $(-)$ strands. At a particular location, it will matter which nucleotide molecule is attached to which strand. For example, if there is an adenine-thymine pair in a particular position where the adenine molecule is attached to the positive strand, this would be denoted by an A. However, if instead the thymine molecule were attached to the positive strand, this would be denoted by a $T$. This means that four possible variants could exist at a given address: A, T, G or C, depending on which nucleotide pair is present, and the position of that pair relative to the positive strand. However, most SNPs are biallelic, meaning that there are only two observed alleles at a particular location. The human genome can therefore be thought of as a series of 3 billion genetic addresses, each of which contains a particular base pair molecule in a particular position.

At the vast majority of such locations (about 99\%), there is no variation in the observed nucleotide pair. A single-nucleotide polymorphism (SNP) exists when there are differences in the nucleotide pair present at a particular location on the genome. A particular SNP can be referred to by a name (e.g. rs7937), which indicates its position in the genome.

\footnotetext{
${ }^{62}$ Most of the background information presented here on the human genome follows Beauchamp et al. (2011) and Benjamin et al. (2012)
} 
An allele refers to one of the variants that may be present at a particular SNP. If T (an adenine-thymine pair with the thymine attached to the positive strand) is more commonly found at a particular SNP, it is referred to as the major allele, and the other observed allele is referred to as the minor allele 63

A traditional approach to the discovery of gene-behavior associations rests on examining candidate genes. Under this paradigm, researchers use some knowledge of the relevant biological processes to suggest places in the genome that might contain SNPs associated with a particular outcome. Unfortunately, this approach to identifying gene-economic outcomes has also generated a large number of reported associations that have failed to replicate outside of their discovery samples. This problem has been so widespread that an editorial statement from the journal Behavior Genetics stated that "The literature on candidate gene associations is full of reports that have not stood up to rigorous replication," and that "it now seems likely that many of the published findings of the last decade are wrong or misleading and have not contributed to real advances in knowledge," (Hewitt, 2012). This pattern has emerged, in part, because traditional candidate gene studies have been severely underpowered to detect real genetic effects. Sample sizes in general have been too small relative to the true effect sizes of individual SNPs, making it likely that statistically significant associations are the result of chance. This problem is exacerbated when studies search over many candidate genes, creating a multiple hypothesis testing problem that increases the likelihood of finding false positive results (Benjamin et al., 2012).

An alternative to candidate genes is an approach called a genome-wide association study (GWAS). Under the GWAS methodology, researchers scan the entire genome for SNPs that are associated with a particular phenotype (trait or outcome), but adopt strong measures to deal with multiple hypothesis-testing. For a particular outcome of interest, $y_{i}$, and for a set of observed SNPs, $\left\{S N P_{i j}\right\}_{j=1}^{N^{J}}$, a GWAS study proceeds by obtaining estimates of $N^{J}$ separate regressions of the form:

$$
y_{i}=\mu X_{i}^{\prime}+\beta_{j} S N P_{i j}+\epsilon_{i j}
$$

Here $S N P_{i j}$ measures the number of copies of a reference allele possessed by individual $i$ for $\mathrm{SNP} j$. For example, if the reference allele at $\mathrm{SNP} j$ is $A T$, then $S N P_{i j}$ could take the values 0,1 , or 2 . The maximum value of 2 reflects the fact that an individual can have at most two copies of the reference allele - one on each inherited chromatid. Additionally, $X_{i}$ is a vector of controls, including principal components of the genetic variables $\left\{S N P_{i j}\right\}_{j=1}^{N^{J}}$. Principal components of the genetic data are added to control for population stratification. For ex-

\footnotetext{
${ }^{63}$ In the case of SNPs that are not biallelic, there may be multiple minor alleles.
} 
ample, it could be that $S N P_{i j}$ is correlated with a particular ethnicity or ancestry group. Failure to control for the principal components could generate observed SNP-phenotype relationships that reflect the influence of broader ethnic differences rather than the influence of a particular genetic marker.

After obtaining estimates for all $N^{J}$ versions of equation (2), those estimated coefficients $\widehat{\beta}_{j}$ with sufficiently small $p$-values are said to reflect relationships that are genome-wide significant. Given the huge number of regressions run under this methodology, the significance thresholds in modern GWAS are typically very strict. A conventional threshold is $5 \times 10^{-8}$. This approach has become popular and as a consequence of its stringency requirements, has led to the discovery of a number of credible genetic associations. For example, the well-known FTO gene for obesity was discovered through a GWAS, despite the lack of any existing biology that would have suggested it as a candidate gene (Benjamin et al., 2012).

Existing work has demonstrated the importance of credibly identified SNPs for several economic outcomes. These SNPs either directly emerged from a GWAS, or were candidate genes that were validated by later GWAS results. An established literature documents a number of credible genetic associations with smoking behaviors (Bierut, 2010; Thorgeirsson et al. 2010). Fletcher (2012) demonstrates that a SNP associated with smoking intensity also appears to moderate the effect of tobacco taxes. More closely related to our work, another set of studies suggests indirect linkages between genetic variants and human capital. For example, Fletcher and Lehrer (2011) use a set of SNPs associated with health outcomes to provide exogenous within-family variation to estimate a causal relationship between health and education. Finally, Thompson (2014) shows that a variant associated with the MAOA gene appears to moderate the relationship between income and education.

Recent work using GWAS has discovered some of the first direct associations between specific SNPs and education. Rietveld et al. (2013) identified three SNPs (rs9320913, rs11584700, rs4851266) attaining genome-wide significance in a GWAS for educational attainment. Follow-up work by the same team (the Social Science and Genetics Consortium) has recently extended the Rietveld et al. (2013) study to perform an educational attainment GWAS with a sample size of 293,723. This follow-up study, Okbay et al. (2016), has discovered 74 SNPs that attain genome-wide significance. We build our analysis here on the gene-education associations found in this follow-up study.

One common technique adopted in the GWAS literature is to take observed SNPs and the estimated GWAS coefficients (the $\widehat{\beta}_{j}$ ) and aggregate them into a polygenic score that 
can be used for prediction. Typically these scores take the following form:

$$
P G S_{i}=\sum_{j} \widetilde{\beta}_{j} S N P_{i j}
$$

where $\widetilde{\beta}_{j}$ is some transformation of the underlying GWAS coefficients. The $\widehat{\beta}_{j}$ estimates are typically corrected to account for correlation between SNPs and prevent over or under prediction. The follow up study Okbay et al. (2016) combines all genotyped SNPs into a polygenic score that attains a predictive power of up to $3.85 \%$ of the variation in educational attainment ${ }^{64}$ In our study, we use SNP weights $\widehat{\beta}_{j}$ that have been adjusted using a technique called LD Pred (Vilhjalmsson, 2015), and applied to the genetic data in the HRS 65 We refer to the polygenic score created using these weights as the EA Score, where "EA" stands for "educational attainment". We refer to it this way since other polygenic scores exist, which capture genetic variation explaining different outcomes.

\footnotetext{
${ }^{64} \mathrm{We}$ note as well that the polygenic score that we use in this study combines all SNPs analyzed in Okbay et al. (2016), not just those reaching genome-wide significance. As noted in Okbay et al. (2016), this maximizes the predictive power out of sample.

${ }^{65}$ We would like to especially thank Aysu Okbay, a member of the Social Science and Genetics Consortium, for graciously generating and sharing this score with us.
} 


\section{B Additional Results on Gender Differences}

Here, we estimate the relationship between genes and years of education by separately by gender. Essentially, we repeat the analysis reported in Table 2, but interact the genetic score coefficients with a Male dummy. Estimates are presented in Table S1. Across the columns, the coefficient on EAScore $\times$ Male are consistently positive, indicating that the association between the polygenic score and years of schooling is larger for males. However, this interaction is only statistically significant in the last two columns, when more extensive controls for SES and family background are included. The estimates in Column (5) suggest that a one standard deviation increase in the polygenic score is associated with about 0.428 extra years of schooling for females, but about 0.528 extra years of schooling for women. This difference is significant at the 0.05 level. 
Appendix Table S1: Polygenic Score and Educational Attainment - EA Score x Male

\begin{tabular}{|c|c|c|c|c|c|}
\hline & $\overline{(1)}$ & $\overline{(2)}$ & $\overline{(3)}$ & (4) & $(5)$ \\
\hline EA Score & $\begin{array}{c}0.641^{* * *} \\
(0.035)\end{array}$ & $\begin{array}{c}0.459^{* * *} \\
(0.032)\end{array}$ & $\begin{array}{c}0.454^{* * *} \\
(0.032)\end{array}$ & $\begin{array}{c}0.436^{* * *} \\
(0.032)\end{array}$ & $\begin{array}{c}0.428^{* * *} \\
(0.032)\end{array}$ \\
\hline EA Score x Male & $\begin{array}{c}0.054 \\
(0.053)\end{array}$ & $\begin{array}{c}0.079 \\
(0.049)\end{array}$ & $\begin{array}{c}0.079 \\
(0.049)\end{array}$ & $\begin{array}{c}0.097^{* *} \\
(0.048)\end{array}$ & $\begin{array}{c}0.104^{* *} \\
(0.048)\end{array}$ \\
\hline Father Educ & & $\begin{array}{c}0.157^{* * *} \\
(0.009)\end{array}$ & $\begin{array}{c}0.153^{* * *} \\
(0.009)\end{array}$ & $\begin{array}{c}0.117^{* * *} \\
(0.009)\end{array}$ & $\begin{array}{c}0.114^{* * *} \\
(0.009)\end{array}$ \\
\hline Mother Educ & & $\begin{array}{c}0.184^{* * *} \\
(0.011)\end{array}$ & $\begin{array}{c}0.181^{* * *} \\
(0.011)\end{array}$ & $\begin{array}{c}0.165^{* * *} \\
(0.011)\end{array}$ & $\begin{array}{c}0.162^{* * *} \\
(0.011)\end{array}$ \\
\hline Child Health: Very Good & & & $\begin{array}{c}-0.233^{* * *} \\
(0.058)\end{array}$ & $\begin{array}{c}-0.227^{* * *} \\
(0.057)\end{array}$ & $\begin{array}{c}-0.231^{* * *} \\
(0.057)\end{array}$ \\
\hline Child Health: Good & & & $\begin{array}{c}-0.480^{* * *} \\
(0.072)\end{array}$ & $\begin{array}{c}-0.434^{\text {*** }} \\
(0.071)\end{array}$ & $\begin{array}{c}-0.444^{* * *} \\
(0.071)\end{array}$ \\
\hline Child Health: Fair & & & $\begin{array}{c}-0.371^{* * *} \\
(0.118)\end{array}$ & $\begin{array}{c}-0.327^{* * *} \\
(0.117)\end{array}$ & $\begin{array}{c}-0.364^{* * *} \\
(0.117)\end{array}$ \\
\hline Child Health: Poor & & & $\begin{array}{c}-0.796^{* * *} \\
(0.223)\end{array}$ & $\begin{array}{c}-0.752^{\text {*** }} \\
(0.222)\end{array}$ & $\begin{array}{c}-0.781^{* * *} \\
(0.221)\end{array}$ \\
\hline Child Health: Missing & & & $\begin{array}{c}1.050 \\
(1.586) \\
\end{array}$ & $\begin{array}{c}1.168 \\
(1.604) \\
\end{array}$ & $\begin{array}{c}0.899 \\
(1.598) \\
\end{array}$ \\
\hline Obs. & 8554 & 8554 & 8554 & 8554 & 8554 \\
\hline$R^{2}$ & 0.125 & 0.260 & 0.265 & 0.285 & 0.294 \\
\hline Child SES Measures & $\mathrm{N}$ & $\mathrm{N}$ & $\mathrm{N}$ & $\mathrm{Y}$ & $\mathrm{Y}$ \\
\hline Child Region & $\mathrm{N}$ & $\mathrm{N}$ & $\mathrm{N}$ & $\mathrm{N}$ & $\mathrm{Y}$ \\
\hline Religion & $\mathrm{N}$ & $\mathrm{N}$ & $\mathrm{N}$ & $\mathrm{N}$ & $\mathrm{Y}$ \\
\hline
\end{tabular}

Regressions relating educational attainment (years) to the EA Score. All regressions include a full set of dummy variables for birth year, a male dummy and a full set of interactions between the birth year and gender dummies. All specifications include the first 10 principle components of the full matrix of genetic data as controls. Some specifications include controls for parental education, childhood health, childhood SES measures, region during childhood and religion, as indicated. 


\section{Bias in Estimated Coefficients}

In this appendix, we discuss potential biases to parameter estimates. A key problem is that innate ability captured by genetic endowments can affect returns to human capital investments, but also drive these investments. One reason is that parents who provide advantageous genetic material may also be more likely to invest in their children. Further problems arise since we do not measure human capital investments directly. Instead, we proxy for them using various measures of parent socio-economic status. These proxies may be systematically mis-measured. Here, we explore the consequences for parameter estimates.

First, suppose we want to relate a continuous economic outcome $y_{i}$ to innate ability, measured by genetic score and denoted $G_{i}$, and a continuous investment in human capital $I_{i}$

$$
y_{i}=G_{i} \phi_{1}+I_{i} \phi_{2}+\left(G_{i} \times I_{i}\right) \phi_{3}+\epsilon_{i}
$$

In this equation, $\epsilon_{i}$ is an iid disturbance. $\phi_{3}$ is of particular policy relevance as it captures whether innate ability and investments are complements $\left(\phi_{3}>0\right)$ or substitutes $\left(\phi_{3}<0\right)$.

There are two difficulties in estimating equation (4) which we emphasize. First, we proxy for investments using family SES, which we denote $S_{i}$. Investments may therefore be systematically mis-measured as follows:

$$
I_{i}=S_{i} \rho_{1}+G_{i} \rho_{2}+G_{i}^{P} \rho_{3}+\nu_{i}
$$

The investment equation captures three features of our setting. First, family SES is an imperfect measurement of human capital investments. Second, the measurement error may be systematically related to genotype $G_{i}$. For example, if $\rho_{2}>0$, then parent socio-economic status systematically underestimates investments in children with high innate abilities. Finally, parents with stronger genetic endowments, which we denote $G_{i}^{P}$, may also provide better environments for their children even after we have controlled for parent socio-economic status.

Another feature of our setting is that the genetic endowment $G_{i}$ reflects parent genetic endowments, which we denote $G_{i}^{P}$. We capture this with the following equation:

$$
G_{i}=G_{i}^{P} \alpha+e_{i}
$$

Notice that investments and socio-economic status, though they may be correlated with unobservable variables that affect outcomes, cannot influence an individual's genetic score. This will prove helpful for inference on how innate abilities interact with investments. In 
particular, we are interested in the structural relationship expressed in equation (4). We rewrite it, but substituting in the investment relationship from equation (5) to obtain an estimable expression:

$$
\begin{aligned}
y_{i} & =G_{i} \phi_{1}+\left[S_{i} \rho_{1}+G_{i} \rho_{2}+G_{i}^{P} \rho_{3}+\nu_{i}\right] \phi_{2}+\left(G_{i} \times\left[S_{i} \rho_{1}+G_{i} \rho_{2}+G_{i}^{P} \rho_{3}+\nu_{i}\right]\right) \phi_{3}+\epsilon_{i} \\
& =G_{i}\left(\phi_{1}+\rho_{2} \phi_{2}\right)+S_{i} \rho_{1} \phi_{2}+\left(G_{i} \times S_{i}\right) \rho_{1} \phi_{3} \\
& +G_{i}^{P} \rho_{3} \phi_{2}+G_{i}^{2} \rho_{2} \phi_{3}+G_{i} G_{i}^{P} \rho_{3} \phi_{3}+\nu_{i} \phi_{2}+G_{i} \nu_{i} \phi_{3}+\epsilon_{i}
\end{aligned}
$$

Next, recognize that $G_{i}^{P}=\frac{G_{i}-e_{i}}{\alpha}$. Thus, we can rewrite the outcome as:

$$
\begin{aligned}
y_{i} & =G_{i}\left(\phi_{1}+\rho_{2} \phi_{2}\right)+S_{i} \rho_{1} \phi_{2}+\left(G_{i} \times S_{i}\right) \rho_{1} \phi_{3} \\
& +G_{i} \frac{\rho_{3} \phi_{2}}{\alpha}+G_{i}^{2} \rho_{2} \phi_{3}+G_{i}^{2} \frac{\rho_{3} \phi_{3}}{\alpha}+\nu_{i} \phi_{2}+G_{i} \nu_{i} \phi_{3}+\epsilon_{i} \\
& -e_{i} \frac{\rho_{3} \phi_{2}}{\alpha}-G_{i} e_{i} \frac{\rho_{3} \phi_{3}}{\alpha}
\end{aligned}
$$

Simplifying, leads us to the following estimable expression:

$$
\begin{aligned}
y_{i} & =G_{i} \kappa_{1}+S_{i} \kappa_{2}+\left(G_{i} \times S_{i}\right) \kappa_{3}+G_{i}^{2} \kappa_{4}+\xi_{i} \\
\kappa_{1} & =\phi_{1}+\rho_{2} \phi_{2}+\frac{\rho_{3} \phi_{2}}{\alpha} \\
\kappa_{2} & =\rho_{2} \phi_{2} \\
\kappa_{3} & =\rho_{1} \phi_{3} \\
\kappa_{4} & =\rho_{2} \phi_{3}+\frac{\rho_{3} \phi_{3}}{\alpha} \\
\xi_{i} & =\nu_{i} \phi_{2}-e_{i} \frac{\rho_{3} \phi_{2}}{\alpha}+G_{i} \nu_{i} \phi_{3}-G_{i} e_{i} \frac{\rho_{3} \phi_{3}}{\alpha}+\epsilon_{i}
\end{aligned}
$$

The final equation is similar to the type of equations we estimate. Estimated parameters are related to the parameters of interest in equation (4). To simplify the discussion, we will maintain the assumption that $\rho_{1}>0$ (higher SES translates to higher investments) and $\rho_{3}>0$ (parents with more advantageous genetic endowments invest more in their children even after we have controlled for SES). Finally, we recognize that parent and child genetic endowments are positively correlated $(\alpha>0)$. The following are true.

1. $\kappa_{1}>\phi_{1}+\rho_{2} \phi_{2}+\frac{\rho_{3} \phi_{2}}{\alpha}$ if $\rho_{2}>0$. If $\rho_{2}<0$, the direction of the bias cannot be signed.

2. We over-estimate $\phi_{2}$ if $\rho_{2}>0$. If $\rho_{2}<0$, then the direction of the bias cannot be signed.

3. As long as SES predicts actual investments $\left(\rho_{1}>0\right)$, the sign of $\kappa_{3}$ is the same as the sign of $\phi_{3}$. In other words, we estimate the correct sign of $\phi_{3}$, which governs whether innate ability and investments in human capital are complements or substitutes. This 
is important as we are particularly interested in understanding how innate ability differences can be mitigated by human capital investments.

4. The estimating equations should control for a second-order polynomial in genetic score. This controls for how genetic score affects $y_{i}$ both directly and through its impact on mis-measured investments.

5. Estimating equations should take account of heteroskedasticity since the variance of $\xi_{i}$ is a function of $G_{i}$.

One of the key results of this exercise is to show that we can identify the correct sign of $\phi_{3}$, which governs interactions between ability (measured by genes) and investments, which are measured using child socio-economic status. We obtain the correct sign even though SES, genes and parent genes can all affect investments. Here, we show that our ability to identify the sign of $\phi_{3}$ rests on the fact that genes are not affected by investments. Suppose instead that we measure ability with cognitive test scores, which are affected by investments. In this case, we can no longer identify the sign of $\phi_{3}$. We illustrate this point with a simpler version of the model. Once again, our goal is to estimate the parameters in equation (4). We add two more equations to the system: a simplified version of the investment equation and an equation relating cognitive test scores (denoted $C_{i}$ ) to genes and investments. The investment equation is

$$
I_{i}=S_{i} \gamma_{1}+G_{i} \gamma_{2}+\nu_{i}^{I}
$$

Here, we have dropped parent genes $G_{i}^{P}$ for ease of exposition. Cognitive test scores are explained by:

$$
C_{i}=I_{i} \alpha_{1}+G_{i} \alpha_{2}+\nu_{i}^{C}
$$

This means that a cognitive test score is a function of investments $I_{i}$ and genes $G_{i}$. The next step is to solve for $G_{i}$ and $I_{i}$ as functions of observable variables $S_{i}$ and $C_{i}$, which are then substituted into equation (4) to obtain an estimable expression. The estimable expression is similar to equation (4), but in place of $G_{i}$, we have $C_{i}$ :

$$
y_{i}=C_{i} \delta_{1}+S_{i} \delta_{2}+\left(C_{i} \times S_{i}\right) \delta_{3}+\nu_{i}^{Y}
$$

It can be shown that $\operatorname{sign}\left(\delta_{3}\right)=\operatorname{sign}\left(\phi_{3}\right)$ if $\frac{\alpha_{2}}{\alpha_{1}}+\gamma_{2}>2 \gamma_{1}$. The interpretation is that if factors other than genetics are important in explaining $C_{i}$, we are more likely to mis-estimate the sign of $\phi_{3}$. 


\section{Additional Specifications Related to Gene - SES Interactions}

In this appendix, we provide robustness checks of results generated from estimating regressions of equation (1) from Section 3 in the main text. Using equation (1), we estimate an interaction between childhood SES and the EAScore to explain educational attainment and plot resulting coefficients for different levels of education in Figure 4 . Recall that the interaction between childhood SES and educational outcomes switches sign when we consider lower to higher levels of educational attainment. Here, we demonstrate that this pattern holds when control for a cubic in the polygenic score. Coefficients are plotted in Figure $\mathrm{S1}{ }^{66}$

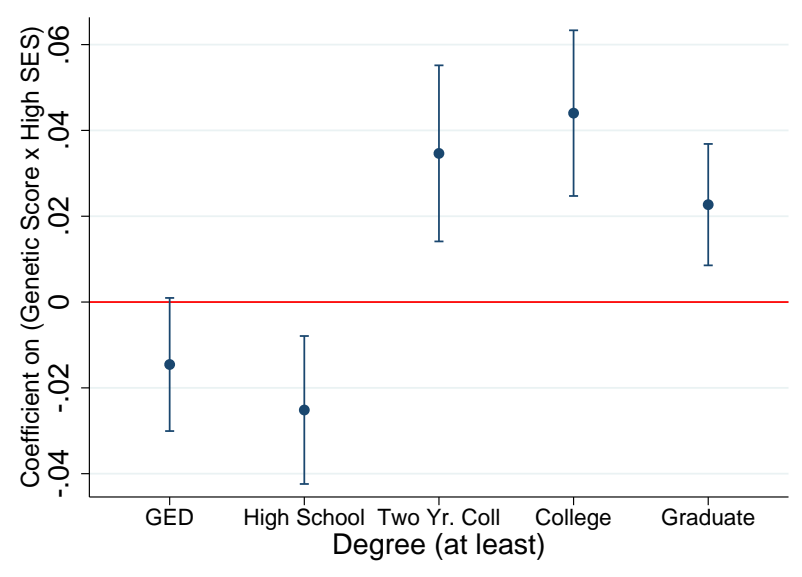

Panel (A) SES Measure: Family Well Off

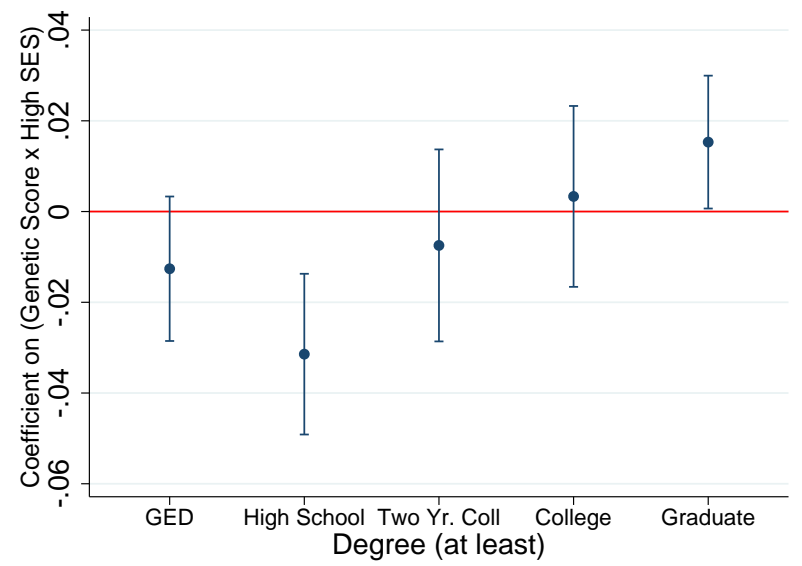

Panel (C) SES Measure: Never Moved/Asked for Help

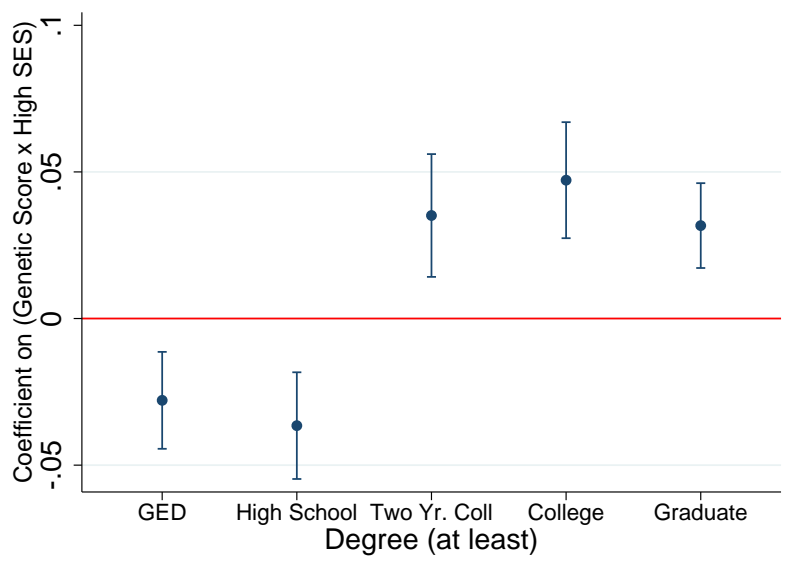

Panel (B) SES Measure: Father's Income

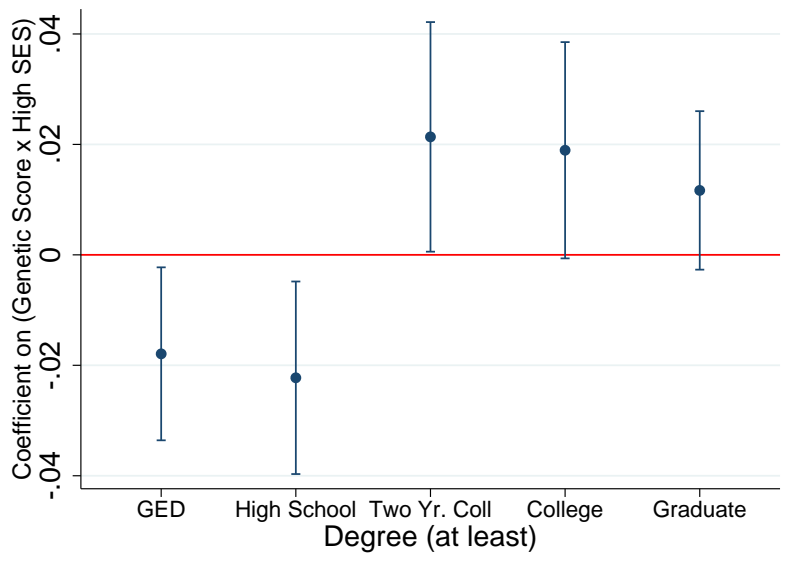

Panel (D) SES Measure: Father's Unemployment

Appendix Figure S1: Coefficient on the interaction between EA Score and high SES for different schooling categories. These specifications include a cubic in the polygenic score.

\footnotetext{
${ }^{66}$ Recall from the statistical model in Appendix C that the sign of the causal interaction is correctly estimated if we control for non-linearities in the polygenic score even if high-score individuals are more likely to face larger investments.
} 


\section{E Additional Results on Birth Cohort Interactions}

Table S2 demonstrates that the results related to log wages continue to hold once we drop earlier birth cohorts. All specifications in Table S2 restrict the wage sample to individuals born in 1944 or later. As indicated in Column (1), with this restricted sample, we continue to find a substantial interaction between the EA Score and completing at least a college degree. We do not find a statistically significant main effect for the EA Score in Column (1), indicating no return for those without a college degree. The median birth year for individuals in this restricted sample is 1949. Columns (2)-(3) of Table S2 test for interactions between the EA Score and being born after 1949 separately for those with and without a college degree. Column (2) restricts the sample to those without a college degree and we find no statistically significant coefficient on the EA Score either the younger or older birth cohorts. Column (3) restricts the sample to those with a college degree and we find a statistically significant coefficient on the EA Score of 0.069. Moreover, the coefficient on the interaction between the EA Score and the indicator for younger cohorts is positive and significant with $p$-value 0.071. The estimates imply that a one standard deviation increase in the EA Score is associated with 6.9 percent higher wages for college graduates born in 1949 or earlier, but it is associated with about 17.1 percent higher wages for college graduates born after 1949 . 
Appendix Table S2: Polygenic Score and Wages

\begin{tabular}{lccc}
\hline \hline & $(1)$ & $(2)$ & $(3)$ \\
\hline \hline EA Score & -0.014 & -0.009 & $0.069^{* *}$ \\
& $(0.024)$ & $(0.033)$ & $(0.034)$ \\
EA Score x College & $0.128^{* * *}$ & & \\
& $(0.036)$ & & \\
EA Score x Post BY 1949 & & -0.007 & $0.102^{*}$ \\
& & $(0.049)$ & $(0.056)$ \\
Obs. & 2821 & 1750 & 1071 \\
$R^{2}$ & 0.225 & 0.118 & 0.195 \\
Ed. Groups & All & No College & College \\
Birth Cohorts & $\geq 1944$ & $\geq 1944$ & $\geq 1944$ \\
Educ. Controls & $\mathrm{Y}$ & $\mathrm{Y}$ & $\mathrm{Y}$ \\
Parent Controls & $\mathrm{Y}$ & $\mathrm{Y}$ & $\mathrm{Y}$ \\
\hline \hline
\end{tabular}

Regressions relating the EA Score to log wages. In all columns the sample is restricted to men between the ages of 50 and 64 who reported working at least 20 hours for pay. The dependent variable is the $\log$ wage. All regressions include the first 10 principle components of the full matrix of genetic data along with a full set of dummy variables for birth year, calendar year and age. Because of collinearity, a subset of these dummies is dropped. All specifications include controls for parental education (years of paternal and maternal education and dummies indicating missing values for each) and own education (years of schooling and a full set of completed degree dummies). Column (1) includes interactions between all principle components and the dummy variable for at least a college degree. The results in Columns (2)(3) include interactions between the principle components and a dummy variable indicating birth years after 1949 . 


\section{F Additional Results Using the Cognitive Test Score}

If the polygenic score captures academic ability, a natural question to ask is how it relates to more typical measures of academic ability, such as cognitive test scores. This question is especially pertinent since typical measures of ability, such as IQ, are subject to the critique that they reflect earlier investments. Genetic information is not since it is not changed by investments made after conception. Fortunately, we are able to compare cognitive test scores to the polygenic score. The HRS features a number of items related to cognition, including two memory tests, two simple math exercises, and eight general knowledge questions, which have been used in prior literature as a measure of cognition (McArdle, Smith, and Willis, 2009).

Each memory test is scored out of ten, for a total of twenty possible points. Subjects' memory was tested using a list of ten common nouns. They were asked to recall as many of the nouns as possible both immediately after the list was read and after a predetermined set of survey questions (or about five minutes). The math exercises account for seven points: two awarded for correctly counting back from 20 to 10 on the first try (or one on a second try), and one each for 5 rounds of correctly subtracting 7 from 100. Eight points are scored by correctly naming the day of the week, date, month, and year, the objects "people usually use to cut paper" and the "kind of prickly plant that grows in the desert", and the sitting President and Vice President.

Our specific measure of cognitive functioning comes from the Imputation of Cognitive Functioning Measures file of the HRS. Specifically, we use the imputed "Total Cognition Summary Score" for each wave. This score aggregates the previously mentioned cognition measures and takes values between 0-35. To remove the effects of age and gender, we regress all observations of the total cognition score for genetic Europeans on a male dummy, a quartic in age, and an interaction between male and the quartic age terms. We then average the residuals for each individual and standardize this average so that it has zero mean and a standard deviation of one.

We plot the distribution of the Cognition Score in Figure S2. Similar to the EA Score (refer back to Figure 1), Cognition Score is approximately normally distributed. The correlation between Cognition Score and EA Score is modest $(\rho=0.193)$. A scatter plot indicates this weak positive correlation (Figure S3).

We next assess whether the EA Score and the Cognitive Score exhibit similar relationships with educational attainment and the labor market outcomes we study. Table S3 presents specifications that add the Cognition Score to our basic set of regressions explaining educational attainment from Table 2, Both the EA Score and the Cognition Score exhibit a 
substantial, highly significant statistical relationship with educational attainment. Since the two scores are somewhat correlated, the coefficient on the EA Score does drop somewhat when the Cognition Score is added. In the full specification with all SES controls, the coefficient on the EA Score is 0.359 , compared to 0.470 in the same specification without the Cognition Score (compare the coefficient attached to EA Score in Column (5) of Table 2 from the main text with the analogous coefficient in Column (5) of Table S3 in this appendix). The relationship between the Cognition Score and education is sizable, with a one standard deviation increase in the Cognition Score being associated with an increase of educational attainment of 0.768 years.

In Table S4, we add the Cognition Score to the regressions explaining degree types and the probability of repeating a grade in childhood. Here again, we find that both the EA Score and the Cognition Score are positively associated with better educational outcomes along all of these dimensions. We also examine whether the EA Score and the Cognition Score are similarly moderated by SES. In Table S5, we present coefficient estimates for a modified version of Equation 1 that also includes the Cognition Score and its interaction with High SES. Adding these regressors will in general reduce the precision of our estimates for either interaction since EA Score and the Cognition Score are correlated. Nevertheless, the non-monotonic pattern of interactions found in Figure 4 holds for both the EA Score and the Cognitive Score in many specifications.

In Table S6, we revisit our specifications for labor market outcomes (Table 7), but now add Cognition Score and, where appropriate, its interaction with an indicator for college degree. In all of these specifications, all of the statistically significant results for the EA Score continue to hold. However, we find some important differences for the Cognitive Score, which reflect that it can vary over time and as a result of endogenous investments. Although both the EA Score and the Cognitive Score are positively associated with working status, the Cognitive Score exhibits a different relationship with retirement probabilities (conditional on working). While the EA Score is negatively associated with retirement for all workers, the Cognitive Score is positively associated with retirement for workers without a college degree, but negatively associated for those with a college degree. Interestingly, although the Cognition Score is positively associated with log wages, we find no evidence for a significant interaction between the Cognition Score and holding a college degree. 
Appendix Table S3: Polygenic Score, Cognition Score, and Educational Attainment

\begin{tabular}{lccccc}
\hline \hline & $(1)$ & $(2)$ & $(3)$ & $(4)$ & $(5)$ \\
\hline \hline EA Score & $0.476^{* * *}$ & $0.371^{* * *}$ & $0.369^{* * *}$ & $0.362^{* * *}$ & $0.360^{* * *}$ \\
& $(0.025)$ & $(0.023)$ & $(0.023)$ & $(0.023)$ & $(0.023)$ \\
CogScore & $0.974^{* * *}$ & $0.804^{* * *}$ & $0.794^{* * *}$ & $0.774^{* * *}$ & $0.768^{* * *}$ \\
& $(0.025)$ & $(0.024)$ & $(0.024)$ & $(0.024)$ & $(0.024)$ \\
Father Educ & & $0.131^{* * *}$ & $0.129^{* * *}$ & $0.097^{* * *}$ & $0.096^{* * *}$ \\
& & $(0.009)$ & $(0.009)$ & $(0.009)$ & $(0.009)$ \\
Mother Educ & & $0.149^{* * *}$ & $0.148^{* * *}$ & $0.134^{* * *}$ & $0.133^{* * *}$ \\
& & $(0.010)$ & $(0.010)$ & $(0.010)$ & $(0.010)$ \\
Obs. & 8473 & 8473 & 8473 & 8473 & 8473 \\
$R^{2}$ & 0.264 & 0.347 & 0.349 & 0.364 & 0.372 \\
Child SES Measures & $\mathrm{N}$ & $\mathrm{N}$ & $\mathrm{Y}$ & $\mathrm{Y}$ & $\mathrm{Y}$ \\
Child Region & $\mathrm{N}$ & $\mathrm{N}$ & $\mathrm{N}$ & $\mathrm{Y}$ & $\mathrm{Y}$ \\
Religion & $\mathrm{N}$ & $\mathrm{N}$ & $\mathrm{N}$ & $\mathrm{N}$ & $\mathrm{Y}$ \\
\hline \hline
\end{tabular}

Regressions relating educational attainment (years) to the EA Score and the Cognition Score. All regressions include a full set of dummy variables for birth year, a male dummy and a full set of interactions between the birth year and gender dummies. All specifications include the first 10 principle components of the full matrix of genetic data as controls. Some specifications include controls for parental education, childhood health, childhood SES measures, region during childhood and religion, as indicated.

Appendix Table S4: Polygenic Score, Cognition Score and Categorical Education Outcomes

\begin{tabular}{lccccc}
\hline \hline & $(1)$ & $(2)$ & $(3)$ & $(4)$ & $(5)$ \\
Dep Var. & No Degree & Two-Year Coll. & College & College Plus & Redo Grade \\
\hline \hline EA Score & $-0.027^{* * *}$ & -0.004 & $0.034^{* * *}$ & $0.033^{* * *}$ & $-0.019^{* * *}$ \\
& $(0.003)$ & $(0.002)$ & $(0.004)$ & $(0.003)$ & $(0.004)$ \\
CogScore & $-0.091^{* * *}$ & $0.008^{* * *}$ & $0.042^{* * *}$ & $0.045^{* * *}$ & $-0.060^{* * *}$ \\
& $(0.003)$ & $(0.003)$ & $(0.004)$ & $(0.003)$ & $(0.004)$ \\
Father Educ & $-0.006^{* * *}$ & 0.000 & $0.012^{* * *}$ & $0.010^{* * *}$ & $-0.006^{* * *}$ \\
& $(0.001)$ & $(0.001)$ & $(0.001)$ & $(0.001)$ & $(0.001)$ \\
Mother Educ & $-0.014^{* * *}$ & $0.002^{*}$ & $0.010^{* * *}$ & $0.007^{* * *}$ & $-0.006^{* * *}$ \\
& $(0.002)$ & $(0.001)$ & $(0.002)$ & $(0.001)$ & $(0.002)$ \\
Obs. & 8449 & 8449 & 8449 & 8449 & 8116 \\
$R^{2}$ & 0.194 & 0.025 & 0.095 & 0.107 & 0.105 \\
\hline \hline
\end{tabular}

Regressions relating educational attainment categories or the probability of repeating a grade to the EA Score and the Cognition Score. All regressions include a full set of dummy variables for birth year, a male dummy, and a full set of interactions between the birth year and gender dummies. Additionally, every specification includes the first 10 principle components of the full matrix of genetic data and controls for parental education (years of paternal and maternal education, and dummies indicating missing values for each) and own education (years of schooling and a full set of completed degree dummies). 
Appendix Table S5: Polygenic Score, Cognition Score and Interactions with SES

\begin{tabular}{|c|c|c|c|c|c|}
\hline Dep Var: At Least & $\begin{array}{l}\quad(1) \\
\text { H.S. Equiv }\end{array}$ & $\begin{array}{c}(2) \\
\text { High School }\end{array}$ & $\begin{array}{c}(3) \\
\text { Two Yr. }\end{array}$ & $\begin{array}{c}(4) \\
\text { College }\end{array}$ & $\begin{array}{c}(5) \\
\text { Grad }\end{array}$ \\
\hline \multicolumn{6}{|c|}{ Panel A: SES Measure - Family Well Off } \\
\hline EA Score & $\begin{array}{c}0.030^{* * *} \\
(0.007)\end{array}$ & $\begin{array}{c}0.047^{* * *} \\
(0.007)\end{array}$ & $\begin{array}{c}0.040^{* * *} \\
(0.009)\end{array}$ & $\begin{array}{c}0.037^{* * *} \\
(0.008)\end{array}$ & $\begin{array}{c}0.016^{* *} \\
(0.006)\end{array}$ \\
\hline EA Score x High SES & $\begin{array}{l}-0.005 \\
(0.008)\end{array}$ & $\begin{array}{l}-0.015^{*} \\
(0.009)\end{array}$ & $\begin{array}{c}0.033^{* * *} \\
(0.010)\end{array}$ & $\begin{array}{c}0.043^{* * *} \\
(0.010)\end{array}$ & $\begin{array}{c}0.024^{* * * *} \\
(0.007)\end{array}$ \\
\hline Cog Score & $\begin{array}{c}0.129^{* * *} \\
(0.006)\end{array}$ & $\begin{array}{c}0.140^{* * * *} \\
(0.007)\end{array}$ & $\begin{array}{c}0.081^{* * *} \\
(0.009)\end{array}$ & $\begin{array}{c}0.072^{* * *} \\
(0.008)\end{array}$ & $\begin{array}{c}0.043^{* * *} \\
(0.006)\end{array}$ \\
\hline Cog Score x High SES & $\begin{array}{c}-0.053^{* * *} \\
(0.008)\end{array}$ & $\begin{array}{c}-0.057^{* * * *} \\
(0.008)\end{array}$ & $\begin{array}{l}0.022^{* *} \\
(0.010)\end{array}$ & $\begin{array}{c}0.023^{* *} \\
(0.010)\end{array}$ & $\begin{array}{c}0.004 \\
(0.007)\end{array}$ \\
\hline Obs. & 8325 & 8325 & 8325 & 8325 & 8325 \\
\hline \multicolumn{6}{|c|}{ Panel B: SES Measure - Father Occ. Income } \\
\hline EA Score & $\begin{array}{c}0.036^{* * *} \\
(0.005)\end{array}$ & $\begin{array}{c}0.048^{* * *} \\
(0.006)\end{array}$ & $\begin{array}{c}0.043^{* * *} \\
(0.007)\end{array}$ & $\begin{array}{c}0.039^{* * *} \\
(0.007)\end{array}$ & $\begin{array}{c}0.016^{* * *} \\
(0.005)\end{array}$ \\
\hline EA Score $x$ HighSES & $\begin{array}{c}-0.017^{* *} \\
(0.008)\end{array}$ & $\begin{array}{c}-0.026^{* * *} \\
(0.009)\end{array}$ & $\begin{array}{c}0.036^{* * *} \\
(0.011)\end{array}$ & $\begin{array}{c}0.046^{* * *} \\
(0.010)\end{array}$ & $\begin{array}{c}0.032^{\text {*** }} \\
(0.007)\end{array}$ \\
\hline Cog Score & $\begin{array}{c}0.123^{* * *} \\
(0.005)\end{array}$ & $\begin{array}{c}0.128^{* * *} \\
(0.006)\end{array}$ & $\begin{array}{c}0.079^{* * *} \\
(0.007)\end{array}$ & $\begin{array}{c}0.069^{* * *} \\
(0.007)\end{array}$ & $\begin{array}{c}0.034^{* * *} \\
(0.005)\end{array}$ \\
\hline Cog Score x High SES & $\begin{array}{c}-0.055^{* * *} \\
(0.008)\end{array}$ & $\begin{array}{c}-0.051^{* * *} \\
(0.009)\end{array}$ & $\begin{array}{c}0.030^{* * *} \\
(0.011)\end{array}$ & $\begin{array}{c}0.038^{* * *} \\
(0.010)\end{array}$ & $\begin{array}{c}0.022^{\text {*** }} \\
(0.008)\end{array}$ \\
\hline Obs. & 6459 & 6459 & 6459 & 6459 & 6459 \\
\hline \multicolumn{6}{|c|}{ Panel C: SES Measure - Move or Asked for Help } \\
\hline EA Score & $\begin{array}{c}0.032^{* * *} \\
(0.007)\end{array}$ & $\begin{array}{c}0.056^{* * *} \\
(0.008)\end{array}$ & $\begin{array}{c}0.070^{* * *} \\
(0.009)\end{array}$ & $\begin{array}{c}0.065^{* * *} \\
(0.009)\end{array}$ & $\begin{array}{c}0.021^{* * *} \\
(0.007)\end{array}$ \\
\hline EA Score x High SES & $\begin{array}{l}-0.007 \\
(0.008)\end{array}$ & $\begin{array}{c}-0.027^{* * * *} \\
(0.009)\end{array}$ & $\begin{array}{l}-0.007 \\
(0.011)\end{array}$ & $\begin{array}{c}0.004 \\
(0.010)\end{array}$ & $\begin{array}{l}0.018^{* *} \\
(0.008)\end{array}$ \\
\hline Cog Score & $\begin{array}{c}0.105^{* * *} \\
(0.007)\end{array}$ & $\begin{array}{c}0.117^{* * *} \\
(0.007)\end{array}$ & $\begin{array}{c}0.080^{* * *} \\
(0.009)\end{array}$ & $\begin{array}{c}0.072^{* * *} \\
(0.009)\end{array}$ & $\begin{array}{c}0.043^{* * *} \\
(0.006)\end{array}$ \\
\hline Cog Score x High SES & $\begin{array}{c}-0.019^{* *} \\
(0.008)\end{array}$ & $\begin{array}{c}-0.023^{* * *} \\
(0.009)\end{array}$ & $\begin{array}{l}0.022^{* *} \\
(0.011)\end{array}$ & $\begin{array}{l}0.022^{* *} \\
(0.010)\end{array}$ & $\begin{array}{l}0.005 \\
(0.007)\end{array}$ \\
\hline Obs. & 8301 & 8301 & 8301 & 8301 & 8301 \\
\hline \multicolumn{6}{|c|}{ Panel D: SES Measure - Father Unemployed } \\
\hline EA Score & $\begin{array}{c}0.036^{* * *} \\
(0.007)\end{array}$ & $\begin{array}{c}0.049^{* * *} \\
(0.008)\end{array}$ & $\begin{array}{c}0.047^{* * *} \\
(0.009)\end{array}$ & $\begin{array}{c}0.053^{* * *} \\
(0.009)\end{array}$ & $\begin{array}{c}0.022^{\text {*** }} \\
(0.006)\end{array}$ \\
\hline EA Score x High SES & $\begin{array}{l}-0.012 \\
(0.008)\end{array}$ & $\begin{array}{c}-0.017^{* *} \\
(0.009)\end{array}$ & $\begin{array}{c}0.023^{* *} \\
(0.011)\end{array}$ & $\begin{array}{l}0.019^{*} \\
(0.010)\end{array}$ & $\begin{array}{l}0.014^{*} \\
(0.007)\end{array}$ \\
\hline Cog Score & $\begin{array}{c}0.108^{* * *} \\
(0.007)\end{array}$ & $\begin{array}{c}0.121^{* * *} \\
(0.007)\end{array}$ & $\begin{array}{c}0.089^{* * *} \\
(0.009)\end{array}$ & $\begin{array}{c}0.074^{* * *} \\
(0.008)\end{array}$ & $\begin{array}{c}0.046^{* * * *} \\
(0.006)\end{array}$ \\
\hline Cog Score x High SES & $\begin{array}{c}-0.024^{* * *} \\
(0.008)\end{array}$ & $\begin{array}{c}-0.030^{* * *} \\
(0.009)\end{array}$ & $\begin{array}{c}0.008 \\
(0.010)\end{array}$ & $\begin{array}{l}0.018^{*} \\
(0.010)\end{array}$ & $\begin{array}{c}0.001 \\
(0.007)\end{array}$ \\
\hline Obs. & 8342 & 8342 & 8342 & 8342 & 8342 \\
\hline
\end{tabular}

Regressions relating educational attainment categories to the EA Score, childhood SES, the Cognition Score and interactions of the EA Score and the Cognition Score with high SES. Regressions also include a full set of dummy variables for birth year, a male dummy and a full set of interactions between the birth year and gender dummies. Additionally, every specification includes the first 10 principle components of the full matrix of genetic data and controls for parental education (years of paternal and maternal education and dummies indicating missing values for each) and own education (years of schooling and a full set of completed degree dummies). 
Appendix Table S6: Polygenic Score, Cognition Score, and Labor Outcomes

\begin{tabular}{|c|c|c|c|}
\hline \multicolumn{4}{|c|}{ Panel A: Dep. Var - Work For Pay } \\
\hline EA Score & $\begin{array}{c}0.022^{* * *} \\
(0.006)\end{array}$ & $\begin{array}{c}0.016^{* *} \\
(0.007)\end{array}$ & $\begin{array}{l}0.015^{*} \\
(0.008)\end{array}$ \\
\hline EA Score x College & & & $\begin{array}{c}0.002 \\
(0.013)\end{array}$ \\
\hline Cog. Score & $\begin{array}{c}0.047^{* * *} \\
(0.007)\end{array}$ & $\begin{array}{c}0.036^{* * *} \\
(0.008)\end{array}$ & $\begin{array}{c}0.028^{* * *} \\
(0.009)\end{array}$ \\
\hline Cog. Score x College & & & $\begin{array}{l}0.027^{*} \\
(0.015)\end{array}$ \\
\hline Obs. & 13300 & 13300 & 13253 \\
\hline Educ. Controls & $\mathrm{N}$ & $\mathrm{Y}$ & $\mathrm{Y}$ \\
\hline Parent Controls & $\mathrm{N}$ & $\mathrm{Y}$ & $\mathrm{Y}$ \\
\hline \multicolumn{4}{|c|}{ Panel B: Dep. Var - Retired } \\
\hline EA Score & $\begin{array}{c}-0.013^{* * *} \\
(0.004)\end{array}$ & $\begin{array}{c}-0.012^{* * *} \\
(0.004)\end{array}$ & $\begin{array}{c}-0.011^{* *} \\
(0.005)\end{array}$ \\
\hline EA Score x College & & & $\begin{array}{l}-0.006 \\
(0.008)\end{array}$ \\
\hline Cog. Score & $\begin{array}{c}0.002 \\
(0.003)\end{array}$ & $\begin{array}{c}0.003 \\
(0.004)\end{array}$ & $\begin{array}{l}0.009^{*} \\
(0.005)\end{array}$ \\
\hline Cog. Score x College & & & $\begin{array}{c}-0.022^{* * *} \\
(0.009)\end{array}$ \\
\hline Obs. & 7921 & 7921 & 7891 \\
\hline Educ. Controls & $\mathrm{N}$ & $\mathrm{Y}$ & $\mathrm{Y}$ \\
\hline Parent Controls & $\mathrm{N}$ & Y & $\mathrm{Y}$ \\
\hline \multicolumn{4}{|c|}{ Panel C: Dep. Var - Log Wage } \\
\hline EA Score & $\begin{array}{c}0.067^{* * *} \\
(0.012)\end{array}$ & $\begin{array}{c}0.018 \\
(0.011)\end{array}$ & $\begin{array}{c}-0.001 \\
(0.013)\end{array}$ \\
\hline EA Score x College & & & $\begin{array}{c}0.059^{* *} \\
(0.024)\end{array}$ \\
\hline Cog. Score & $\begin{array}{c}0.156^{* * *} \\
(0.013)\end{array}$ & $\begin{array}{c}0.060 * * * \\
(0.014)\end{array}$ & $\begin{array}{c}0.070^{* * *} \\
(0.016)\end{array}$ \\
\hline Cog. Score x College & & & $\begin{array}{l}-0.028 \\
(0.030)\end{array}$ \\
\hline Obs. & 6508 & 6508 & 6480 \\
\hline Educ. Controls & $\mathrm{N}$ & Y & $\mathrm{Y}$ \\
\hline Parent Controls & $\mathrm{N}$ & $\mathrm{Y}$ & $\mathrm{Y}$ \\
\hline
\end{tabular}

Regressions relating labor market outcomes to the EA Score, the Cognition Score and interactions between these two variables and an indicator for having a college degree. In Panel A, the dependent variable is employment (working for pay). In Panel B, the dependent variable is retirement and conditions on not being retired in the previous period. In Panel $\mathrm{C}$, the dependent variable is log wage conditional on working for pay. All regressions include a full set of dummy variables for birth year and the first 10 principle components of the full matrix of genetic data. The specifications in Columns 2 and 3 include controls for parental education (years of paternal and maternal education and dummies indicating missing values for each) and own education (years of schooling and a full set of completed degree dummies). The sample in Panel A is restricted to men between the ages of 50 and 64. The sample in Panel B is restricted to men between the ages of 50 and 64 who worked for pay in the last period and were not retired in the last period. The sample in Panel $\mathrm{C}$ is restricted to men between the ages of 50 and 64 who worked at least 20 hours for pay. 


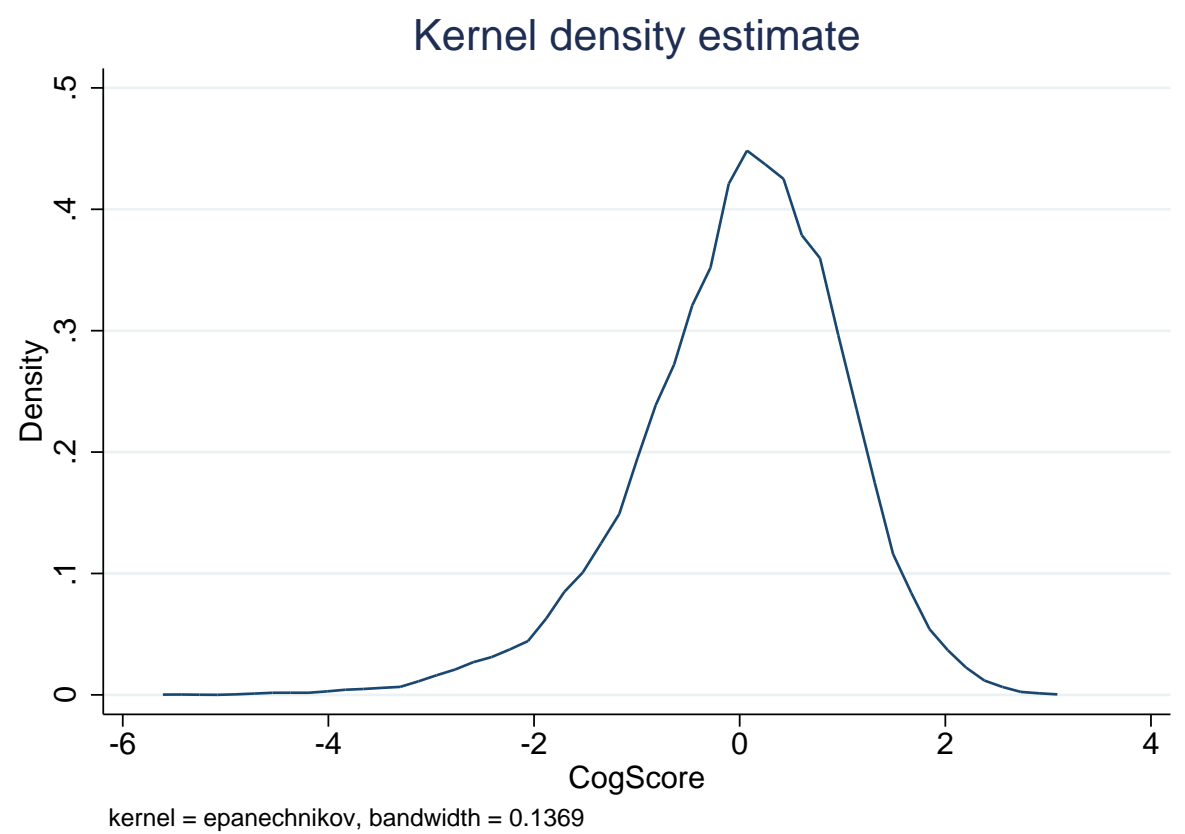

Appendix Figure S2: Distribution of cognitive test scores (Cognition Score), which is the standardized individual-level average residual from a regression of cognition on age

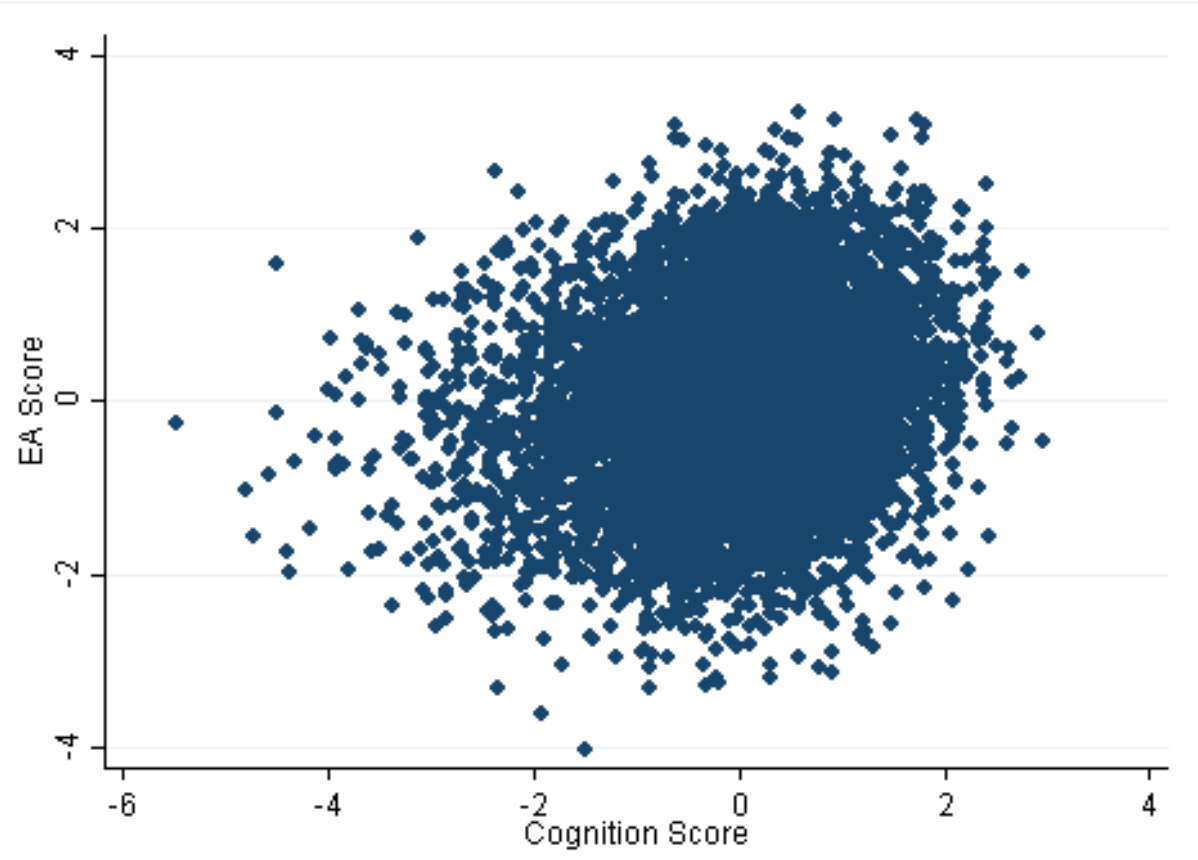

Appendix Figure S3: Scatter plot by individual of EA Score and Cognition Score. 